\title{
Inorganic Pyrophosphate Promotes Osteoclastogenic Commitment and Survival of Bone Marrow Derived Monocytes mediated by Egr-1 up- regulation and MITF phosphorylation
}

\author{
Samir M. Abdelmagid ${ }^{1 *}$, Allison Zajac ${ }^{2}$, Imad Salhab ${ }^{2}$, Hyun-Duck Nah ${ }^{2}$ \\ ${ }^{1}$ Department of Anatomy and Neurobiology, Northeast Ohio Medical University (NEOMED) \\ School of Medicine, Rootstown, OH 44272, USA. \\ ${ }^{2}$ Division of Plastic and Reconstructive, Department of Surgery, Children's Hospital of \\ Philadelphia, Philadelphia, PA 19104 USA
}

*To whom correspondence may be addressed: Samir M. Abdelmagid, M.D., Ph. ${ }^{\text {DD. }}$ samirabdelmagid@gmail.com.

Keywords: Monocytes, Osteoclast, Pyrophosphate, Bone Resorption 
bioRxiv preprint doi: https://doi.org/10.1101/2020.10.01.321976; this version posted October 1, 2020. The copyright holder for this preprint (which was not certified by peer review) is the author/funder, who has granted bioRxiv a license to display the preprint in perpetuity. It is made available under aCC-BY 4.0 International license.

\section{CONFLICT OF INTEREST}

The authors have no conflict of interests 


\section{ABSTRACT}

Several reports emphasized the importance of inorganic pyrophosphate $\left(\mathrm{PP}_{\mathrm{i}}\right)$ in hindering osteoblast differentiation and bone matrix mineralization. Its ubiquitous presence is thought to prevent "soft" tissue calcification, whereas its degradation to $\mathrm{P}_{\mathrm{i}}$ in bones and teeth by alkaline phosphatase (ALP) may facilitate crystal growth. While the inhibiting role of PP on osteoblast differentiation and function is largely understood, less is known about its effects on osteoclast determination and activity. In this study, we investigated the role of $\mathrm{PP}_{\mathrm{i}}$ in bone resorption using calverial organ cultures ex vivo. We present an evidence that $\mathrm{PP}_{\mathrm{i}}$ stimulated calvarial bone resorption marked by calcium $\left(\mathrm{Ca}^{2+}\right)$ release in the condition media $(\mathrm{CM})$. We then examined $\mathrm{PP}_{\mathrm{i}}$ effects on osteoclast differentiation using mouse bone marrow-derived monocytes (BMMs). Our results revealed that $\mathrm{PP}_{\mathrm{i}}$ enhanced osteoclast differentiation ex vivo, marked by increased number and size of TRAP-stained mature osteoclasts. Moreover, $\mathrm{PP}_{\mathrm{i}}$ stimulated osteoclastogenesis in BMMs co-cultured with osteoblasts. These data supported the increased osteoclast activity in bone resorption using functional osteo-assays. The finding of PU.1-Egr-1 dependent upregulation of c-FMS and RANK receptors in BMMs supported the enhanced pre-osteoclast commitment and differentiation. Moreover, osteoclast survival was enhanced by activation of MITF-BCL-2 pathway that was mediated by MAPK-ERK1/2 signaling. Last, our data showed that $\mathrm{PP}_{\mathrm{i}}$ up-regulated $\mathrm{ANK} ; \mathrm{PP}_{\mathrm{i}}$ transporter, during osteoclast differentiation through ERK1/2 phosphorylation whereas mutation of ANK inhibited osteoclastogenesis. Collectively, our data suggest that $\mathrm{PP}_{\mathrm{i}}$ promotes osteoclast differentiation, survival, and function through PU.1 upregulation and MITF phosphorylation whereas ANK loss-of-function inhibited osteoclastogenesis. 


\section{INTRODUCTION}

Mineralization of the mammalian skeleton is a tightly regulated process, in which the key regulators play critical roles in defining the site, timing and the extent of mineral deposition. In bone, calcium $\left(\mathrm{Ca}^{2+}\right)$ and phosphate-based apatite crystal formation is initiated by membrane bound matrix vesicles, deposited to the type I collagen-rich organic matrix and propagate along the collagen fibrils $(4,35)$. Unlike in the highly insoluble exoskeleton of numerous invertebrates, the calcium phosphate apatite crystal in mammalian skeleton is not a perfect crystalline with its stability subjected to a local $\mathrm{pH}$ change (46). A slight shift from neutral to acidic $\mathrm{pH}$ converts bone apatite crystals to soluble ions, and vice versa. The dynamic nature of vertebral skeleton is important not only to support homeostasis of serum mineral ions but also to facilitate bone remodeling, allowing enlargement, contouring and repair of bones (46).

Inorganic pyrophosphate $\left(\mathrm{PP}_{\mathrm{i}}\right)$, which consists of two molecules of inorganic phosphates connected by a high-energy ester bond, is best known for its ability to inhibit tissue calcification (49). In mammalian cells, $\mathrm{PP}_{\mathrm{i}}$ does not appear to be synthesized de novo. Instead, it is generated as an abundant byproduct or metabolic intermediate of numerous intracellular and extracellular biochemical reactions (55). Intracellular $\mathrm{PP}_{\mathrm{i}}$ is generated and stored largely in mitochondria, but it is also detected in endoplasmic reticulum and Golgi (27). The extracellular $\mathrm{PP}_{\mathrm{i}}$ concentration in the skeletal tissue is determined by several types of plasma membrane proteins: ectonucleotide pyrophosphatase (ENPP), which generates $\mathrm{PP}_{\mathrm{i}}$ from ATP (51), tissue non-specific alkaline phosphatase (TNAP), which hydrolyzes $\mathrm{PP}_{\mathrm{i}}$ into two inorganic phosphates $\left(\mathrm{P}_{\mathrm{i}}\right)(58)$, and progressive ankyloses $(\mathrm{ANKH})$ transporter; which is involved in $\mathrm{PP}_{\mathrm{i}}$ in- and efflux (8).

While the functional role of intracellular $\mathrm{PP}_{\mathrm{i}}$ in mammalian cells remains elusive, extracellular $\mathrm{PP}_{\mathrm{i}}$ has been extensively studied for its inhibitory role in tissue calcification (28). Extracellular $\mathrm{PP}_{\mathrm{i}}$ directly binds to the surface of basic calcium phosphate hydroxyapatites and 
interferes with the propagation of crystal formation, contributing to the formation of poorly ordered bone crystal structure (3). In addition, exogenous $\mathrm{PP}_{\mathrm{i}}$ at micro-molar concentrations stimulates the expression of osteopontin; a negative regulator of mineralization that also inhibits the $\mathrm{PP}_{\mathrm{i}}$ hydrolyzing activity of TNAP in MC3T3-E1 osteoblast cultures (3).

The physiological significance of extracellular $\mathrm{PP}_{\mathrm{i}}$ in tissue calcification is observed in various human pathologies and genetically modified mouse strains with dysregulated $\mathrm{PP}_{\mathrm{i}}$ metabolism, where a reduction of extracellular $\mathrm{PP}_{\mathrm{i}}$ is associated with ectopic calcification of arteries (48), joint tissues (65), renal stone formation (43), and hyperostosis of craniofacial bones (50). Under physiological concentrations, it is well documented that the mineral crystals formed of extracellular $\mathrm{PP}_{\mathrm{i}}$ are mainly the basic calcium phosphate crystals (29). Increased extracellular $\mathrm{PP}_{\mathrm{i}}$ concentrations, on the other hand, is associated with hypo-mineralization of the bone matrix as in Tnap $^{-/}$mice or patients with deficient TNAP activities (20). Moreover, higher concentrations of $\mathrm{PP}_{\mathrm{i}}$ results in formation of calcium pyrophosphate dihydrate (CPPD) crystals with spontaneous deposition in the articular tissues leading to an arthritis condition called; chondrocalcinosis (29).

Another syndrome characterized by $\mathrm{PP}_{\mathrm{i}}$ metabolic disorder is the craniometaphyseal dysplasia (CMD) with genetic nonsense mutation of ankh that underlie increased intracellular and decreased extracellular $\mathrm{PP}_{\mathrm{i}}$ (11). The ankh protein is type II transmembrane with 10-12 helices, spanning the outer cell membrane, and is associated with $\mathrm{PP}_{\mathrm{i}}$ efflux. Most of the $A N K H$ mutations are located in cytoplasmic domains close to the C-terminus (44). Previous study reported $A N K H$ gene mutation impairs osteoclast differentiation and function that will disrupt bone remodeling (50). Reduced bone turnover can contribute to the bone thickening characteristic of CMD. Another study showed that $A N K H$ gene mutation increases osteoblast activity rather than a defect in bone remodeling (53). Moreover, $A N K H$ gene mutation reduces 
$\mathrm{PP}_{\mathrm{i}}$ transportation out of the cells. A shortage of extracellular $\mathrm{PP}_{\mathrm{i}}$ will increase bone mineralization, which also contribute to the bone overgrowth of CMD (53). Earlier studies of CMD point to the important regulatory role of $\mathrm{PP}_{\mathrm{i}}$ in bone modeling/remodeling process (6). Given the expanding functional implication of $\mathrm{PP}_{\mathrm{i}}$ in bone remodeling, it is imperative to test the role of $\mathrm{PP}_{\mathrm{i}}$ in bone resorption. We hypothesize that extracellular $\mathrm{PP}_{\mathrm{i}}$ has a direct stimulating effect on osteoclasts, promoting differentiation of bone marrow-derived monocytes (BMMs) into mature osteoclasts that are active in bone resorption. In this study, murine calvarial organ cultures and $\mathrm{BMMs}$ have been essentially used to determine the potential role of exogenous $\mathrm{PP}_{\mathrm{i}}$ in pre-osteoclast differentiation, and function. Here, we report that $\mathrm{PP}_{\mathrm{i}}$ enhances commitment and survival of BMMs into mature osteoclasts in a PU.1 dependent up-regulation of EGR-1, and MAPK-dependent phosphorylation of MITF. Thus, our data suggest $\mathrm{PP}_{\mathrm{i}}$ works as a positive regulator of osteoclastogenesis and osteoclast-mediated bone resorption.

\section{EXPERIMENTAL PROCEDURES}

\section{Materials.}

Tetrasodium pyrophosphate $\left(\mathrm{NaPP}_{\mathrm{i}}\right)$, sodium phosphate $\left(\mathrm{NaP}_{\mathrm{i}}\right)$; monobasic and dibasic, phosphonoformic acid (PFA), 1 alpha 25 Dihydroxy vitamin D3, levamisole, Hydroxytamoxifen, and dimethyl sulfoxide (DMSO) were purchased from Sigma-Aldrich (St. Louis, MO).

Recombinant human TNF- $\alpha$, RANKL, and MCSF were purchased from Peprotech EC (London, UK). Disodium clodronate and quinazoline were purchased from Calbiochem (La Jolla, CA,). Probenecid, DMEM, $\alpha$-MEM, IMDM, recombinant mouse IL-3, L-glutamine, $\beta$ mercaptoethanol, Penicillin- Stereptomycin, and Fungizone ${ }^{\circledR}$ Antimycotic were purchased from Invitrogen (Carlsbad, CA). L-Ascorbic acid, MEM Non-essential Amino Acid Solution (100X), and bovine serum albumin, Fraction V (BSA) were purchased from Sigma-Aldrich. Fetal bovine 
serum (FBS) was purchased from Gemini Bio-Products (West Sacramento, CA). Calf serum (CS) was purchased from Thermo Scientific ATLC (Rockford, IL). U0126 (MAPK inhibitor) and SB203580 (p38 MAPK inhibitor) were purchased from Calbiochem (Gibbstown, NJ).

\section{Antibodies.}

All antibodies were used for protein blotting as described below. Rabbit anti-mouse phospho-p38 MAPK (Thr180/Tyr182) (Cat\# 9211), p38 MAPK (Cat\# 9212), and GAPDH antibodies (Cat\# 97166) were purchased from Cell Signaling (Boston, MA). Rabbit anti-mouse phospho-ERK 1/2 (Thr202, Tyr204) (Cat\# sc-136521) and ERK 1/2 (Cat\# sc-292838) were purchased from Santa Cruz (Santa Cruz, CA). Anti-mouse phospho-MITF-S307 was gift from Dr Michael Ostrowski (Ohio State University, Columbus, OH)). Rabbit anti-mouse MITF (Cat\# ab20663) was purchased from abcam (Cambridge, MA). Horseradish Peroxidase (HRP)-conjugated anti-mouse antibody (Cat\# NA931) or anti-rabbit antibody (Cat\# NA934) was purchased from GE Healthcare (Buckinghamshire, UK). ank-specific antibody was raised in a rabbit against Cterminal peptide sequence TEEVTDIVEMREENE (Proteintech, Chicago, IL), purified from the antiserum and confirmed for its specificity on immunoblots as described previously (63).

\section{Calvarial Organ Culture.}

Intact cranial vaults that include frontal, parietal and interparietal bones were dissected from C57BL/6J mice, postnatal day 6 . They were placed with the concave side down on a stainless steel grids in 12-well, and cultured in $\alpha$-MEM containing $0.1 \% \mathrm{BSA}, 50 \mu \mathrm{g} / \mathrm{ml}$ ascorbic acid, and antibiotics-antimycotic $(50 \mu \mathrm{g} / \mathrm{ml}$ penicillin, $50 \mu \mathrm{g} / \mathrm{ml}$ streptomycin, and $0.25 \mu \mathrm{g} / \mathrm{ml}$ amphotericin B) for 24 hours. Murine calvaria were washed with phosphate buffered saline solution (PBS) and cultured for additional three days in the fresh medium containing various combinations of chemical and biochemical reagents, as indicated in the Result section. The calvarial organs were then assessed for osteoclast bone resorption, as described below. 


\section{ANK-mutant Mice.}

C3FeB6 $A / A^{W-J}-A N K^{a n k} / \mathrm{J}$ : (ank/ank) mice, and their wild-type: C3FeB6 $A / A^{W-J}$ were obtained from the Jackson Laboratory, JAX stock \#000200 (Bar Harbor, ME). Heterozygote breeders were used to generate and study ank/ank littermates, with genotypes analyzed by RT-PCR, as described previously (23). All mouse colonies were maintained in The Children Hospital of Philadelphia facility accredited by the Association for Assessment and Accreditation of Laboratory Animal Care International (AAALAC), under veterinary supervision and according to the guidelines of the National Institutes of Health Guide for the Care and Use of Laboratory Animals.

\section{Cell Culture.}

Mouse macrophage cell line RAW 264.7 (ATCC, Manassas, VA) was maintained in DMEM containing $10 \%$ FBS supplemented with $1 \%$ nonessential amino acids, $1 \%$ L-glutamine and antibiotics-antimycotic. For osteoclast differentiation, the RAW cells were cultured for 7 days in the medium supplemented with $35 \mathrm{ng} / \mathrm{ml}$ RANKL.

RAW 264.7/C4 cells are stably transfected cell line for MITF expression (RAW ${ }^{\mathrm{MITF}}$ ) was a kind gift from Dr. David Hume (University of Edinburgh). RAW ${ }^{\mathrm{MITF}}$ cells were maintained in a complete DMEM media as described above with geneticin $(450 \mu \mathrm{g} / \mathrm{ml})$, added for selection. Mouse bone marrow-derived monocytes (BMMs) were isolated from 8-week old C57BL/6J, $\mathrm{C} 3 \mathrm{FeB} 6 \mathrm{~A} / \mathrm{A}^{\mathrm{W}-\mathrm{J}}-\mathrm{ANK}^{\mathrm{ank}} / \mathrm{J}$ : (ank/ank) male mice, and their wild-type: $\mathrm{C} 3 \mathrm{FeB} 6 \mathrm{~A} / \mathrm{A}^{\mathrm{W}-\mathrm{J}}$, as described previously (2). Briefly, Mice were euthanized, and their tibiae and femurs were dissected using sterile technique, scraped off adherent soft tissue, and placed in ice-chilled complete media ( $\alpha$-MEM containing 10\% FBS, and antibiotics-antimycotic). The ends of the bone were cut off, and the bone marrow was flushed out from the shaft, using PBS in syringe with a 26-gauge needle. The extruded bone marrow was triturated by repeatedly pipetting up and 
down, and centrifuged. The cell pellet was re-suspended in complete medium and cultured overnight. Next day, non-adherent BMMs were collected, passed through a $40 \mu \mathrm{m}$ nylon mesh cell strainer, counted, and plated for future experiments.

For the experiments requiring $\mathrm{NaPP}_{\mathrm{i}}$ pretreatment, $\mathrm{BMMs}$ were plated at $2 \times 10^{5}$ cells $/$ well in a 96-well and cultured for 48 hours in a complete medium supplemented with $25 \mathrm{ng} / \mathrm{ml} \mathrm{MCSF}$ and $\mathrm{PP}_{\mathrm{i}}(100-1000 \mu \mathrm{M})$. The pretreated cells were washed with PBS and switched to a complete medium supplemented with $35 \mathrm{ng} / \mathrm{ml}$ RANKL in addition to $25 \mathrm{ng} / \mathrm{ml} \mathrm{MCSF}$. Cells were fed every two days by replacing $50 \%$ of the medium with a fresh complete medium containing $2 \mathrm{X}$ concentration of RANKL and MCSF. After 7-day culture period, cells were analyzed for TRAP activity and TRAP+ osteoclasts as described below.

For the co-culture experiments requiring $\mathrm{NaPP}_{\mathrm{i}}$ pretreatment, primary calvarial osteoblasts were isolated as described previously (1). Osteoblasts were plated at $1.8 \times 10^{4} \mathrm{cell} / \mathrm{cm}^{2}$ in 48 -well plate with or without $\mathrm{PP}_{\mathrm{i}}(100-1000 \mu \mathrm{M})$ or vitamin $\mathrm{D}_{3}\left(10^{-8} \mathrm{M}\right)$. The next day, BMM cells were plated at $2.8 \times 10^{5}$ cells $/ \mathrm{cm}^{2}$ on top of osteoblasts. Co-cultured cells were fed on day 6 , replacing half of the media with fresh media containing $2 \mathrm{x}$ concentration of $\mathrm{PP}_{\mathrm{i}}$ or vitamin $\mathrm{D}_{3}$. Large osteoclasts were evident by day 9, then cells were fixed for measurement of TRAP activity, cell count, and size of TRAP+ osteoclasts. In parallel experiments, condition media (CM) were collected from osteoblasts cultures treated with $\mathrm{PP}_{\mathrm{i}}(1000 \mu \mathrm{M})$ or vitamin $\mathrm{D}_{3}\left(10^{-8} \mathrm{M}\right)$ for 48 hours. The CM were concentrated using Amicon Ultra-15 centrifugal filter device (MilliporeSigma, St. Louis, MO) to collect proteins with molecular weight $<3 \mathrm{~K}$. BMMs were cultured in 96-well plate and treated with the CM. Culture media were replaced with fresh CM every 48 hours for total of 9 days cultures. Cells were fixed for measurement of TRAP activity and TRAP+ osteoclasts as described below. 
For the experiments requiring the immunoblot detection of the phosphorylated forms of ERK, P38 MAPK and MITF, non-adherent BMMs were collected, plated in 6-well (1.6 x $10^{6}$ cells/well) and cultured with $25 \mathrm{ng} / \mathrm{ml}$ MCSF for 48 hours. BMMs were now called bone marrow-derived macrophages. The BMM were serum and MCSF deprived overnight. BMMs were treated with $\mathrm{NaPP}_{\mathrm{i}}(1000 \mu \mathrm{M})$ and/or U0126 $(10 \mu \mathrm{M})$ or SB203580 $(10 \mu \mathrm{M})$ in serum freemedium for $0,5,10,30,60$, and 90 minutes, and total proteins were isolated at the specific time points.

For cell survival assay experiments, BMMs and RAW ${ }^{\mathrm{MITF}}$ were harvested as described previously, counted and plated in 24-well (4 x $10^{5}$ cells/well) with $25 \mathrm{ng} / \mathrm{ml} \mathrm{MCSF}$ for BMMs only, for 48 hours. Bone marrow-derived macrophages were treated with $\mathrm{NaPP}_{\mathrm{i}}(1000 \mu \mathrm{M})$ and/or U0126 $(10 \mu \mathrm{M})$ or SB203580 $(10 \mu \mathrm{M})$ in MCSF and serum deprived medium for 48 hours.

PU.1 cell culture - PU.1 low (PU.1 $\left.{ }^{\text {lo }}\right)$, and PU.1 high (PU.1 $\left.{ }^{\text {hi }}\right)$ fetal liver progenitor cells were a kind gift from Dr Harinder Singh (University of Chicago). PU.1-hematopoietic progenitors were maintained in Iscove's Modified Dulbeco's Medium (IMDM) containing 10\% calf serum, $50 \mu \mathrm{M}$ $\beta$-mercaptoethanol, $2 \mathrm{mM}$ L-glutamine, IL-3 (5 ng/ml) and antibiotech-anti-mycotics. As PU.1 cell line comes from murine fetal liver hematopoietic cells, they stay floating for days in IMDM media. The PU.1 cells don't adhere to the culture plate unless cells were passaged for few times. Only the adherent PU.1 cells differentiate and the rest of floating cells became apoptotic. PU.1-cells were collected, counted, divided into $10 \mathrm{~cm}$ plates $\left(3.5 \times 10^{6}\right)$ and treated with $\mathrm{NaPP}_{\mathrm{i}}$ $(1000 \mu \mathrm{M})$ and/or Hydroxytamoxifen $(100 \mathrm{nM})$ in complete medium for 72 hours. The PU.1cells treated versus untreated with $\mathrm{NaPP}_{\mathrm{i}}$ and/or Hydroxytamoxifen were collected and centrifuged. Cell pellets were washed in 1X HBSS and total RNA was extracted from the cells, using TRIzol® Reagent (Invitrogen). 


\section{Calcium Measurement.}

Calcium $\left(\mathrm{Ca}^{2+}\right)$ levels in conditioned media (CM) from cell and organ cultures were determined using the QuantiChrom ${ }^{\mathrm{TM}}$ Calcium Assay Kit (Bioassay System, Hayward, CA), as instructed by the manufacturer. Calcium concentrations have been calculated by measuring the net change $(\Delta)$ of total calcium in the CM minus calcium concentration in the initial culture media. Each treatment group consisted of 3-replicates.

\section{Enzyme Immunoassay (EIA) for Collagen Helical Peptide (CTX-1).}

The MicroVue ${ }^{\mathrm{TM}}$ Helical Peptide EIA kit (Quidel, San Diego, CA) was used to measure the level of a helical peptide containing the residues $620-633$ of the type I collagen $\alpha 1$ chain or more formally carboxy-terminal collagen crosslinks, known by the acronym (CTX-1) in conditioned media from cell and organ cultures, as instructed by the manufacturer. Each treatment group consisted of 3-replicates.

\section{Quantitative TRAP Activity Solution Assay and TRAP Staining.}

BMM and osteoclasts cultures in a 96 well plate were fixed with $10 \%$ formalin for 15 minutes, washed in PBS, permeabilized with a mixture of methanol and acetone (1:1) for 5 minutes, and then air-dried. For TRAP; Tartrate-resistant acid phosphatase activity assays, the formalin-fixed cells were incubated with a TRAP buffer $(52 \mathrm{mM}$ of Na-tartrate in $0.1 \mathrm{M} \mathrm{Na}$-acetate buffer, $\mathrm{pH}$ 5.2) containing $0.1 \mathrm{mg} / \mathrm{ml}$ of $p$-nitrophenyl phosphate ( $p$-NPP) for one hour at $37^{\circ} \mathrm{C}$. The reaction was stopped by adding $50 \mu 1$ of $0.1 \mathrm{~N} \mathrm{NaOH}$ to $100 \mu \mathrm{l}$ of the reaction mixture and read for optical density at $405 \mathrm{~nm}$. For TRAP staining, cell and organ cultures were incubated with the TRAP buffer containing $1.5 \mathrm{mM}$ naphthol AX-MX phosphate (Sigma) and $0.5 \mathrm{mM}$ Fast Red Violet LB salt (Sigma) for one hour at $37^{\circ} \mathrm{C}$. TRAP positive cells with $\geq 3$ nuclei were counted as mature osteoclasts. TRAP activity and staining data are averages of 3-replicates per condition. 
BMMs were cultured for 48 hours in the OsteoAssay ${ }^{\mathrm{TM}}$ Human Bone Plate (Lonza, Walkersville, MD) coated with a thin layer of adherent human bone particles in complete medium containing $25 \mathrm{ng} / \mathrm{ml} \mathrm{MCSF}$ and PP $(100-1000 \mu \mathrm{M})$. BMMs were then switched to RANKL and MCSF for additional 10 days as described above. Bone resorption was assessed by measuring $\mathrm{Ca}^{2+}$ and type I collagen helical peptide 620-633 (CTX-1) in conditioned media harvested at the end of culture. In parallel experiments, murine $\mathrm{BMMs}$ were cultured with MCSF and $\mathrm{NaPP}_{\mathrm{i}}$ for 48 hours and then differentiated with RANKL for additional 8 days on BD BioCoat ${ }^{\mathrm{TM}}$ Osteologic ${ }^{\mathrm{TM}}$ MultiTest Slides (BD Biosciences, Bedford, MA) coated with a synthetic calcium phosphate film. The cell culture condition was same as that for the OsteoAssay ${ }^{\mathrm{TM}}$ Human Bone Plate. At the end of culture, multi-well slides were treated with $1 \mathrm{M} \mathrm{NH} 4 \mathrm{OH}$ to remove cells, washed 3 times with $\mathrm{ddH}_{2} \mathrm{O}$, and processed for von Kossa staining and visualized using Olympus IX71 microscope. The total number and area of resorption pits were captured and analyzed using image $J$ program as described below.

In parallel experiments, co-culture of murine BMMs and osteoblasts were established on dentin discs (OsteoSite, Boldon, UK) in 96-well and treated as described above. On day 12, cells were removed with $1 \mathrm{M} \mathrm{NH}_{4} \mathrm{OH}$ and discs were stained with $1 \%$ toluidine blue. The total bone resorption area was captured and analyzed using image $\mathbf{J}$ program as described below. Cell survival Assays - Cell survival of BMMs and RAW ${ }^{\mathrm{MITF}}$ cells were measured after 48 hours treatment with $\mathrm{NaPP}_{\mathrm{i}}$ and/or U0126 or SB203580 in complete or serum-free medium as described previously. Twelve mM of MTT substrate (Thiazolyl Blue Tetrazolium Bromide) (Sigma) was added to the 24-well plate and was incubated at $37^{\circ} \mathrm{C}$. Dimethyl sulfoxide (DMSO); (200 $\mu \mathrm{l} /$ well) was added to solubilize the formazan reaction and read for optical density at 570 $\mathrm{nm}$.

\section{Northern Blot Analysis.}


Total RNA was isolated from cells using TRIzol® Reagent (Invitrogen) and confirmed for RNA integrity on an agarose gel. Five $\mu \mathrm{g}$ of RNA was separated on a $1 \%$ denaturing agarose gel, containing 2.2 M formaldehyde, and transferred onto a nylon membrane (Maximum Strength Nytran, Schleicher \& Schuell, Keene, NH). The membrane was hybridized with cDNA probes for mouse $A N K$ labeled with $\left[\alpha-{ }^{32} \mathrm{P}\right]$ dCTP using Rediprime ${ }^{\mathrm{TM}} \mathrm{II}$ (Amersham Biosciences, Piscataway, NJ), washed, and exposed on X-ray film (Denville Scientific, Metuchen, NJ).

\section{RT-PCR.}

BMM cultures were treated with $\mathrm{NaPP}_{\mathrm{i}}$ at various concentrations $(100-1000 \mu \mathrm{M})$ for 48 hours, as described above. Total RNA was isolated from cells using TRIzol® Reagent (Invitrogen) and confirmed for integrity on an agarose gel. Three $\mu \mathrm{g}$ of total RNA were reverse transcribed to cDNA in a volume of $10 \mu \mathrm{l}$ containing the following: $150 \mathrm{ng}$ Random Hexamers, $10 \mathrm{mM}$ dNTP (Invitrogen), $\mathrm{ddH}_{2} \mathrm{O}$ and incubated at $65^{\circ} \mathrm{C}$ for 5 minutes. Ten $\mu$ of the reaction mixture that contain 10X RT buffer, $25 \mathrm{mM} \mathrm{MgCl} 2,0.1 \mathrm{mM}$ DTT and $1 \mu \mathrm{l}$ of SuperScript II RT (Invitrogen) was added to each RNA/primer sample and incubated at $25^{\circ} \mathrm{C}$ for 10 minutes and at $42^{\circ} \mathrm{C}$ for 50 minutes. The reaction was terminated at $70^{\circ} \mathrm{C}$ for 15 minutes then $1 \mu \mathrm{l}$ of RNase $\mathrm{H}$ (Invitrogen) was added to each reaction and incubated at $37^{\circ} \mathrm{C}$ for 20 minutes. Two microliters aliquots of the generated cDNA was amplified in $50 \mu$ of PCR reaction mixture containing $2 \mathrm{X}$ GoTaq ${ }^{\circledR}$ green master mix (Promega, Madison, WI), $100 \mathrm{nM}$ of each primer and $\mathrm{ddH}_{2} \mathrm{O}$. PCR cycles consisted of the initial cycle of $95^{\circ} \mathrm{C}$ for 2 minutes followed by a three step-program of $95^{\circ} \mathrm{C}$ for 45 seconds, $56^{\circ} \mathrm{C}$ for 45 seconds and $72^{\circ} \mathrm{C}$ for 45 seconds for 25 cycles. Twenty $\mu 1$ of RT-PCR reactions were mixed with $2 \mathrm{X}$ DNA dye and loaded on $1 \%$ agarose gel, run for 30 minutes in ENDURO gel XL electrophoresis system (Labnet, Edison, NJ). Gel images were captured using SafeBlue imager system (MajorScience, Saratoga, CA)

\section{Quantitative Real Time RT-PCR.}


$\mathrm{BMM}$ and osteoblast cultures were treated with $\mathrm{NaPP}_{\mathrm{i}}$ at various concentrations $(100-1000 \mu \mathrm{M})$

for 48 hours, as described above. Total RNA was extracted from the cells, using TRIzol®

Reagent (Invitrogen). After confirming the RNA integrity on an agarose gel, cDNA was

prepared using a High Capacity cDNA Reverse Transcription kit (Applied Biosystems ${ }^{\mathrm{TM}}$, Foster

City, CA). PCR was performed with the 7500 Fast Real-Time PCR system (Applied

Biosystems $^{\mathrm{TM}}$ ) in duplicate of $20 \mu \mathrm{l}$ reactions, each containing $1 \mu \mathrm{cDNA}$ reaction mix, $100 \mathrm{nM}$

of each primer and $10 \mu 12 x$ SYBR ${ }^{\circledR}$ Green PCR Master Mix (Applied Biosystems ${ }^{\mathrm{TM}}$ ). qPCR

cycles consisted of the initial cycle of $50^{\circ} \mathrm{C}$ for 2 minutes and the second cycle of $95^{\circ} \mathrm{C}$ for 10

minutes, followed by a two-step program of $95^{\circ} \mathrm{C}$ for 15 seconds and $60^{\circ} \mathrm{C}$ for 1 minute for 40

cycles. Using GAPDH as the internal control, relative gene expression among samples was

calculated by comparison of $\mathrm{C}_{\mathrm{t}}$ values. A dissociation curve was checked for each PCR run to

confirm specific amplification of target RNA. The PCR primer sets used in this study are listed

in Table 1.

Immunoblot Analysis - Protein was isolated in RIPA buffer (Sigma) and subjected to SDS-

PAGE as described previously. Briefly, proteins isolated from primary cultures were mixed with Laemmli denature buffer (Bio-Rad, Hercules, CA) and heated at $100^{\circ} \mathrm{C}$ for 5 minutes. Samples were subjected to $10 \%$ SDS-PAGE in $1 \times$ TGS (Bio-Rad) for one and half hour with current settings at $30 \mathrm{~mA}$ per gel. Gel was then transferred to Hybond ECL nitrocellulose membrane (Amersham Bioscience, UK) by semi-dry transfer apparatus (Bio-Rad) for two hours with current settings at $50 \mathrm{~mA}$ per gel. The blot was incubated in blocking buffer $(5 \%$ skim milk in TTBS) (Bio-Rad) for one hour. The blot was then incubated with the primary antibody diluted in fresh blocking buffer $(1: 1000)$ overnight at $4^{\circ} \mathrm{C}$. The blot was washed in $1 \mathrm{X}$ TTBS for 3 times, 5 minutes each, and then incubated with HRP-conjugated secondary anti-mouse or anti-rabbit antibody diluted in fresh blocking buffer (1:5000), for one hour. The blot was washed in TTBS 
for 3 times and the signal was developed using Western Lightening Plus-ECL kit (PerkinElmer, Waltham, MA) and detected on HyBlot CL X-ray films (Denville).

\section{Morphometric Image Analysis.}

All images were captured using a Canon EOS 5D 12.8 MP digital SLR camera with EF 24-105 mm f/4 L IS USM Lens. All images were analyzed with Java-based image-processing program developed at the NIH and the Laboratory for Optical and Computational Instrumentation, Image $\mathrm{J}(\mathrm{v} .1 .49 \mathrm{o})$. The percent area fraction of TRAP positive staining was calculated for calvarial organ cultures as follow: dividing six randomly selected area fraction (The percentage of pixels in the selected image that have been highlighted in red), at or above the limit of threshold, by the same area fraction for total number of pixels through the entire field. Each treatment group consisted of three different murine calvaria.

Osteoclast activity of cells on synthetic calcium phosphate and dentin discs was assessed by counting resorption pits from six randomly selected fields per well, three wells per treatment group. The total resorption area was computed using the area measurement function in the image J program.

\section{Statistical Analysis.}

Statistical analyses were performed using Prism 4 (GraphPad Software, La Jolla, CA). one-way ANOVA was used to analyze quantitative PCR, semi-quantitative RT-PCR, Northern, and Western blot densitometry results for differences in analytes between groups. Then, post hoc analyses were carried out using the Bonferroni test for multiple comparisons and adjusted $\mathrm{p}$ values are reported. An adjusted $\mathrm{p}$ value of $<0.05$ was considered significant for all analyses. A $p$-value of less than 0.05 was considered statistically significant. Data are presented as the mean + standard error (SE) of at least three independent assays. 


\section{RESULTS}

Pyrophosphate $\left(\mathbf{P P}_{\mathbf{i}}\right)$ stimulates bone resorption ex vivo. Previous reports investigated the role of $\mathrm{PP}_{\mathrm{i}}$ in skeletal hypo-mineralization (21). In this study we asked whether exogenous $\mathrm{PP}_{\mathrm{i}}$ has a direct impact on bone resorption, using ex vivo murine calvarial bone dissected from C57BL/6 mice at postnatal day 6 . The organ cultures were treated with sodium pyrophosphates $\left(\mathrm{Na} \mathrm{PP}_{\mathrm{i}}\right)$ for 72 hours at final concentrations of $(0-1000) \mu \mathrm{M}$ and assayed for the $\mathrm{Ca}^{2+}$ level in the conditioned media $(\mathrm{CM})$. Lower doses of $\mathrm{Na} \mathrm{PP}_{\mathrm{i}}<100 \mu \mathrm{M}$ have no effect in calvarial bone resorption (data not shown), however higher doses of $\mathrm{Na} \mathrm{PP}_{\mathrm{i}} \geq 100 \mu \mathrm{M}$ promoted osteolysis. As shown in Fig-1A, $\mathrm{PP}_{\mathrm{i}}$ treatment increased the $\mathrm{Ca}^{2+}$ release from calvarial bone cultures into the media in a dose dependent manner $(p<0.01)$, compared to the untreated controls, suggesting that exogenous $\mathrm{PP}_{\mathrm{i}}$ has a calciotropic role. To verify the previous data, we measured CTX-1; an indicator for osteoclast activity, in conditioned media. $\mathrm{PP}_{\mathrm{i}}$ treatment increased the level of CTX$1(p<0.01)$, compared to the untreated controls (Fig-1B). These data were confirmed by the whole mount TRAP staining of calvarial organ cultures. $\mathrm{PP}_{\mathrm{i}}$ treatment increased the TRAP staining intensity (Fig-1C). Calculated percent area fraction of the stained calvaria confirmed the increased TRAP staining of PP treated calvaria in a dose dependent manner $(p<0.01)$ (Fig-1D). Moreover, calvarial organs treatment with $\mathrm{PP}_{\mathrm{i}}(1000 \mu \mathrm{M})$ increased size of TRAP positive multinucleated osteoclasts in the whole mount calvaria, compared to untreated control (Fig-1E). Sagittal sections of TRAP stained calvaria and counterstained with von Kossa showed larger multinucleated osteoclasts in large and deep resorption pit compared to untreated control (Fig1F). To gain a further insight of $\mathrm{PP}_{\mathrm{i}}$ effects on osteoclast activity in bone resorption, calvarial organs were treated with $\mathrm{PP}_{\mathrm{i}}$ and/or quinazoline; an inhibitor of NFкB activation (59).

Quinazoline inhibited $\mathrm{PP}_{\mathrm{i}}$-mediated bone resorption marked by reduced $\mathrm{Ca}^{2+}$ levels in a dose dependent manner $(p<0.01)$, compared to calvarial treatment with $\mathrm{PP}_{\mathrm{i}}$ alone (Fig-1G). Taken 
together, these data provide an evidence that exogenous $\mathrm{PP}_{\mathrm{i}}$ stimulates osteoclast activity in bone resorption.

To investigate the calciotropic role of $\mathrm{PP}_{\mathrm{i}}$ on cytokines-mediated bone resorption, we measured $\mathrm{Ca}^{2+}$ levels in conditioned media of calvaria treated with cytokines and/or $\mathrm{PP}_{\mathrm{i}}$. Interestingly, $\mathrm{PP}_{\mathrm{i}}$ enhanced TNF $\alpha$-mediated $\mathrm{Ca}^{2+}$ release in a dose dependent manner $(p<0.01)$, compared to $\mathrm{TNF} \alpha$ or $\mathrm{PP}_{\mathrm{i}}$ treated controls (Fig-2A). In contrast, the pyrophosphate analogue; disodium clodronates inhibited TNF $\alpha$-mediated $\mathrm{Ca}^{2+}$ release in a dose dependent manner $(p<0.01)$, compared to TNF $\alpha$ treated controls (Fig-2B).

As previously indicated that transmembrane alkaline phosphatase; TNAP hydrolyzes $\mathrm{PP}_{\mathrm{i}}$ into two inorganic phosphates $\left(\mathrm{P}_{\mathrm{i}}\right)(58)$, we sought that Levamisole; TNAP inhibitor (14) will

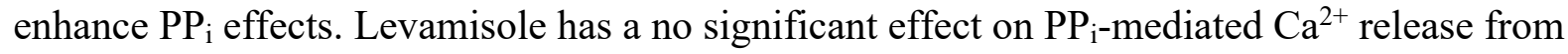
calvarial bones $(p>0.05)$, compared to $\mathrm{PP}_{\mathrm{i}}$ treated controls (Fig-2C). Moreover, treatment of calvarial organs with phosphonoformic acid (PFA); $\mathrm{P}_{\mathrm{i}}$ transport inhibitor (17) and $\mathrm{PP}_{\mathrm{i}}$ has no additive effects on $\mathrm{PP}_{\mathrm{i}}$-mediated $\mathrm{Ca}^{2+}$ release, compared to $\mathrm{PP}_{\mathrm{i}}$ treated controls (Fig-2D).

To exclude the possibility of $\mathrm{P}_{\mathrm{i}}$ action in $\mathrm{PP}_{\mathrm{i}}$-stimulated bone resorption, calvarial bones were treated with sodium phosphates $\left(\mathrm{Na} \mathrm{P}_{\mathrm{i}}\right)$ for 72 hours and assayed for the $\mathrm{Ca}^{2+}$ level in conditioned media. Interestingly, $\mathrm{Na} \mathrm{P}_{\mathrm{i}}$ treatment shifted the $\mathrm{Ca}^{2+}$ off media in a dose dependent manner $(p<0.001)$, compared to controls (Fig-2E). This effect was reversed when PFA was added to $\mathrm{P}_{\mathrm{i}}$-treated calvarial bones (Fig-2F). These data restrain the possibility of $\mathrm{PP}_{\mathrm{i}}$ hydrolysis into $\mathrm{P}_{\mathrm{i}}$ in the culture media, and also constrain the effect of $\mathrm{P}_{\mathrm{i}}$ in $\mathrm{PP}_{\mathrm{i}}$-mediated $\mathrm{Ca}^{2+}$ release.

To further confirm the potential role of $\mathrm{PP}_{\mathrm{i}}$ in bone resorption, calvarial organ cultures were treated with probenecid; an anion transport inhibitor, that decrease $\mathrm{PP}_{\mathrm{i}}$ entrance intracellular. Interestingly, probenecid inhibited $\mathrm{PP}_{\mathrm{i}}$-mediated $\mathrm{Ca}^{2+}$ release in a dose dependent 
manner $(p<0.001)$, compared to $\mathrm{PP}_{\mathrm{i}}$ treated controls $($ Fig-2G). Taken together, these results unleash the authentic role of $\mathrm{NaPP}$ in stimulation of bone resorption.

\section{Pyrophosphate enhances osteoclast differentiation and function ex vivo.}

In the following study, we investigated whether $\mathrm{PP}_{\mathrm{i}}$ has an effect on bone marrow-derived monocytes (BMMs) to differentiate into mature osteoclasts. Quantitative PCR analysis showed an increased TRAP expression in BMMs treated with exogenous $\mathrm{PP}_{\mathrm{i}}$ in a dose dependent manner $(p<0.01)$, compared to control (Fig-3A). Next, BMMs were treated with $\mathrm{PP}_{\mathrm{i}}(100-1000) \mu \mathrm{M}$ and stained for TRAP. As shown in Fig-3B, BMMs treated with $\mathrm{PP}_{\mathrm{i}}$ demonstrated an increased number of TRAP positive mononuclear cells (osteoclast precursors; pre-osteoclasts) compared to control. Consistent with the previous data, TRAP activity was higher in BMMs treated with $\mathrm{PP}_{\mathrm{i}}$ $(p<0.001)$ (Fig-3C). Next, we examined osteoclast differentiation in BMMs treated with PP $\mathrm{i}_{\mathrm{i}}$ Interestingly, BMMs pretreated with $\mathrm{PP}_{\mathrm{i}}$ showed a significant osteoclast differentiation, in response to RANKL, as indicated by larger TRAP-positive osteoclasts, compared to untreated counterparts (Fig-3D). These findings were supported with significant increase in TRAP activity,

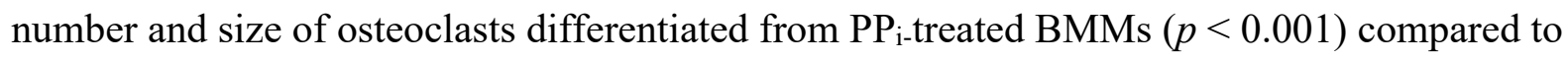
control (Fig-3E, F, G, and H). To further support our data, BMMs were treated with $\mathrm{PP}_{\mathrm{i}}$ and differentiated on glass slides then stained with Rhodamine for actin cytoskeleton. Consistently, the size of osteoclast was larger in BMMs pretreated with $\mathrm{PP}_{\mathrm{i}}$ then differentiated with RANKL compared to untreated controls (Fig-3I). Moreover, the acting ring was sharp and prominent in osteoclasts treated with $\mathrm{PP}_{\mathrm{i}}$ compared to control. These data suggest that $\mathrm{PP}_{\mathrm{i}}$ treatment enhance osteoclastogenesis.

Given that $\mathrm{PP}_{\mathrm{i}}$ promoted osteoclast differentiation, we explored the osteolytic activity of those mature osteoclasts. $\mathrm{BMMs}$ treated with $\mathrm{PP}_{\mathrm{i}}$ were differentiated into osteoclasts in response to RANKL, over human bone chips. Photomicrographs of bone chips showed large TRAP-positive 
osteoclasts with decrease of bone chips fragments in BMMs treated with $\mathrm{PP}_{\mathrm{i}}$ compared to untreated controls (Fig-4A). These findings were confirmed with marked increase in TRAP activity, $\mathrm{Ca}^{2+}$ and CTX-1 levels in the CM of osteoclasts promoted from BMMs treated with $\mathrm{PP}_{\mathrm{i}}$ $(p<0.001)$ in a dose dependent manner (Fig-4B, C, and D).

These data were supported by testing the osteolytic activity of $\mathrm{PP}_{\mathrm{i}}$ promoted osteoclasts on bone discs. Photomicrographs of bone discs, after removal of osteoclasts, showed large pit

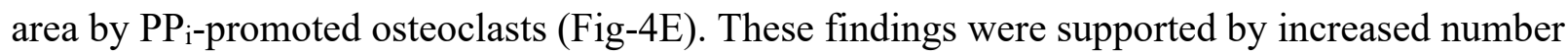
of resorption pits, total resorbed surface area, and the average pit size in $\mathrm{PP}_{\mathrm{i}}$-promoted osteoclasts $(p<0.01)$ in a dose dependent manner (Fig-4F, G, and H). Collectively, these results

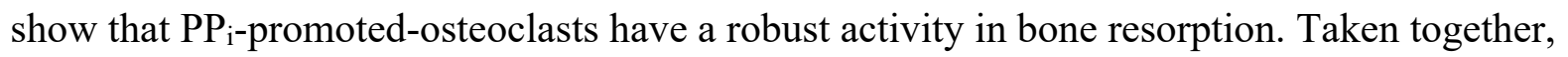
these data provide a pivotal evidence on the regulatory role of $\mathrm{PP}_{\mathrm{i}}$ in osteoclast differentiation and function.

\section{Pyrophosphate stimulates osteoclast differentiation and function in co-culture system.}

As $\mathrm{PP}_{\mathrm{i}}$ stimulated bone resorption in murine calvarial organs in the data described above, we investigated the contribution of osteoblasts in $\mathrm{PP}_{\mathrm{i}}$-enhanced pre-osteoclasts and osteoclastogenesis. Co-culture system of murine osteoblasts and BMMs was established and treated with vitamin $\mathrm{D}_{3}$ (positive control) or $\mathrm{PP}_{\mathrm{i}}(100-1000) \mu \mathrm{M}$ and stained for TRAP. Interestingly, BMMs co-cultured with osteoblasts and treated with $\mathrm{PP}_{\mathrm{i}}$ demonstrated obvious osteoclast differentiation indicated by large TRAP + mature osteoclasts compared to untreated control (Fig-5A). These data were supported with marked increase in TRAP activity, number and

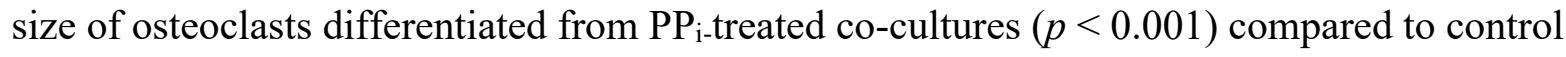
(Fig-5B, C, and D). Surprisingly, the number and size of TRAP+ osteoclasts was not different ( $p$ $>0.05)$ in $\mathrm{PP}_{\mathrm{i}}$-treated co-culture, compared to vitamin $\mathrm{D}_{3}$ positive control. 
Given that $\mathrm{PP}_{\mathrm{i}}$ promoted osteoclast differentiation in co-culture system, we test the osteolytic activity of those mature osteoclasts. The co-culture system of murine Osteoblasts and BMMs was established on dentin discs and treated with vitamin $\mathrm{D}_{3}$ or $\mathrm{PP}_{\mathrm{i}}(1000) \mu \mathrm{M}$. Photomicrographs of dentin discs displayed an obvious bone resorption marked by large resorption pits and tracks

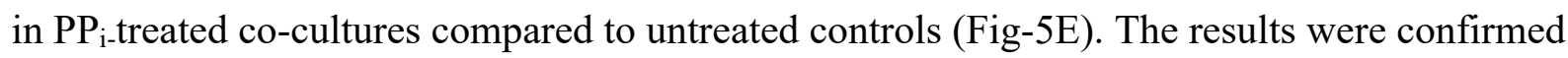
with marked increase $(p<0.001)$ in CTX-1 levels in the CM (Fig-5F) and the average total resorption area of dentin discs (Fig-5G) in $\mathrm{PP}_{\mathrm{i}}$-treated co-cultures compared to untreated control. Interestingly, the dentin discs displayed more complex bone resorption tracks in $\mathrm{PP}_{\mathrm{i}}$-stimulated osteoclasts, compared to vitamin $\mathrm{D}_{3}$ positive control in the co-culture system (Fig-5E). These data suggest that $\mathrm{PP}_{\mathrm{i}}$-stimulated osteoclastogenesis and bone resorption is mediated at least in part by osteoblasts.

To gain insight on the underlying mechanism of $\mathrm{PP}_{\mathrm{i}}$-promoted osteoclasts in co-culture, we examined RANKL and OPG gene expressions in murine calvrial osteoblasts treated with $\mathrm{PP}_{\mathrm{i}}$ (100-1000) $\mu \mathrm{M}$ or vitamin $\mathrm{D}_{3}$ positive control. Quantitative (q)RT-PCR showed up-regulation of RANKL mRNA $(p<0.01)$ and RANKL/OPG ratio $(p<0.001)$ in osteoblasts treated with PP ${ }_{\mathrm{i}}$ (1000) $\mu \mathrm{M}$, compared to the untreated control (Fig-5H and I). Interestingly, the RANKL expression and RANKL/OPG ratio were not different $(p>0.05)$ in $(1000) \mu \mathrm{M} \mathrm{PP}_{\mathrm{i}}$-treated osteoblasts compared to vitamin $\mathrm{D}_{3}$ positive control. Although RANKL mRNA expression was not different, RANKL/OPG ratio was increased $(p<0.05)$ in lower dose $(100) \mu \mathrm{M}$ of PPi-treated osteoblasts compared to the untreated control. In parallel experiments, we differentiated BMMs with concentrated condition medium $(\mathrm{CM})$ from osteoblasts treated with $\mathrm{PP}_{\mathrm{i}}$. Our results revealed increased TRAP activity and TRAP + mature osteoclasts treated with concentrated osteoblast CM compared to the untreated control (data not shown). Taken together, these data 
showed a clear evidence that $\mathrm{PP}_{\mathrm{i}}$ increased RANKL by osteoblasts that is responsible, at least in

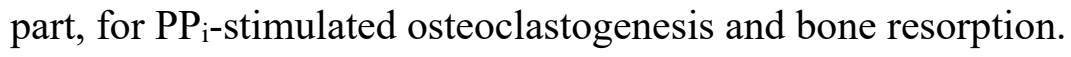

\section{Activation of RANK-RANKL pathway in Pyrophosphate-enhanced pre-osteoclasts.}

Next, we explored the down-stream signaling pathway that mediates enhanced

osteoclastogenesis in $\mathrm{PP}_{\mathrm{i}}$-treated $\mathrm{BMMs}$. In this study, BMMs-treated $\mathrm{PP}_{\mathrm{i}}$ were analyzed for the early transcription factors responsible for BMM commitment, using semi-quantitative RT-PCR (RT-PCR) analysis. The transcription factors; PU.1 and MITF responsible for hematopoietic stem cells commitment into osteoclast progenitors (47), showed an up-regulation in $\mathrm{PP}_{\mathrm{i}}$-treated BMMs in a dose dependent manner (Fig-6A). Similarly, the cFMS (MCSF receptor) and RANK receptor gene expressions were also increased in $\mathrm{PP}_{\mathrm{i}}$-treated BMMs (Fig-6A). These data were confirmed by quantitative $(q)$ RT-PCR that showed up-regulation $(p<0.01)$ of cFMS and RANK in PP ${ }_{\mathrm{i}}$-treated BMMs (Fig-6B and C). Moreover, the transcription factors; c-Fos and c-Jun (AP-1 heterodimeric complex); downstream of MAPK signaling, also showed higher expression in $\mathrm{PP}_{\mathrm{i}^{-}}$ treated BMMs (Fig-6D and E). By examining the NF-кB mRNA, our findings showed a $\sim 2$-fold increase of NF-кB (P50/P65) expression in $\mathrm{PP}_{\mathrm{i}}$-treated BMMs compared to untreated control (Fig-6F).

Next, we examined activation of MAP-Kinase (ERK1/2 and P38) which is downstream of RANK receptor in osteoclast differentiation (37). BMMs were treated with $\mathrm{PP}_{\mathrm{i}}$ and/or ERK1/2 inhibitor (U0126) and/or P38 inhibitor (SB203580) for up to 90 minutes. Western blot data showed increased phosphorylation of ERK1/2 (pERK) in $\mathrm{PP}_{\mathrm{i}}$-treated BMMs reaching the maximum at 10 minutes, compared to untreated control (Fig-6G). On the other hand, U0126 inhibited $P_{i}$ effect on ERK phosphorylation at 5 and 10 minutes (Fig-6G). Densitometric analysis confirmed $\sim 3$-fold inhibition of ERK phosphorylation in U0126-treated conditions, compared to $\mathrm{PP}_{\mathrm{i}}$ treatment alone (Fig-6H). Similarly, phosphorylation of P38 was increased 
significantly in $\mathrm{PP}_{\mathrm{i}}$-treated BMMs, compared to untreated control, whereas SB203580 inhibited $\mathrm{PP}_{\mathrm{i}}$ effect on P38 phosphorylation (Fig-6I). Densitometry showed approximately $\sim 2$-fold decrease of P38 phosphorylation in SB203580-treated conditions, compared to $\mathrm{PP}_{\mathrm{i}}$ treatment alone (Fig-6J). Collectively, these data support the activation of downstream signaling cascade of RANK and MAPK in PPi-treated BMMs.

\section{Pyrophosphate regulates PU.1 signaling pathway in BMMs.}

As PU.1 is an early transcription factor in BMM pre-osteoclasts and has a pivotal role in regulation of cFMS; MCSF receptors (38), we investigated the role of $\mathrm{PP}_{\mathrm{i}}$ in the downstream signaling pathway of cFMS in PP ${ }_{\mathrm{i}}$-treated BMMs. Interestingly, qRT-PCR showed that PU.1 is up-regulated ( 2.5-fold) in $\mathrm{PP}_{\mathrm{i}}$-treated BMMs in a dose dependent manner (Fig-7A). Next, we examined the transcription factors; Egr-1 and Egr-2 that have been reported as downstream mediators of PU.1 in BMMs (16). qRT-PCR analysis of Egr-1 gene expression was 2.5-fold higher in $\mathrm{PP}_{\mathrm{i}}$-treated $\mathrm{BMMs}$ in a dose dependent manner (Fig-7B). In contrast, Egr-2 expression was not different in $\mathrm{PP}_{\mathrm{i}}$-treated BMMs and control (Fig-7C). To support our data and define the precise role of $\mathrm{PP}_{\mathrm{i}}$ on PU.1, we treated PUER cells with $\mathrm{PP}_{\mathrm{i}}$ and examined cFMS and RANK, Egr-1, and Egr-2 expressions. PUER cells are murine hematopoietic precursor cells that have been retro-virally transduced to express PU.1 fused to the estrogen receptor (ER) (57). PUER ${ }^{\text {hi }}$ cells was used as appositive control to PUER ${ }^{\text {lo }}$ cells. RT-PCR data showed marked up-regulation of cFMS and RANK expressions, when hydroxytamoxifen (OHT) is added to PUER ${ }^{\text {hi }}$ cells, compared to untreated PUER ${ }^{\text {hi }}$ cells (Fig-7D). On the other hand, PUER ${ }^{\text {lo }}$ treated with $\mathrm{PP}_{\mathrm{i}}$ showed relative up-regulation of cFMS and RANK expressions compared to untreated PUER ${ }^{\text {lo }}$ control by RT-PCR (Fig-7D). Densitometric analyses of RT-PCR data demonstrated $\sim 2$ to 6-fold increased levels of cFMS and RANK in $\mathrm{PP}_{\mathrm{i}}$-treated $\mathrm{PUER}^{\text {lo }}$ cells compared to untreated $\mathrm{PUER}^{\mathrm{lo}}$ 
control (Fig-7E, F). Interestingly, expression levels of cFMS and RANK were relatively similar $(p>0.05)$ in PP $_{\text {i-treated PUER }}^{\text {lo }}$ cells and untreated PUER ${ }^{\text {hi }}$ cells (Fig-7D, E, F).

Next, we characterized expression of Egr-1 and -2 in PUER ${ }^{\text {lo }}$ and PUER ${ }^{\text {hi }}$ cells. Interestingly, Egr-1 expression was up-regulated in $\mathrm{PP}_{\mathrm{i}}$-treated PUER ${ }^{\text {lo }}$ cells, compared to untreated PUER ${ }^{10}$ control Fig-7D). These data were verified by densitometric analysis as $\sim 3$-fold

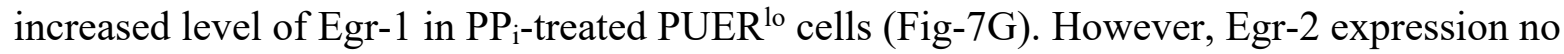
significant difference in $\mathrm{PP}_{\mathrm{i}}$-treated PUER ${ }^{\text {lo }}$ cells, untreated PUER ${ }^{\text {lo }}$ cells, and OHT treated or untreated PUER ${ }^{\text {hi }}$ cells (Fig-7D). These data were confirmed by densitometric analysis that showed relatively equal level of Egr-2 $(p>0.05)$ in all treated and untreated conditions (Fig-7H). Taken together, we conclude that $\mathrm{PP}_{\mathrm{i}}$ stimulates PU.1 and its downstream signaling in osteoclast progenitors.

\section{Pyrophosphate enhances differentiation and survival of pre-osteoclasts in MITF-dependent}

\section{pathway.}

Because we showed above that $\mathrm{PP}_{\mathrm{i}}$ up-regulated MITF expression in $\mathrm{BMM}$ differentiation, we investigated if MITF signaling pathway might be involved in BMM survival as well. MITF is a key transcription factor, responsible for BMM commitment into osteoclast progenitors (41), we

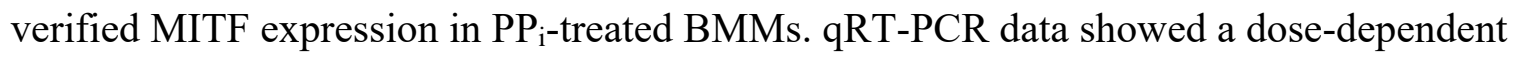
increase of MITF expression $(p<0.01)$ in $\mathrm{PP}_{\mathrm{i}}$-treated BMMs, compared to untreated control (Fig-8A). MITF has several isoforms where MITF-A and -E have been reported to regulate macrophage polarization and osteoclastogenesis, respectively (5). Semi-quantitative RT-PCR data showed relevant higher expressions of MITF-A and -E in $\mathrm{PP}_{\mathrm{i}}$-treated BMMs in a dose dependent manner, compared to untreated control (Fig-8B). These data were confirmed by densitometry analysis that showed $\sim 6$ to 10 -fold increase in MITF-A and MITF-E in PP -treated $^{-}$ BMMs compared to untreated control (Fig-8C, D). Next, we examined survival of osteoclast 
progenitors, where BMMs were primed with MCSF then treated with $\mathrm{PP}_{\mathrm{i}}$ in serum deprived conditions for 48 hours. Interestingly, BCL-2, a pro-survival transcription factor, showed a dosedependent increase $(p<0.01)$ in $\mathrm{PP}_{\mathrm{i}}$-treated osteoclast progenitors compared to untreated control (Fig-8E). To study the downstream mechanism by which $\mathrm{PP}_{\mathrm{i}}$ stimulates BCL-2 expression, we examined BCL-2 in RAW 264.7 macrophage-cell lines, treated with $\mathrm{PP}_{\mathrm{i}}$ in comparison to RAW cells over-expressing MITF. Interestingly, $\mathrm{PP}_{\mathrm{i}}$ stimulated 2 -fold increase of BCL-2 in wild-type

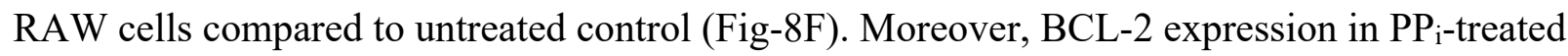
wild-type RAW cells was comparable to its expression in RAW cells over-expressing MITF. Interestingly, ERK-1 and -2 inhibitor (U0126) inhibited BCL-2 expression in PP $\mathrm{P}_{\mathrm{i}}$-treated wildtype RAW cells compared to $\mathrm{PP}_{\mathrm{i}}$ alone or RAW overexpressing MITF controls (Fig-8F). Collectively, these data provide a supportive evidence that $\mathrm{PP}_{\mathrm{i}}$ stimulates survival of osteoclast progenitors, MITF and BCL-2, an effect mediated by MAPK signaling pathway.

Several studies affirmed the regulatory effects of MAP-Kinase on MITF in osteoclast progenitors (41). In this study, we examined if activation of MAPK controls survival of osteoclast progenitors, BMMs were primed with MCSF then treated with $\mathrm{PP}_{\mathrm{i}}$ and/or ERK-1 and 2 inhibitor (U0126), and/or P38 inhibitor (SB203580), in serum deprived conditions. Survival of osteoclast progenitor was enhanced $(p<0.01)$ when treated with $\mathrm{PP}_{\mathrm{i}}$ compared to untreated control (Fig-8G). However, treatment of osteoclast progenitors with $\mathrm{PP}_{\mathrm{i}}$ and U0126 decreased osteoclast survival significantly $(p<0.01)$ compared to $\mathrm{PP}_{\mathrm{i}}$ alone and comparable to untreated control (Fig-8G). On the other hand, SB203580 has no effect on $\mathrm{PP}_{\mathrm{i}}$-enhanced survival of osteoclast progenitors, compared to $\mathrm{PP}_{\mathrm{i}}$ treatment alone. Moreover, U0126 has a dominant inhibitory effect $(p<0.05)$ on survival of osteoclast progenitors when treated with $\mathrm{PP}_{\mathrm{i}}$ and SB203580 (Fig-8G). To confirm that MAPK regulates MITF-mediated survival of osteoclast progenitors, we treated wild-type RAW cells and RAW cells overexpressing MITF with PP 
and/or U0126, and/or SB203580 in serum deprived conditions. Consistent with the previous data, $\mathrm{PP}_{\mathrm{i}}$ treatment increased survival of wild-type RAW cells $(p<0.05)$ compared to untreated control and comparable to RAW overexpressing MITF (Fig-8H). Moreover, U0126 inhibited survival of PP $\mathrm{i}_{\mathrm{i}}$-treated wild-type RAW cells $(p<0.05)$ compared to $\mathrm{PP}_{\mathrm{i}}$ alone or RAW overexpressing MITF controls. However, U0126 didn't inhibit survival of RAW overexpressing

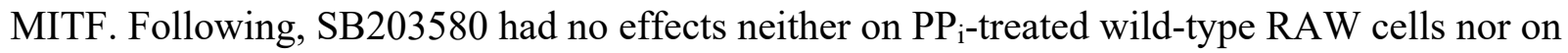
RAW overexpressing MITF (Fig-8H). Combined treatment with U0126 and SB203580 reduced survival of $\mathrm{PP}_{\mathrm{i}}$-treated wild-type RAW cells $(p<0.05)$ compared to untreated control. However, U0126 and SB203580 didn't affect survival of RAW overexpressing MITF (Fig-8H). To support our conclusions, we tested MITF phosphorylation in osteoclast progenitors by Western blot. Osteoclast progenitors were primed with MCSF then serum starved and treated with $\mathrm{PP}_{\mathrm{i}}$ and/or U0126 for the indicated time points. Interestingly, $\mathrm{PP}_{\mathrm{i}}$ treatment increased MITF phosphorylation on the Serine 307 residue at all-time points reaching the maximum at 90 minutes, compared to 0minute control (Fig-8I). In accordance with the previous data, U0126 inhibited $\mathrm{PP}_{\mathrm{i}}$ effects on MITF phosphorylation. Treatment of RAW cells with $\mathrm{PP}_{\mathrm{i}}$ and/or U0126 showed similar results (data not shown). Densitometric analysis of the Western blot demonstrated $\sim$ - to 8-fold increase in MITF phosphorylation at 60 and 90 minutes in $\mathrm{PP}_{\mathrm{i}}$-treated osteoclast progenitors compared to 0-minute control (Fig-8J). Moreover, U0126 inhibited MITF phosphorylation significantly compared to $\mathrm{PP}_{\mathrm{i}}$ alone at 60 and 90 minutes. Taken together, we conclude that $\mathrm{PP}_{\mathrm{i}}$ stimulates survival of osteoclast progenitors and MITF phosphorylation through ERK-1/2 signaling pathway.

\section{Role of ANK in Pyrophosphate-mediated osteoclastogenesis.}

The data above described the roles of $\mathrm{PP}_{\mathrm{i}}$ in $\mathrm{BMM}$ survival, differentiation, and osteoclast function, so we pursued to examine the importance of $\mathrm{ANK}$ in regulation of $\mathrm{PP}_{\mathrm{i}}$ effects on 
osteoclastogenesis. ANK has been reported in various studies to transport inorganic $\mathrm{PP}_{\mathrm{i}}$ across the cell membrane (64). In the beginning, we examined ank mRNA during osteoclast differentiation by Northern blot. Expression of ank mRNA demonstrated a temporal increase during osteoclast differentiation, coming from BMMs and RAW 264.7 cells, respectively (Fig9A). Densitometry showed a significant increase of ank expression during osteoclast differentiation reaching the maximum at $11(p<0.01)$ with BMMs and 6 days $(p<0.05)$ with RAW cells, respectively (Fig-9B). Western blot supported the significant increase in ANK levels in BMMs differentiated into osteoclasts (data not shown). Consistent with the previous data, ANK protein showed a temporal increase in osteoclasts differentiated from RAW cells reaching the highest level at day $6(p<0.01)$, compared to 0 -undifferentiated control (Fig-9C, D). Next, we tested if $\mathrm{PP}_{\mathrm{i}}$ regulates ank in osteoclast progenitors. Interestingly, $\mathrm{qPCR}$ analysis of $\mathrm{PP}_{\mathrm{i}}$ treated BMMs showed a dose dependent increase in ank expression $(p<0.01)$, (Fig-9E).

To characterize the calciotropic role of $\mathrm{PP}_{\mathrm{i}}$ transporter; ANK, we treated calvarial bone organs with $\mathrm{PP}_{\mathrm{i}}$ and/or probenecid; an anion $\mathrm{ANK}$ inhibitor (12). $\mathrm{PP}_{\mathrm{i}}$ stimulated bone resorption marked by $\mathrm{Ca}^{2+}$ release $(p<0.01)$, compared to untreated control (Fig-9F). However, probenecid inhibited $\mathrm{PP}_{\mathrm{i}}$-mediated $\mathrm{Ca}^{2+}$ release in a dose dependent manner $(p<0.001)$. To support these data, we treated $\mathrm{BMMs}$ with $\mathrm{PP}_{\mathrm{i}}$ and/or probenecid then osteoclast progenitors were differentiated with RANKL. TRAP activity was increased $(p<0.01)$ in osteoclast differentiated from $\mathrm{PP}_{\mathrm{i}}$-treated BMMs, compared to RANK-L alone (Fig-9G). However, combined treatment of BMMs with $\mathrm{PP}_{\mathrm{i}}$ and probenecid decreased TRAP activity of osteoclasts, compared to $\mathrm{PP}_{\mathrm{i}}$ treatment alone $(p<0.05)$. To confirm the selective role of $\mathrm{ANK}$ in $\mathrm{PP}_{\mathrm{i}}$ transport during osteoclast differentiation, we used BMMs isolated from ank/ank mice and their wild-type littermates. ank/ank mice are characterized with nonsense mutation of ank gene leading to loss of function in active $\mathrm{PP}_{\mathrm{i}}$ transport (15). Treatment of ank/ank BMMs with $\mathrm{PP}_{\mathrm{i}}$ didn't have an effect, 
compared to upstroke increase $(p<0.01)$ in osteoclast differentiation in their wild-type $\mathrm{PP}_{\mathrm{i}^{-}}$ treated BMMs (Fig-9H). To investigate if ANK-PP ${ }_{i}$ transport regulates ERK-1/2

phosphorylation, WT-ank BMMs were treated with $\mathrm{PP}_{\mathrm{i}}$ and/or probenecid in serum-deprived conditions. probenecid inhibited $\mathrm{PP}_{\mathrm{i}}$-mediated ERK-1/2 phosphorylation in WT-ank $\mathrm{BMMs}$,

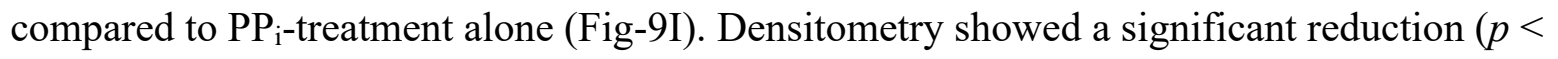
0.05) of ERK-1/2 phosphorylation in probenecid/ PP $\mathrm{P}_{\mathrm{i}}$ treated WT-ank BMMs at 5 and 10 minutes (Fig-9J). Taken together, these data provide a strong evidence that ANK transporter regulates $\mathrm{PP}_{\mathrm{i}}$ effects during osteoclast differentiation.

\section{DISCUSSION}

The role of pyrophosphates $\left(\mathrm{PP}_{\mathrm{i}}\right)$ in tissue remodeling has been controversial. $\mathrm{PP}_{\mathrm{i}}$ preserve the differentiated phenotype of articular chondrocytes, whereas several studies have documented $\mathrm{PP}_{\mathrm{i}}$ generation, transport, and activity in vivo, most notably for chondrocytes and the tissues of joints (8). It is well established that pyrophosphates $\left(\mathrm{PP}_{\mathrm{i}}\right)$ inhibit tissue calcification in normal conditions $(45,56)$. In bone, several studies reported $\mathrm{PP}_{\mathrm{i}}$ as a negative regulator of osteoblast differentiation and matrix mineralization $(3,24) . \mathrm{PP}_{\mathrm{i}}$ was reported to inhibit mineralization by direct binding to hydroxyapatite crystals and inhibiting alkaline phosphatase activity (ALP) (3). However, the significance of $\mathrm{PP}_{\mathrm{i}}$ in osteoclast differentiation and function was yet to be determined. This led us to further investigate the impact of $\mathrm{PP}_{\mathrm{i}}$ on osteoclastogenesis and so bone resorption.

In this study, we examined the direct effect of $\mathrm{PP}_{\mathrm{i}}$ on calvarial bone resorption and osteoclast differentiation ex vivo. Concentration of $\mathrm{PP}_{\mathrm{i}}$ reaches the saturation level $\geq 100 \mu \mathrm{M}$ and form CPPD crystals in culture media. We hypothesized that CPPD microcrystals promoted bone resorption in vitro. Interestingly, only higher doses of $\mathrm{PP}_{\mathrm{i}}$ that form $\mathrm{CPPD}$ microcrystals are 
effective inducers of osteolysis. CPPD microcrystals stimulated osteolysis in calvarial organs over 3 days, as indicated by $\mathrm{Ca}^{2+}$ and CTX-1 data. It could be explained by CPPD microcrystals regulate pre-osteoclast differentiation at simultaneous stages in the context of cell milieu of calvaria. Another possibility is CPPD microcrystals increase RANKL expression by calvarial osteoblasts, promoting BMMs to differentiate to osteoclasts. The CPPD-mediated bone resorption might also due to direct activation of mature calvarial osteoclasts. These possibilities plus others warrant further analysis in future studies.

It is important to distinguish the effect of $\mathrm{PP}_{\mathrm{i}}$ from bisphosphonates on osteoclast-stimulated bone resorption. Although bisphosphonates are stable analogue of pyrophosphates $\left(\mathrm{PP}_{\mathrm{i}}\right)$, previous reports well documented bisphosphonates to inhibit bone resorption and treat patients with osteoporosis (33).

Consistent with the previous reports, indeed bisphosphonates decreased calvarial bone resorption. These data yet provide a clear evidence on the unique positive role of $\mathrm{PP}_{\mathrm{i}}$ in osteolysis. Next, pyrophosphates anions $\left(\mathrm{PP}_{\mathrm{i}}\right)$ are formed of two phosphate $\left(\mathrm{P}_{\mathrm{i}}\right)$ ions linked by ester bond and it is the simplest condensed phosphate. In contrast to $\mathrm{PP}_{\mathrm{i}}$ bone resorptive effects, $\mathrm{P}_{\mathrm{i}}$ was found to inhibit osteolysis in consistent with the previous published reports of the inhibitory role of $\mathrm{P}_{\mathrm{i}}$ on osteoclast differentiation and function (62). Although, $\mathrm{P}_{\mathrm{i}}$ are released from $\mathrm{PP}_{\mathrm{i}}$ by hydrolysis upon stimulation of the ectoenzyme alkaline phosphatase (ALP) on osteoblasts, however, inhibition of ALP was not different to $\mathrm{PP}_{\mathrm{i}}$ effect on bone resorption. Suppression of ALP activity not only inhibit osteoblast function, but also decrease osteoclast differentiation factors and the overall bone remodeling (62). That may explain the trivial decline in osteoclast mediated $\mathrm{Ca}^{2+}$ release in $\mathrm{PP}_{\mathrm{i}}$-stimulated bone resorption. Another possibility is suppression of ALP has no role in formation of CPPD microcrystals. The $\mathrm{PP}_{\mathrm{i}}$ effects on calvarial bone resorption was also clarified by its indirect effect on osteoblasts and release of osteoclast 
differentiation factors. The note of presence of large mature osteoclasts when differentiated in co-culture with calvarial osteoblasts ex vivo, was explained, at least in part, by RANKL overexpression in $\mathrm{PP}_{\mathrm{i}}$-treated osteoblasts.

Initial depiction of BMMs showed hyper-responsiveness to RANKL, which can be confirmed by the high expression of RANK and cFMS receptor mRNA in pre-osteoclasts treated with $\mathrm{PP}_{\mathrm{i}}$. Vast reports have shown that overexpression of RANK receptors in osteoclast precursors, accelerated osteoclast differentiation in response to RANKL (30) whereas BMMs isolated from RANK -/- mice failed to respond to RANKL because of the apparent block in osteoclast differentiation (13). In addition, we have observed a marked increase in osteoclast number and size in BMMs treated with $\mathrm{PP}_{\mathrm{i}}$. Our data suggest that RANKL-induced signaling in

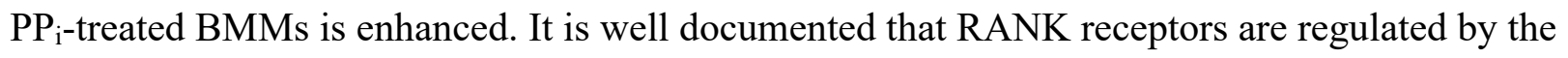
transcription factors PU.1 and MITF in osteoclasts (34). Moreover, Egr-1 and Egr-2 transcription factors are reported to work as downstream mediators of PU.1 in BMMs (16). Our study showed an increased expression of PU.1 in $\mathrm{PP}_{\mathrm{i}}$-treated-BMMs and -PUER ${ }^{\text {lo }}$ cells, which is correlated with increased RANK expression. Knowing that Egr-1 regulates osteoclastogenesis and Egr-1 deficiency block pre-osteoclast differentiation and osteoclast function (9). In our study, upregulation of Egr-1 was evidenced in $\mathrm{PP}_{\mathrm{i}}$-treated BMM cultures. Conversely, Egr-2 expression was not altered in $\mathrm{PP}_{\mathrm{i}}$-treated BMMs. One study identified Egr-2 as a negative modulator of osteoclast differentiation using gain-of-function and loss-of-function approaches (31). On the other hand, Bradley and her group claimed the importance of Egr-2 in promotion of osteoclast survival through activation of MEK/ERK-dependent pathway (7). Our data suggest that stimulation of PU.1 dependent pathway in $\mathrm{PP}_{\mathrm{i}}$-treated BMMs, resulted in osteoclast differentiation in response to RANKL. As enhanced OCL survival can possibly add to the increased number and size of osteoclasts, we investigated $\mathrm{BMM}$ survival programs in these $\mathrm{PP}_{\mathrm{i}^{-}}$ 
treated BMMs. Our data showed that survival of BMMs is enhanced and mediated by MAPKMITF phosphorylation. Expression analysis of overall MITF mRNA was also high in $\mathrm{PP}_{\mathrm{i}}$-treated BMMs. There are 7 isoforms of MITF (40). Previous studies showed that MITF-A isoform is expressed in similar amounts in macrophages (BMMs) and osteoclasts, however MITF-E isoform is almost non-noticeable in BMMs, and its expression is considerably up-regulated during osteoclastogenesis (39). Moreover, MITF activation by serine phosphorylation at residue 307 was reported to recruit P38 MAPK and NFATc1 target genes during osteoclastogenesis (52). Because enhanced osteoclast survival could possibly contribute to increased osteoclast number and size, we investigated osteoclast survival pathway in these $\mathrm{PP}_{\mathrm{i}}$-treated conditions. Our data showed that $\mathrm{PP}_{\mathrm{i}}$ stimulated pre-osteoclast survival and BCL-2 mediated by MAPK signaling pathway. It is well supported the crucial role of BCL-2 as anti-apoptotic in osteoclastogenesis and osteoclast survival (42). Indeed, our data supported up-regulation of BCL-2 in PP -treated $^{-}$ pre-osteoclasts. Yamashita et al., reported the critical importance of BCL-2 in osteoclast survival using $\mathrm{Bcl}-2^{-/-}$mice with increased bone mass due to at least in part declined osteoclastogenesis (61). Moreover, our study showed BCL-2 was downregulated in pre-osteoclasts treated with $\mathrm{PP}_{\mathrm{i}}$ and ERK inhibitor (U0126). In previous study, Subramanian and Shaha reported ERK phosphorylation up-regulates BCL-2 expression, associated with increased human macrophage survival (54). The overall cell survival of $\mathrm{PP}_{\mathrm{i}}$ treated pre-osteoclasts was decreased with ERK inhibitor, but not with P38 inhibitor. Interestingly, P38 was shown to induce the intrinsic apoptotic (Bim) molecule in human osteoclasts downstream of TGF $\beta 1$-Smad-2 signaling pathway. Furthermore, TGF $\beta 1$-induced osteoclast apoptosis was declined by inhibiting the Smad pathway with abolished Bim up-regulation following TGF- $\beta$ stimulation (25). Collectively, survival of $\mathrm{PP}_{\mathrm{i}}$-treated pre-osteoclasts is enhanced, perhaps due to controlled up-regulation of MAPK-BCL-2 pathway. 
Next, our data showed an increased RANK signaling in $\mathrm{PP}_{\mathrm{i}}$-treated BMMs resulted in activation of MAP kinase pathways through ERK (pERK) and P38 (pP38) phosphorylation. Indeed, ERK inhibitor (U0126) and P38 inhibitor (SB280) decreased ERK and P38 phosphorylation in $\mathrm{PP}_{\mathrm{i}}$-treated pre-osteoclasts. ERK1 was reported to stimulate osteoclast differentiation and their bone resorptive activity, as genetic disruption of ERK1 reduced numbers of osteoclast progenitors, and compromised pit formation (22). Moreover, it was reported that P38-MAPK activation is required for inducing osteoclast differentiation but not for their function (37).

Next, several reports well documented that RANK signaling activates MAP kinase, which in-turn activates AP-1 transcription factors (members of the Fra, Fos, and Jun) that activate downstream MITF, and thus, regulate osteoclastogenesis (36). Interestingly, our qPCR data showed up-regulation of c-Fos, c-Jun, and NFKB in PP $\mathrm{P}_{\mathrm{i}}$-treated pre-osteoclasts. A previous report has demonstrated that deletion of the $c-F O S$ gene resulted in osteopetrosis by arresting osteoclast differentiation at the macrophage stage and this defect was completely rescued by expressing Fos protein (18). The role of $\mathrm{PP}_{\mathrm{i}}$ in activation of $\mathrm{AP}-1$ warrant further investigation in future studies.

Next, it is well documented that $\mathrm{PP}_{\mathrm{i}}$ molecules are transported across the cell membrane through ank transporter (8). Specific rare genetic bone disorder known as craniometaphyseal dysplasia (CMD), characterized by progressive sclerosis and hyperostosis of the craniofacial bones has been linked to $A N K H$ nonsense mutations resulting in increased intracellular and decreased extracellular $\mathrm{PP}_{\mathrm{i}}(19)$. Recent studies of CMD pointed to the role of $\mathrm{PP}_{\mathrm{i}}$ in regulation of bone modeling/remodeling process (26). Thus, a decrease in extracellular $\mathrm{PP}_{\mathrm{i}}$ may hinder normal bone remodeling, for instance, by inhibiting osteoclast differentiation or activity. In support of this notion, bone marrow-derived monocytes (BMMs) from a CMD knock-in mouse 
$\left(a n k^{k i} / a n k^{k i}\right)$ poorly differentiated to osteoclasts in cultures, compared to those from wild type mice (10). Consistent with the mouse data, the number of bone marrow-derived osteoclast-like cells from a CMD patient was only $40 \%$ of a normal individual, and they lacked osteoclastspecific vacuolar proton pump and the ability to absorb a dentin slice (60). Interestingly, our results showed temporal increase of ANK levels during osteoclast differentiation. Moreover, the ANK expression was escalated in $\mathrm{PP}_{\mathrm{i}}$ enhanced pre-osteoclasts that possibly indicate a positive feedback loop between $\mathrm{PP}_{\mathrm{i}}$ and $\mathrm{ANK}$. In addition, probenecid; ANK inhibitor abrogated osteoclast differentiation and their function in $\mathrm{PP}_{\mathrm{i}}$ enhanced pre-osteoclasts. These data are supported by previous study showing $\mathrm{PP}_{\mathrm{i}}$ as a positive regulator of osteoclast differentiation events toward an osteoclast phenotype (32). Kim el al., reported the diminished osteoclast differentiation and activity of BMMs coming from ank/ank mutant mice (32). Since $\mathrm{PP}_{\mathrm{i}}$ stimulated temporal expression of ANK during osteoclast differentiation, and on the other hand probenecid limited $\mathrm{PP}_{\mathrm{i}}$ induced phosphorylation of ERK1/2. We conclude there's an increased possibility that $\mathrm{PP}_{\mathrm{i}}$ induces ANK expression through MAPK phosphorylation that will require further investigations. Interestingly, we showed that extracellular $\mathrm{PP}_{\mathrm{i}}$ was not able to rescue osteoclast differentiation in BMMs coming from ank/ank mutant mice compared to their wildtype littermates. These findings indicate that ANK is essential to transport $\mathrm{PP}_{\mathrm{i}}$ intracellular that up-regulate signaling pathways critical for osteoclast differentiation and thereby function. This notion is supported by the decreased osteoclastogenesis in knock-in ank $k^{k i} / a n k^{k i}$ mice probably due to reduced pre-osteoclast fusion and migration capability; disrupted osteoclast actin ring formation; and abnormal osteoblast-osteoclast communication. In conclusion, our findings provide an evidence that $\mathrm{PP}_{\mathrm{i}}$ enhances pre-osteoclast commitment leading to increased osteoclast differentiation, survival, and function. The positive effects of $\mathrm{PP}_{\mathrm{i}}$ on pre-osteoclast commitment are mediated by PU.1-dependent up-regulation of c-FMS, RANK and MAPK- 
dependent phosphorylation of MITF signaling pathways (Fig-10). The PP $\mathrm{P}_{\mathrm{i}}$-enhanced pre-

osteoclasts may be at least in part due to temporal increase of ANK expression during osteoclast differentiation, despite the fact that extracellular $\mathrm{PP}_{\mathrm{i}}$ did not rescue the osteoclast phenotype in ank/ank mutant mice. Generation of other genetically engineered mouse models, such as an osteoclast-specific knockout of ank, will help us to understand and identify the distinct signaling pathway(s) of ANK in osteoclast differentiation and thereby activity in bone resorption.

\section{ACKNOWLEGMENT}

This research work was supported by R01 grant (AR050627) from the National Institute of Arthritis and Musculoskeletal and Skin Diseases (NIAMS). The authors will also like to thank Dr. Yongwin Choi for his insightful comments and suggestions.

\section{REFERENCES}

1. Abdelmagid SM, Belcher JY, Moussa FM, Lababidi SL, Sondag GR, Novak KM, Sanyurah AS, Frara NA, Razmpour R, Del Carpio-Cano FE, and Safadi FF. Mutation in osteoactivin decreases bone formation in vivo and osteoblast differentiation in vitro. Am J Pathol 184: 697713, 2014.

2. Abdelmagid SM, Sondag GR, Moussa FM, Belcher JY, Yu B, Stinnett H, Novak K, Mbimba T, Khol M, Hankenson KD, Malcuit C, and Safadi FF. Mutation in Osteoactivin Promotes Receptor Activator of NFkappaB Ligand (RANKL)-mediated Osteoclast Differentiation and Survival but Inhibits Osteoclast Function. J Biol Chem 290: 20128-20146, 2015.

3. Addison WN, Azari F, Sorensen ES, Kaartinen MT, and McKee MD. Pyrophosphate inhibits mineralization of osteoblast cultures by binding to mineral, up-regulating osteopontin, and inhibiting alkaline phosphatase activity. The Journal of biological chemistry 282: 1587215883, 2007.

4. Anderson HC, and Reynolds JJ. Pyrophosphate stimulation of calcium uptake into cultured embryonic bones. Fine structure of matrix vesicles and their role in calcification. Dev Biol 34: 211-227, 1973.

5. Asai K, Funaba M, and Murakami M. Enhancement of RANKL-induced MITF-E expression and osteoclastogenesis by TGF-beta. Cell biochemistry and function 32: 401-409, 2014. 
6. Bezuur JN, Habets LL, and Hansson TL. The recognition of craniomandibular disorders--a comparison between clinical, tomographical, and dental panoramic radiographical findings in thirty-one subjects. J Oral Rehabil 15: 549-554, 1988.

7. Bradley EW, Ruan MM, and Oursler MJ. Novel pro-survival functions of the Kruppel-like transcription factor Egr2 in promotion of macrophage colony-stimulating factor-mediated osteoclast survival downstream of the MEK/ERK pathway. The Journal of biological chemistry 283: 8055-8064, 2008.

8. Cailotto F, Sebillaud S, Netter P, Jouzeau JY, and Bianchi A. The inorganic pyrophosphate transporter ANK preserves the differentiated phenotype of articular chondrocyte. J Biol Chem 285: 10572-10582, 2010.

9. Cenci S, Weitzmann MN, Gentile MA, Aisa MC, and Pacifici R. M-CSF neutralization and egr-1 deficiency prevent ovariectomy-induced bone loss. The Journal of clinical investigation 105: 1279-1287, 2000.

10. Chen IP, Wang CJ, Strecker S, Koczon-Jaremko B, Boskey A, and Reichenberger EJ. Introduction of a Phe377del mutation in ANK creates a mouse model for craniometaphyseal dysplasia. J Bone Miner Res 24: 1206-1215, 2009.

11. Chen IP, Wang L, Jiang X, Aguila HL, and Reichenberger EJ. A Phe377del mutation in ANK leads to impaired osteoblastogenesis and osteoclastogenesis in a mouse model for craniometaphyseal dysplasia (CMD). Hum Mol Genet 20: 948-961, 2011.

12. Costello JC, Rosenthal AK, Kurup IV, Masuda I, Medhora M, and Ryan LM. Parallel regulation of extracellular ATP and inorganic pyrophosphate: roles of growth factors, transduction modulators, and ANK. Connective tissue research 52: 139-146, 2011.

13. Dougall WC, Glaccum M, Charrier K, Rohrbach K, Brasel K, De Smedt T, Daro E, Smith J, Tometsko ME, Maliszewski CR, Armstrong A, Shen V, Bain S, Cosman D, Anderson D, Morrissey PJ, Peschon JJ, and Schuh J. RANK is essential for osteoclast and lymph node development. Genes Dev 13: 2412-2424, 1999.

14. Fallon MD, Whyte MP, and Teitelbaum SL. Stereospecific inhibition of alkaline phosphatase by L-tetramisole prevents in vitro cartilage calcification. Laboratory investigation; a journal of technical methods and pathology 43: 489-494, 1980.

15. Fong $\mathbf{H}$, Foster BL, Sarikaya $\mathbf{M}$, and Somerman MJ. Structure and mechanical properties of Ank/Ank mutant mouse dental tissues--an animal model for studying periodontal regeneration. Arch Oral Biol 54: 570-576, 2009.

16. Friedman AD. Transcriptional control of granulocyte and monocyte development. Oncogene 26: 6816-6828, 2007.

17. Giachelli CM, Jono S, Shioi A, Nishizawa Y, Mori K, and Morii H. Vascular calcification and inorganic phosphate. American journal of kidney diseases : the official journal of the National Kidney Foundation 38: S34-37, 2001.

18. Grigoriadis AE, Wang ZQ, Cecchini MG, Hofstetter W, Felix R, Fleisch HA, and Wagner EF. c-Fos: a key regulator of osteoclast-macrophage lineage determination and bone remodeling. Science 266: 443-448, 1994.

19. Gurley KA, Reimer RJ, and Kingsley DM. Biochemical and genetic analysis of ANK in arthritis and bone disease. Am J Hum Genet 79: 1017-1029, 2006.

20. Harmey D, Johnson KA, Zelken J, Camacho NP, Hoylaerts MF, Noda M, Terkeltaub R, and Millan JL. Elevated skeletal osteopontin levels contribute to the hypophosphatasia phenotype in Akp2(-/-) mice. J Bone Miner Res 21: 1377-1386, 2006. 
21. Hatch NE, and Franceschi RT. Osteoblast differentiation stage-specific expression of the pyrophosphate-generating enzyme PC-1. Cells, tissues, organs 189: 65-69, 2009.

22. He Y, Staser K, Rhodes SD, Liu Y, Wu X, Park SJ, Yuan J, Yang X, Li X, Jiang L, Chen S, and Yang FC. Erk1 positively regulates osteoclast differentiation and bone resorptive activity. PLoS One 6: e24780, 2011.

23. Ho AM, Johnson MD, and Kingsley DM. Role of the mouse ank gene in control of tissue calcification and arthritis. Science 289: 265-270, 2000.

24. Hoac B, Kiffer-Moreira T, Millan JL, and McKee MD. Polyphosphates inhibit extracellular matrix mineralization in MC3T3-E1 osteoblast cultures. Bone 53: 478-486, 2013. 25. Houde N, Chamoux E, Bisson M, and Roux S. Transforming growth factor-beta1 (TGFbeta1) induces human osteoclast apoptosis by up-regulating Bim. J Biol Chem 284: 2339723404, 2009.

26. Hu Y, Chen IP, de Almeida S, Tiziani V, Do Amaral CM, Gowrishankar K, Passos-Bueno MR, and Reichenberger EJ. A novel autosomal recessive GJA1 missense mutation linked to Craniometaphyseal dysplasia. PLoS One 8: e73576, 2013.

27. Johnson K, Jung A, Murphy A, Andreyev A, Dykens J, and Terkeltaub R. Mitochondrial oxidative phosphorylation is a downstream regulator of nitric oxide effects on chondrocyte matrix synthesis and mineralization. Arthritis Rheum 43: 1560-1570, 2000.

28. Johnson K, Polewski M, van Etten D, and Terkeltaub R. Chondrogenesis mediated by PPi depletion promotes spontaneous aortic calcification in NPP1-/- mice. Arterioscler Thromb Vasc Biol 25: 686-691, 2005.

29. Johnson K, and Terkeltaub R. Inorganic pyrophosphate (PPI) in pathologic calcification of articular cartilage. Front Biosci 10: 988-997, 2005.

30. Kanazawa K, and Kudo A. Self-assembled RANK induces osteoclastogenesis ligandindependently. J Bone Miner Res 20: 2053-2060, 2005.

31. Kim HJ, Hong JM, Yoon KA, Kim N, Cho DW, Choi JY, Lee IK, and Kim SY. Early growth response 2 negatively modulates osteoclast differentiation through upregulation of Id helixloop-helix proteins. Bone 51: 643-650, 2012.

32. Kim HJ, Minashima T, McCarthy EF, Winkles JA, and Kirsch T. Progressive ankylosis protein (ANK) in osteoblasts and osteoclasts controls bone formation and bone remodeling. $J$ Bone Miner Res 25: 1771-1783, 2010.

33. Kim MJ, Kim SN, Lee IS, Chung S, Lee J, Yang Y, Lee I, and Koh SE. Effects of bisphosphonates to treat osteoporosis in children with cerebral palsy: a meta-analysis. J Pediatr Endocrinol Metab 28: 1343-1350, 2015.

34. Kwon $\mathrm{OH}$, Lee CK, Lee YI, Paik SG, and Lee HJ. The hematopoietic transcription factor PU.1 regulates RANK gene expression in myeloid progenitors. Biochemical and biophysical research communications 335: 437-446, 2005.

35. Lee DD, and Glimcher MJ. Three-dimensional spatial relationship between the collagen fibrils and the inorganic calcium phosphate crystals of pickerel (Americanus americanus) and herring (Clupea harengus) bone. J Mol Biol 217: 487-501, 1991.

36. Lee $\mathbf{Z H}$, and $\mathbf{K i m} \mathbf{H H}$. Signal transduction by receptor activator of nuclear factor kappa $\mathrm{B}$ in osteoclasts. Biochemical and biophysical research communications 305: 211-214, 2003.

37. Li X, Udagawa N, Itoh K, Suda K, Murase Y, Nishihara T, Suda T, and Takahashi N. p38 MAPK-mediated signals are required for inducing osteoclast differentiation but not for osteoclast function. Endocrinology 143: 3105-3113, 2002. 
38. Li X, Vradii D, Gutierrez S, Lian JB, van Wijnen AJ, Stein JL, Stein GS, and Javed A. Subnuclear targeting of Runx1 is required for synergistic activation of the myeloid specific $M$ CSF receptor promoter by PU.1. Journal of cellular biochemistry 96: 795-809, 2005.

39. Lu SY, Li M, and Lin YL. Mitf induction by RANKL is critical for osteoclastogenesis. Molecular biology of the cell 21: 1763-1771, 2010.

40. Lu SY, Wan HC, Li M, and Lin YL. Subcellular localization of Mitf in monocytic cells. Histochem Cell Biol 133: 651-658, 2010.

41. Mansky KC, Sankar U, Han J, and Ostrowski MC. Microphthalmia transcription factor is a target of the p38 MAPK pathway in response to receptor activator of NF-kappa B ligand signaling. The Journal of biological chemistry 277: 11077-11083, 2002.

42. Masuda H, Hirose J, Omata Y, Tokuyama N, Yasui T, Kadono Y, Miyazaki T, and Tanaka S. Anti-apoptotic $\mathrm{Bcl}-2$ family member $\mathrm{Mcl}-1$ regulates cell viability and bone-resorbing activity of osteoclasts. Bone 58: 1-10, 2014.

43. Moochhala SH, Sayer JA, Carr G, and Simmons NL. Renal calcium stones: insights from the control of bone mineralization. Exp Physiol 93: 43-49, 2008.

44. Nurnberg P, Thiele H, Chandler D, Hohne W, Cunningham ML, Ritter H, Leschik G, Uhlmann K, Mischung C, Harrop K, Goldblatt J, Borochowitz ZU, Kotzot D, Westermann F, Mundlos S, Braun HS, Laing N, and Tinschert S. Heterozygous mutations in ANKH, the human ortholog of the mouse progressive ankylosis gene, result in craniometaphyseal dysplasia. Nat Genet 28: 37-41, 2001.

45. O'Neill WC, Lomashvili KA, Malluche HH, Faugere MC, and Riser BL. Treatment with pyrophosphate inhibits uremic vascular calcification. Kidney Int 79: 512-517, 2011.

46. Omelon S, Georgiou J, Henneman ZJ, Wise LM, Sukhu B, Hunt T, Wynnyckyj C, Holmyard D, Bielecki R, and Grynpas MD. Control of vertebrate skeletal mineralization by polyphosphates. PLoS One 4: e5634, 2009.

47. Partington GA, Fuller K, Chambers TJ, and Pondel M. Mitf-PU.1 interactions with the tartrate-resistant acid phosphatase gene promoter during osteoclast differentiation. Bone 34: 237-245, 2004.

48. Prosdocimo DA, Wyler SC, Romani A, O'Neill WC, and Dubyak GR. Regulation of vascular smooth muscle cell calcification by extracellular pyrophosphate homeostasis: synergistic modulation by cyclic AMP and hyperphosphatemia. Am J Physiol Cell Physiol 2009. 49. Prosdocimo DA, Wyler SC, Romani AM, O'Neill WC, and Dubyak GR. Regulation of vascular smooth muscle cell calcification by extracellular pyrophosphate homeostasis: synergistic modulation by cyclic AMP and hyperphosphatemia. Am J Physiol Cell Physiol 298: C702-713, 2010.

50. Reichenberger E, Tiziani V, Watanabe S, Park L, Ueki Y, Santanna C, Baur ST, Shiang R, Grange DK, Beighton P, Gardner J, Hamersma H, Sellars S, Ramesar R, Lidral AC, Sommer A, Raposo do Amaral CM, Gorlin RJ, Mulliken JB, and Olsen BR. Autosomal dominant craniometaphyseal dysplasia is caused by mutations in the transmembrane protein ANK. Am J Hum Genet 68: 1321-1326, 2001.

51. Rutsch F, Vaingankar S, Johnson K, Goldfine I, Maddux B, Schauerte P, Kalhoff H, Sano K, Boisvert WA, Superti-Furga A, and Terkeltaub R. PC-1 nucleoside triphosphate pyrophosphohydrolase deficiency in idiopathic infantile arterial calcification. Am J Pathol 158: 543-554, 2001. 
52. Sharma SM, Bronisz A, Hu R, Patel K, Mansky KC, Sif S, and Ostrowski MC. MITF and PU.1 recruit p38 MAPK and NFATc1 to target genes during osteoclast differentiation. The Journal of biological chemistry 282: 15921-15929, 2007.

53. Singh S, Qin C, Medarametla S, and Hegde SV. Craniometaphyseal dysplasia in a 14month old: a case report and review of imaging differential diagnosis. Radiol Case Rep 11: 260265, 2016.

54. Subramanian $\mathbf{M}$, and Shaha $\mathbf{C}$. Up-regulation of $\mathrm{Bcl}-2$ through ERK phosphorylation is associated with human macrophage survival in an estrogen microenvironment. J Immunol 179: 2330-2338, 2007.

55. Terkeltaub RA. Inorganic pyrophosphate generation and disposition in pathophysiology. Am J Physiol Cell Physiol 281: C1-C11, 2001.

56. Villa-Bellosta R, Rivera-Torres J, Osorio FG, Acin-Perez R, Enriquez JA, Lopez-Otin C, and Andres V. Defective extracellular pyrophosphate metabolism promotes vascular calcification in a mouse model of Hutchinson-Gilford progeria syndrome that is ameliorated on pyrophosphate treatment. Circulation 127: 2442-2451, 2013.

57. Weigelt $\mathbf{K}$, Lichtinger $\mathbf{M}$, Rehli $\mathbf{M}$, and Langmann $\mathbf{T}$. Transcriptomic profiling identifies a PU.1 regulatory network in macrophages. Biochemical and biophysical research communications 380: 308-312, 2009.

58. Whyte MP, Landt M, Ryan LM, Mulivor RA, Henthorn PS, Fedde KN, Mahuren JD, and Coburn SP. Alkaline phosphatase: placental and tissue-nonspecific isoenzymes hydrolyze phosphoethanolamine, inorganic pyrophosphate, and pyridoxal 5'-phosphate. Substrate accumulation in carriers of hypophosphatasia corrects during pregnancy. The Journal of clinical investigation 95: 1440-1445, 1995.

59. Xu L, and Russu WA. Molecular docking and synthesis of novel quinazoline analogues as inhibitors of transcription factors NF-kappaB activation and their anti-cancer activities. Bioorganic \& medicinal chemistry 21: 540-546, 2013.

60. Yamamoto T, Kurihara N, Yamaoka K, Ozono K, Okada M, Yamamoto K, Matsumoto S, Michigami T, Ono J, and Okada S. Bone marrow-derived osteoclast-like cells from a patient with craniometaphyseal dysplasia lack expression of osteoclast-reactive vacuolar proton pump. J Clin Invest 91: 362-367, 1993.

61. Yamashita J, Datta NS, Chun YH, Yang DY, Carey AA, Kreider JM, Goldstein SA, and McCauley LK. Role of Bcl2 in osteoclastogenesis and PTH anabolic actions in bone. J Bone Miner Res 23: 621-632, 2008.

62. Yates AJ, Oreffo RO, Mayor K, and Mundy GR. Inhibition of bone resorption by inorganic phosphate is mediated by both reduced osteoclast formation and decreased activity of mature osteoclasts. J Bone Miner Res 6: 473-478, 1991.

63. Zajac A, Baek SH, Salhab I, Radecki MA, Kim S, Hakonarson H, and Nah HD. Novel ANKH mutation in a patient with sporadic craniometaphyseal dysplasia. Am J Med Genet $A$ 152A: 770-776, 2010.

64. Zaka R, Stokes D, Dion AS, Kusnierz A, Han F, and Williams CJ. P5L mutation in Ank results in an increase in extracellular inorganic pyrophosphate during proliferation and nonmineralizing hypertrophy in stably transduced ATDC5 cells. Arthritis research \& therapy 8: R164, 2006.

65. Zhang Y, Johnson K, Russell RG, Wordsworth BP, Carr AJ, Terkeltaub RA, and Brown MA. Association of sporadic chondrocalcinosis with a -4-basepair G-to-A transition in the 5'- 
untranslated region of ANKH that promotes enhanced expression of ANKH protein and excess generation of extracellular inorganic pyrophosphate. Arthritis Rheum 52: 1110-1117, 2005.

\section{FIGURE LEGENDS}

\section{Table-1.}

Oligonucleotide primer sequences used in quantitative $(\mathrm{q})$ real time polymerase chain reaction

Figure-1. Pyrophosphate activates bone resorption ex vivo. Murine calvaria were treated with $\mathrm{PP}_{\mathrm{i}}(100-1000 \mu \mathrm{M})$ for $72 \mathrm{hrs}$. The conditioned media $(\mathrm{CM})$ were then harvested for calcium

$\left(\mathrm{Ca}^{2+}\right)(\mathrm{A})$ and collagen peptide (CTX-1) (B) measurements and calvaria were stained for TRAP. (C) Macroscopic images of a whole representative calvarium treated with and without $\mathrm{PP}_{\mathrm{i}}$. Scale bars, $2500 \mu \mathrm{m}$. (D) Percent fraction area of the TRAP-stained-calvarial surfaces in in $\mathrm{PP}_{\mathrm{i}-}$ treatment and control. (E) Microscopic images of the TRAP-stained-calvaria showing multinucleated osteoclast on the calvarial surfaces (arrows) in $\mathrm{PP}_{\mathrm{i}-\text { treatment versus control }}$ conditions. (F) Microscopic images of sagittal sections in TRAP-stained-calvaria and counterstained with von Kossa showing osteoclast in their resorption lacunae (arrows), in $\mathrm{PP}_{\mathrm{i}}$ treatment versus control. Scale bars, $200 \mu \mathrm{m}$. (G) $\mathrm{Ca}^{2+}$ assay of murine calvarial bones treated with $\mathrm{PP}_{\mathrm{i}}(1000 \mu \mathrm{M})$ and/or quinazoline; $\mathrm{NF \kappa B}$ inhibitor $(0.01-1) \mu \mathrm{M}$. Results are shown as mean and SEM. Experiments were repeated at least 3 times and showed comparable results. $\mathrm{N}=3$ per group. The Mean value is represented in all graphs + SEM. The data points $(\diamond)$ are represented in all graphs. *, $p<0.05 ; * *, p<0.01$.

Figure-2. Pyrophosphate action on bone resorption is selective and specific. $\mathrm{Ca}^{2+}$ measurements in the 72-hour CM of murine calvaria treated with $\mathrm{TNF} \alpha(20 \mathrm{ng} / \mathrm{ml})$ and/or PP (500-1000) $\mu \mathrm{M}$ in (A), TNF $\alpha$ (20 ng/ml) and/or bisphosphonate (25-50) $\mu \mathrm{M}$ in (B), $\mathrm{PP}_{\mathrm{i}}(1000)$ $\mu \mathrm{M}$ and/or levamisole (10-50) $\mu \mathrm{M}$ in (C), $\mathrm{PP}_{\mathrm{i}}(1000) \mu \mathrm{M}$ and/or PFA (100-500) $\mu \mathrm{M}$ in (D), $\mathrm{P}_{\mathrm{i}}$ (500-2000) $\mu \mathrm{M}$ alone in (E), $\mathrm{P}_{\mathrm{i}}(2000) \mu \mathrm{M}$ and/or PFA (100-500) $\mu \mathrm{M}$ in (F). Experiments were 
repeated at least 3 times and showed similar results. N=3 per group. The Mean value is

represented in all graphs $+\mathrm{SEM}$. The data points $(\diamond)$ are represented in all graphs. *, $p<0.05$; $* *, p<0.01, * * *, p<0.001$.

Figure-3. Pyrophosphate enhances osteoclastogenesis ex vivo. (A) BMMs were treated with $\mathrm{PP}_{\mathrm{i}}(100-1000) \mu \mathrm{M}$ for 48 hours and examined for TRAP mRNA expression by quantitative (q)RT-PCR. (B-C) BMMs were treated with PP $\mathrm{i}_{\mathrm{i}}(100-1000) \mu \mathrm{M}$ and stained for TRAP. (B) Microscopic images show higher number of TRAP-positive mono-nuclear cells in $\mathrm{PP}_{\mathrm{i}}$-treated BMMs (arrows), compared to control. (C) TRAP activity was significantly higher in the $\mathrm{PP}_{\mathrm{i}^{-}}$ treated conditions. (D-I) BMMs were treated with $\mathrm{PP}_{\mathrm{i}}(100-1000) \mu \mathrm{M}$ then differentiated with RANK-L (35 ng) for 7 days. (D) Microscopic images show more number and larger size osteoclasts in $\mathrm{PP}_{\mathrm{i}}$-treated BMMs (arrows), compared to control. Parameters of osteoclast differentiation that include; TRAP activity (E); count of TRAP-positive osteoclasts ( $\geq 3$ nuclei) (F); differential count of osteoclasts $\geq 20$ nuclei, and (G); size of TRAP-positive osteoclasts (H) are significantly increased in $\mathrm{PP}_{\mathrm{i}}$-treated $\mathrm{BMMs}$, compared to control. (I) BMMs were treated with $\mathrm{PP}_{\mathrm{i}}(1000) \mu \mathrm{M}$ then differentiated with RANK-L on glass slides and immunostained with rhodamin phalloidin for the actin ring (red) and counterstained with DAPI for the nuclei (blue). Microscopic images show larger size osteoclasts with distinct acting ring in $\mathrm{PP}_{\mathrm{i}}$-treated BMMs. Experiments were repeated at least 3 times and showed comparable results. $\mathrm{N}=6$ per group. The Mean value is represented in all graphs + SEM. ${ }^{*}, p<0.05 ; * *, p<0.01,{ }^{* * *}, p<0.001$. Scale bars, $200 \mu \mathrm{m}$.

Figure-4. Pyrophosphate stimulates osteoclast function ex vivo. (A-D) BMMs were treated with $\mathrm{PP}_{\mathrm{i}}(100-1000) \mu \mathrm{M}$ then differentiated with RANK-L (35 ng) over human OsteoAssay bone chips and examined for TRAP. (A) Microscopic images show larger TRAP+ osteoclasts (arrows) and less bone chips (asterisk) in PPi-treated BMMs, compared to control. (B) TRAP activity of 
differentiated osteoclasts are significantly up in $\mathrm{PP}_{\mathrm{i}}$-treated BMMs. Parameters of osteoclast function that include; $\mathrm{Ca}^{2+}(\mathbf{C})$, and $\mathrm{CTX}-1$ (D) in the $\mathrm{CM}$ are increased in $\mathrm{PP}_{\mathrm{i}}$-treated $\mathrm{BMMs}$, compared to control. (E-H) BMMs were treated with $\mathrm{PP}_{\mathrm{i}}(100-1000) \mu \mathrm{M}$ then differentiated with RANKL (35 ng) over OsteoAssay discs. (E) Microscopic images of von kossa stained discs, after removal of osteoclasts, show increased number and size of resorption pits in $\mathrm{PP}_{\mathrm{i}}$-treated BMMs. Parameters of bone resorptions that include; number of resorption pits (N. pits) (F), total resorption area (Tt. Ar) (G), and average pit size per osteoclast (pit Ar) are higher in $\mathrm{PP}_{\mathrm{i}}$-treated BMMs, compared to control. Experiments were repeated at least 3 times and showed similar results. $\mathrm{N}=6$ per group. $\mathrm{N}=6$ per group. The Mean value is represented in all graphs $+\mathrm{SEM} .{ }^{*}$, $p<0.05 ; * *, p<0.01$. Scale bars, $200 \mu \mathrm{m}$.

\section{Figure-5. Pyrophosphate stimulate osteoclastogenesis in BMMs-osteoblast co-cultures.}

Murine BMMs were co-cultured with calvarial osteoblasts and with treated with vitamin $\mathrm{D}_{3}\left(10^{-8} \mathrm{M}\right)$; positive control or $\mathrm{PP}_{\mathrm{i}}(100-1000) \mu \mathrm{M}$ for 9 days and examined for TRAP+ osteoclasts. (A) Microscopic images show more number and larger size osteoclasts in vitamin $\mathrm{D}_{3}$ and $\mathrm{PP}_{\mathrm{i}}$-treated BMMs (blue arrows), compared to control. Parameters of osteoclast differentiation that include; TRAP activity (B); count of TRAP+ osteoclasts ( $\geq 3$ nuclei) (C); size of TRAP+ osteoclasts (D) are significantly increased in $\mathrm{PP}_{\mathrm{i}}$-treated BMMs, compared to control. (E-G) BMMs were co-cultured with osteoblasts on dentin discs and treated for 12 days, as described above. (E) Microscopic images show active osteoclasts (yellow arrow heads) in their lacunae. Note the osteoclast resorption tracks, stained with toluidine blue (yellow arrows) that extend from lacuna. Parameters of osteoclast function that include; CTX-1 in the CM (F) and average bone resorption area $(\mathbf{G})$ are significantly higher in BMMs treated with vitamin $\mathrm{D}_{3}$ and $\mathrm{PP}_{\mathrm{i}}(1000) \mu \mathrm{M}$, compared to (-) control. (H and I) comparative quantitative (q)RT-PCR analysis of murine calvarial osteoblasts, treated with vitamin $\mathrm{D}_{3}\left(10^{-8} \mathrm{M}\right)$ or $\mathrm{PP}_{\mathrm{i}}(100-1000 \mu \mathrm{M})$ showing 
increased RANKL mRNA expression $(\mathbf{H})$ and RANKL/OPG ratio (I) in vitamin $\mathrm{D}_{3}$ and $\mathrm{PP}_{\mathrm{i}^{-}}$ treated osteoblasts, compared to (-) control. Experiments were repeated at least 3 times and showed similar results. Data presented in all graphs represent Mean + SEM in duplicate per sample. $\mathrm{N}=4$ per group. $*=p<0.05 ; * *=p<0.01 ; * * *=p<0.001$. Scale bars, $200 \mu \mathrm{m}$.

Figure-6. Pyrophosphate stimulates osteoclast markers and MAP-K pathway. (A) Semiquantitative RT-PCR analysis of PU.1, MITF transcription factors, cFMS, RANK receptors in PP $\mathrm{P}_{\mathrm{i}}$-treated BMMs. (B-F) Comparative qRT-PCR analyses of mRNA expressions from three replicates were performed for cFMS (B), RANK (C), c-Fos (D), c-Jun (E), and NFkB (F). Note the significant increase in all gene expressions with $\mathrm{PP}_{\mathrm{i}}$ treatment. (G-J) BMMs were serum starved and treated with $\mathrm{PP}_{\mathrm{i}}$ for the indicated time points. (G) Representative Western blot of the phosphorylated (p) ERK1/2 in BMMs treated with $\mathrm{PP}_{\mathrm{i}}$ and/or ERK inhibitor (U0126). (H) Densitometric analyses of the pERK1/2 (44 and 42KDa) from three replicate Western blots after normalization to ERK1/2 (44 and 42KDa) levels show the ratio of pERK1/2 to ERK1/2 at 5 and 10 minutes. (I) Representative Western blot of the phosphorylated (p) P38 in BMMs treated with $\mathrm{PP}_{\mathrm{i}}$ and/or P38 inhibitor (SB203580). (J) Densitometric analyses of the pP38 (41KDa) from three replicate Western blots after normalization to P38 (41KDa) levels show the ratio of pP38 to P38 at 5 and 10 minutes. Experiments were repeated at least 3 times and showed comparable results. $\mathrm{N}=3$ per group. The Mean value is represented in all graphs $+\mathrm{SEM} .{ }^{*}, p<0.05 ; * *, p<0.01$.

Figure-7. Pyrophosphate-enhanced osteoclastogenesis is mediated by PU.1. (A-C) Comparative qRT-PCR analyses of mRNA collected from $\mathrm{PP}_{\mathrm{i}}$-treated BMMs (three replicates) were performed for the following genes: PU.1 (A), Egr-1 (B), and Egr-2 (C). Note the PP ${ }_{\mathrm{i}-\mathrm{dose}}$ dependent increase in all gene expressions except Egr-2. (D-H). PUER ${ }^{\text {lo }}$ and PUER ${ }^{\text {hi }}$ stem cells were treated with $\mathrm{PP}_{\mathrm{i}}(1000) \mu \mathrm{M}$ and/or OHT for 48 hours. (D) Semi-quantitative RT-PCR analysis of cFMS, RANK, Egr-1 and Egr-2 gene expressions in PUER ${ }^{\text {lo }}$ treated with $\mathrm{PP}_{\mathrm{i}}$ and 
PUER $^{\text {hi }}$ treated with OHT compared to untreated PUER ${ }^{\text {lo }}$ and PUER ${ }^{\text {hi }}$ cells. Densitometric analyses show the following gene expressions in $\mathrm{PP}_{\mathrm{i}}$-treated $\mathrm{PUER}^{\text {lo }}$ and $\mathrm{OHT}$-treated PUER ${ }^{\text {hi }}$ compared to untreated PUER ${ }^{10}$ cells: cFMS (E), RANK (F), Egr-1 (G), and Egr-2 (D).

Experiments were repeated at least 3 times and showed similar results. Data presented in all graphs represent Mean + SEM in duplicate per sample. $*=p<0.05 ; * *=p<0.01$.

Figure-8. Pyrophosphate-enhanced pre-osteoclast survival is mediated by MITF. (A) qRTPCR analysis of total MITF in PPi-treated BMMs. (B-D) Semi-quantitative RT-PCR analysis of

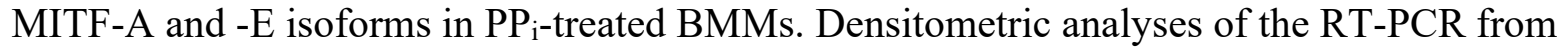
three replicates show higher expressions of MITF-A (C), and MITF-E (D), compared to untreated control. (E) qRT-PCR analysis of BCL-2 in BMMs treated with PP $(100-1000 \mu \mathrm{M})$ in serum-free conditions. (F) qRT-PCR analysis of BCL-2 in RAW MITF $^{\text {or RAW }}{ }^{\mathrm{WT}}$ cells with PP $(1000 \mu \mathrm{M})$ and/or U0126 in serum-free conditions. (G) Survival assay of BMMs treated with $\mathrm{PP}_{\mathrm{i}}$ (1000 $\mu \mathrm{M})$ and/or U0126 and/or SB203580 for 48 hours in serum-free conditions. Notice the lower cell viability with $\mathrm{PP}_{\mathrm{i}}$ and U0126. (H) Survival assay of RAW 264.7 ${ }^{\mathrm{WT}}$ or RAW ${ }^{\mathrm{MITF}}$ cells treated with $\mathrm{PP}_{\mathrm{i}}$ and/or U0126, and/or SB203580 for 48 hours in serum-free conditions. Notice the decreased cell viability of RAW ${ }^{\mathrm{WT}}$ with $\mathrm{PP}_{\mathrm{i}}$ and U0126, compared to no effect on RAW ${ }^{\mathrm{MITF}}$ cells. (I) Representative Western blot of the phosphorylated (p) MITF in BMMs treated with PP and/or U0126 in serum-free conditions. (J) Densitometric analyses of the pMITF (52KDa) from three replicate Western blots after normalization to MITF (52KDa) levels show the ratio of pMITF to MITF at 60 and 90 minutes. Experiments were repeated at least 3 times and showed similar results. $\mathrm{N}=3$ per group. Data presented in all graphs represent Mean $+\mathrm{SEM}$ in duplicate per sample. $*=p<0.05 ; * *=p<0.01 ; * * *=p<0.001$.

Figure-9. ANK regulates Pyrophosphate effects in osteoclast differentiation and function. (A) Northern blot of ank mRNA in osteoclasts differentiated from BMMs or RAW 264.7 cells 
for the indicated time points. (B) Densitometry analyses of the ank from three replicate Northern blots show the ratio of ank mRNA to internal control rRNA. Note the highest ank mRNA in osteoclasts at 11 days for BMMs and 6 days for RAW. (C) Representative Western blot of ANK protein in osteoclasts differentiated from RAW cells. (D) Densitometric analyses of the ANK (48KDa) from three replicate Western blots after normalization to GAPDH (37KDa) levels. (E) qRT-PCR analysis of ank in BMMs treated with $\mathrm{PP}_{\mathrm{i}}(100-1000) \mu \mathrm{M}$ for 48 hours. (F) $\mathrm{Ca}^{2+}$ measurements in the 72-hour condition medium $(\mathrm{CM})$ of murine calvaria treated with $\mathrm{PP}_{\mathrm{i}}(1000$ $\mu \mathrm{M})$ and/or probenecide (500-1000) $\mu \mathrm{M}$. (G) TRAP activity of BMMs treated with $\mathrm{PP}_{\mathrm{i}}(1000$ $\mu \mathrm{M}$ ) and/or probenecide then differentiated with RANK-L (35 ng) for 7 days. (H) TRAP activity of ank/ank and WT BMMs treated with $\mathrm{PP}_{\mathrm{i}}(100-1000) \mu \mathrm{M}$ for 48 hours then differentiated with RANK-L. (I) Representative Western blot of pERK in WT BMMs treated with PP $(1000 \mu \mathrm{M})$ and/or probenecid (1000 $\mu \mathrm{M})$. (J) Densitometric analyses of the pERK1/2 (44 and 42KDa) from three replicate Western blots after normalization to ERK (44 and 42KDa) levels show the ratio of pERK to ERK at 5 and 10 minutes. Experiments were repeated at least 3 times and showed similar results. $\mathrm{N}=3$ per group. Data presented in all graphs represent Mean $+\mathrm{SEM}$ in duplicate per sample. $*=p<0.05 ; * *=p<0.01 ; * * *=p<0.001$.

\section{Figure-10. Schematic diagram of Pyrophosphate effects on osteoclast differentiation,}

survival and function. Pyrophosphate promotes osteoclast differentiation mediated by PU.1, Egr-1, and up-regulation of cFMS and RANK receptors. Pyrophosphate also enhances osteoclast survival through MAPK and MITF phosphorylation and up-regulation of the downstream BCL2. Pyrophosphate promotes osteoclastogenesis indirectly by stimulating RANKL production by osteoblasts. Pyrophosphate improves the OCL activity in bone resorption perhaps by upregulation of ank and modulating the actin cytoskeleton through unknown mechanism yet need to be determined. 
bioRxiv preprint doi: https://doi.org/10.1101/2020.10.01.321976; this version posted October 1,2020 . The copyright holder for this preprint (which was not certified by peer review) is the author/funder, who has granted bioRxiv a license to display the preprint in perpetuity. It is made available under aCC-BY 4.0 International license. 

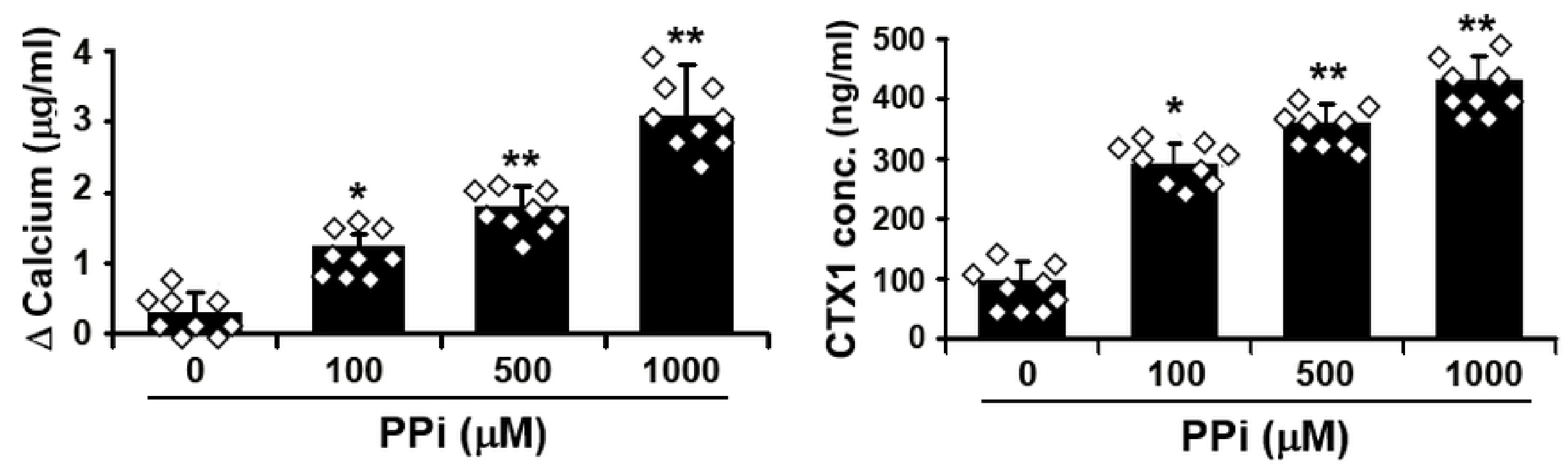

C PPi:

$0 \mu \mathrm{M}$

$100 \mu \mathrm{M}$

$500 \mu \mathrm{M}$

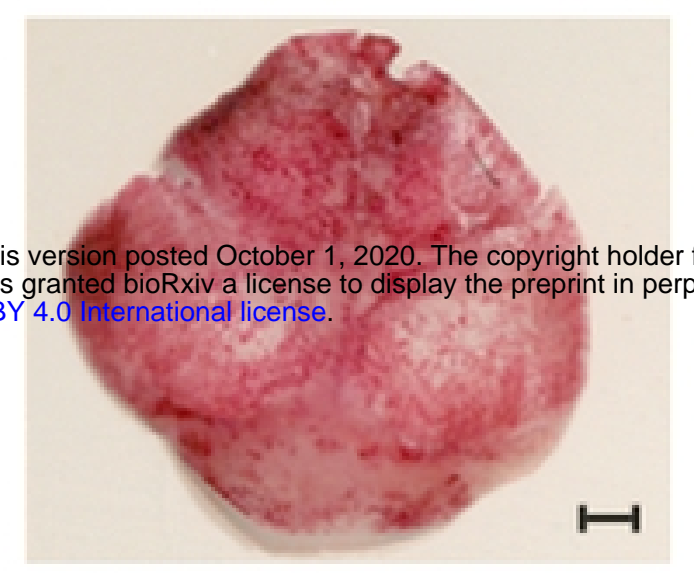

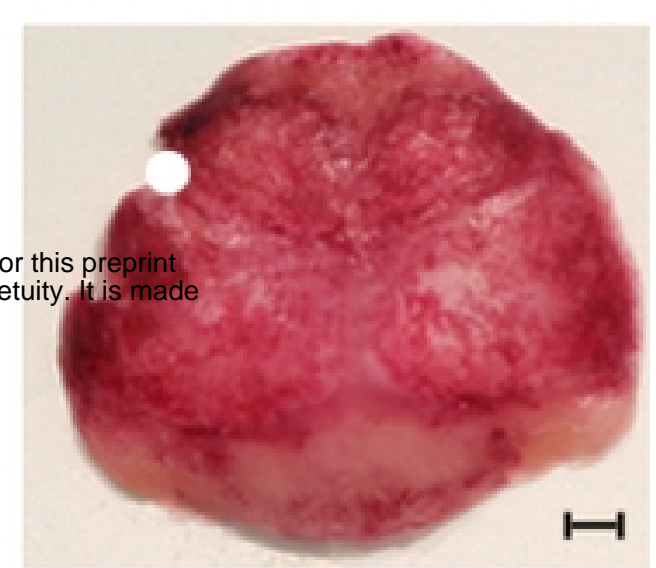

$1000 \mu \mathrm{M}$

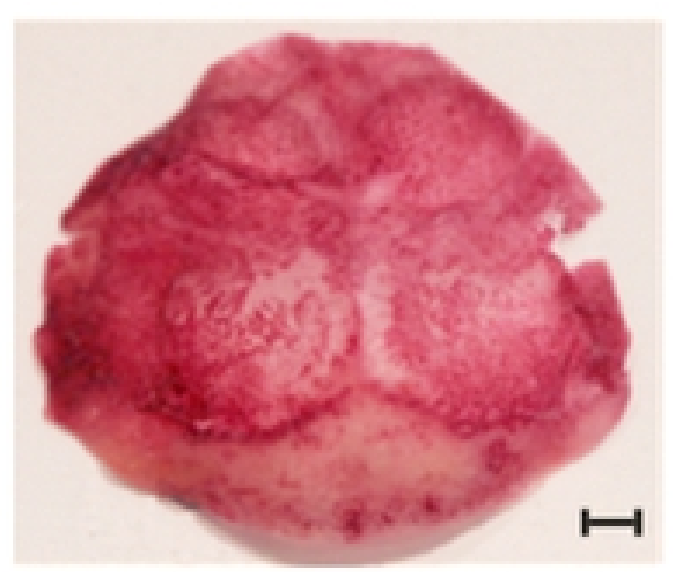

\section{D}

F"

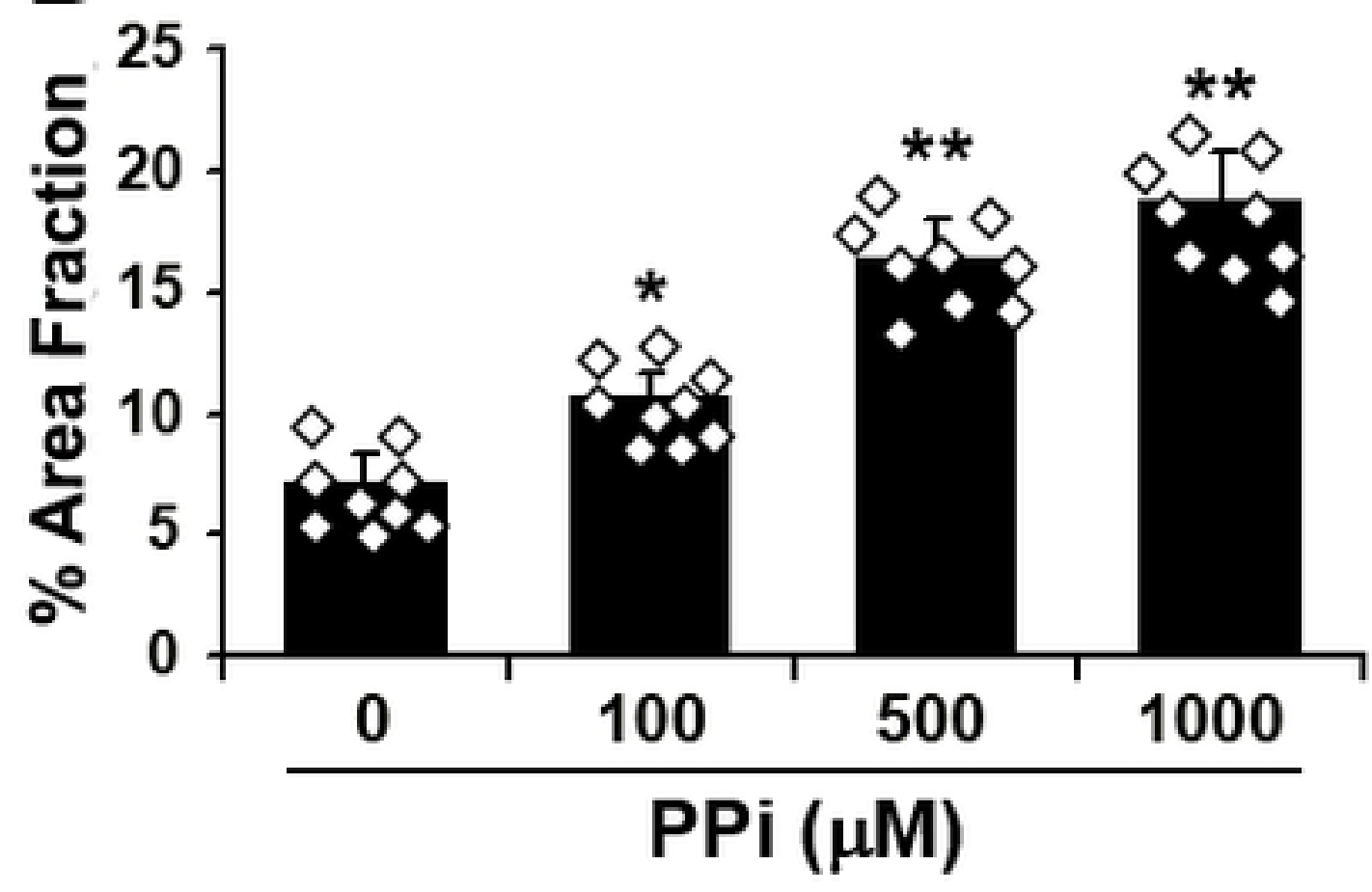

\section{E}

(-) Control

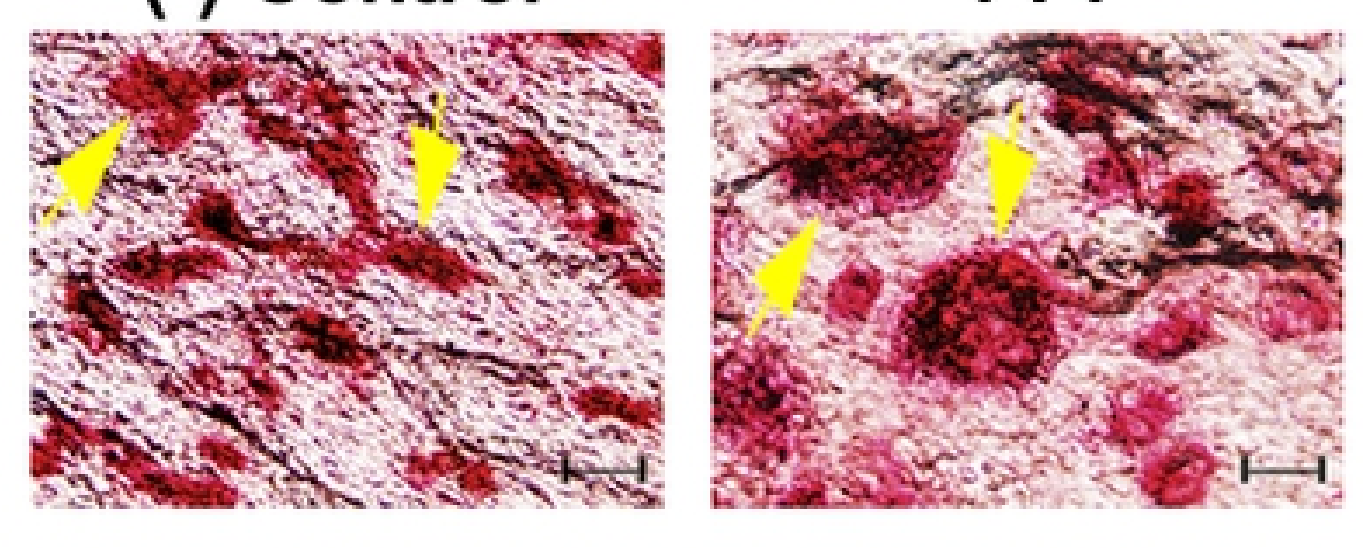

(-) Control

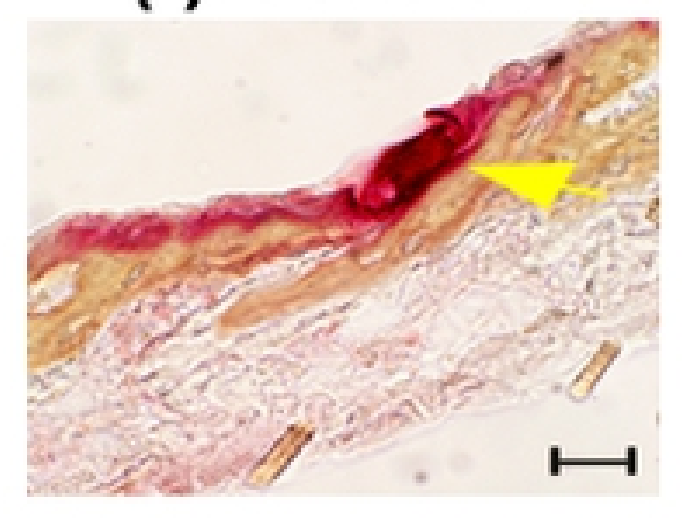

G

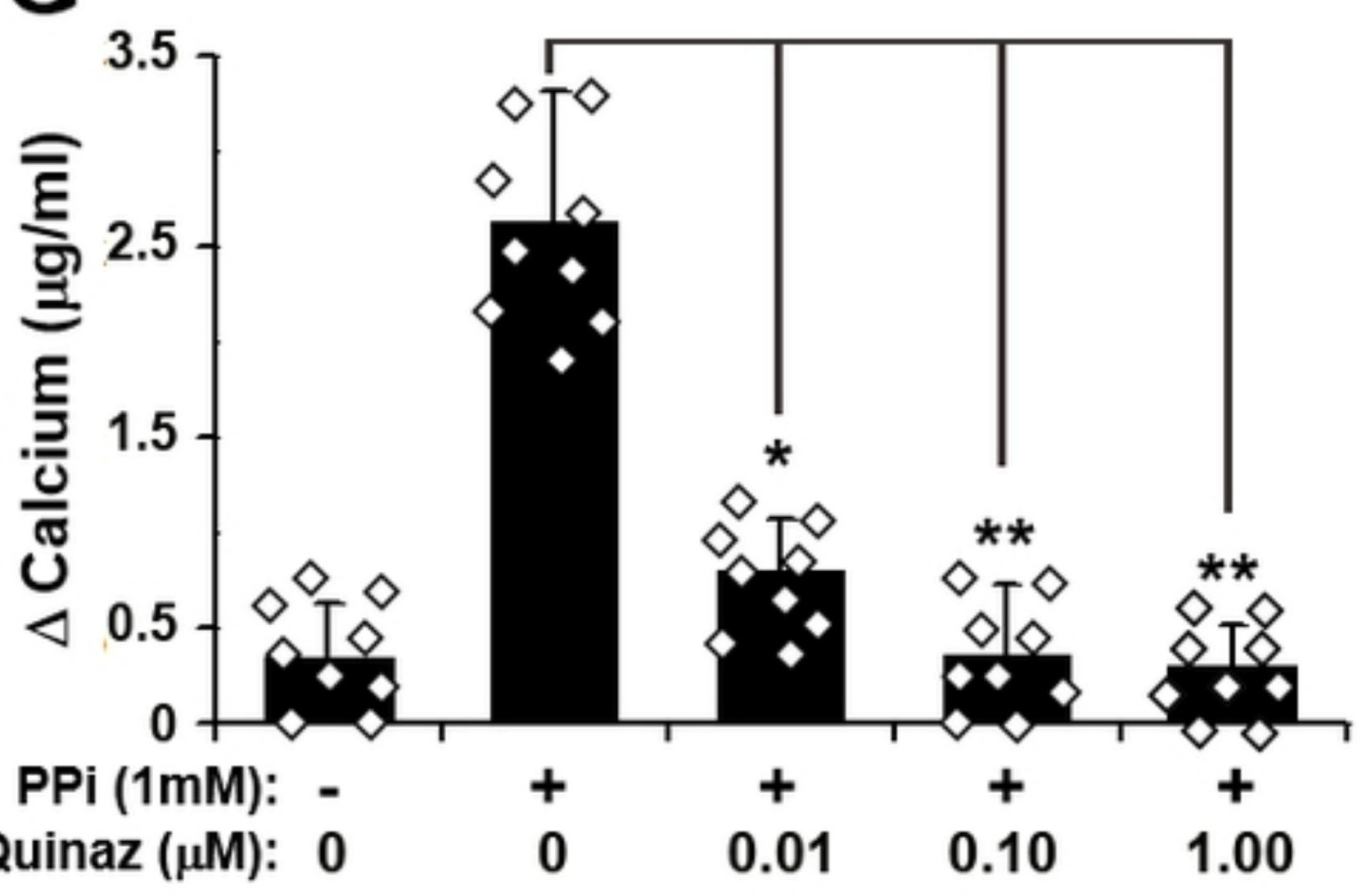

Figure-1 
A

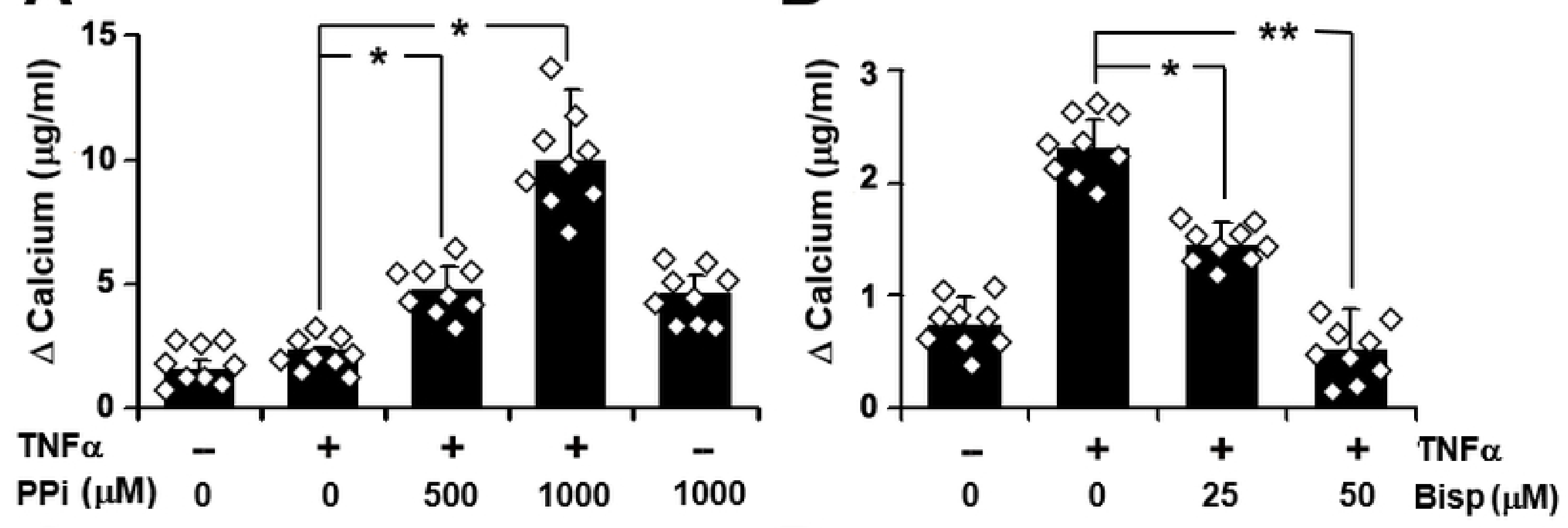

C
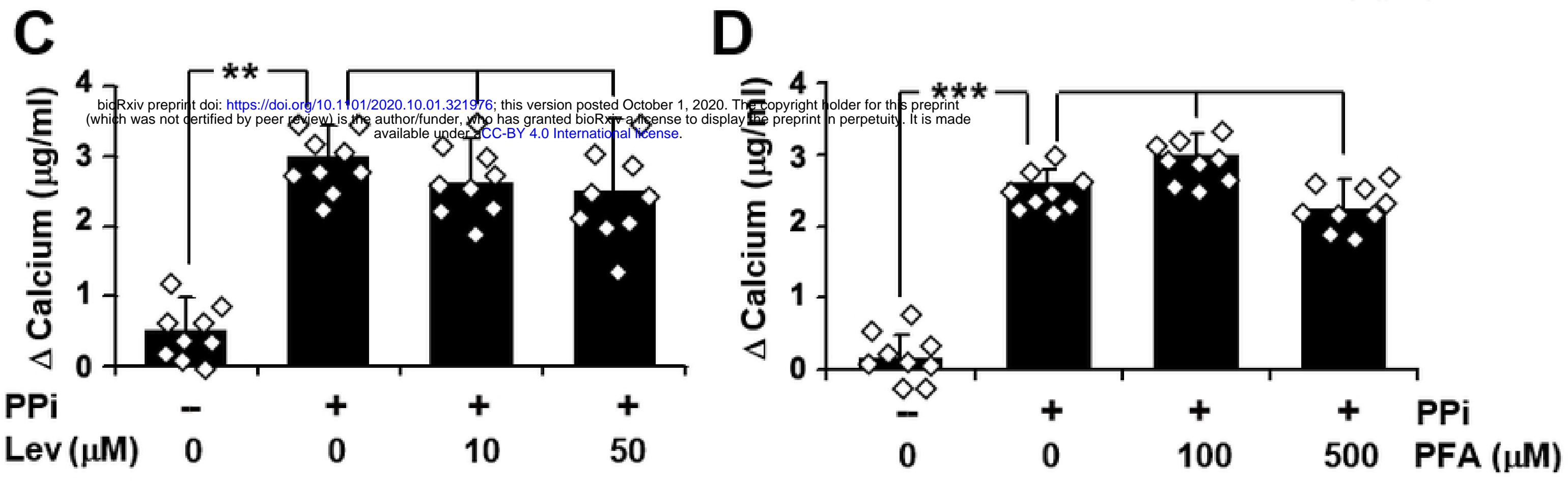

E

F

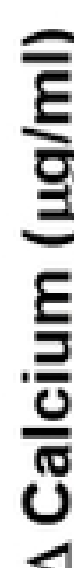

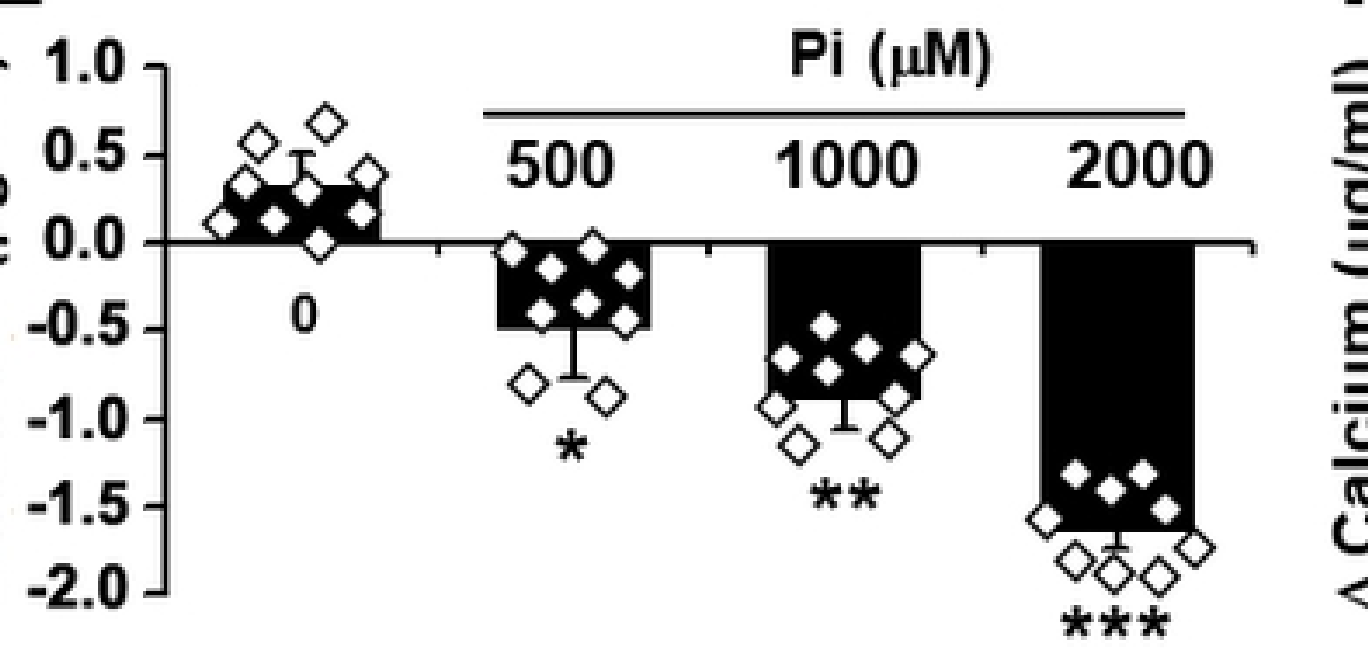

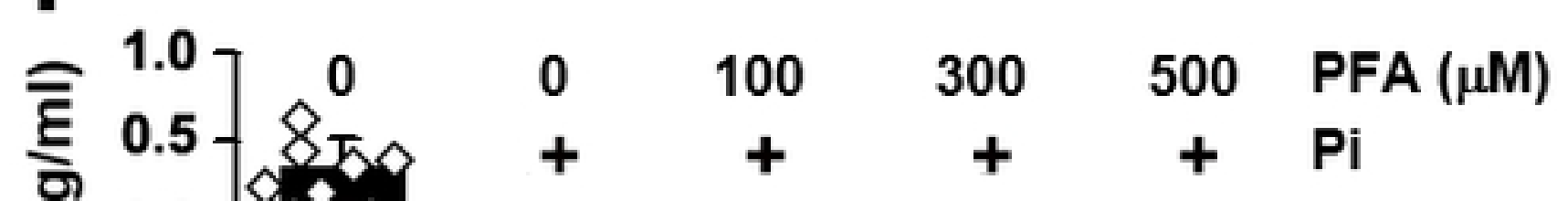

$=$

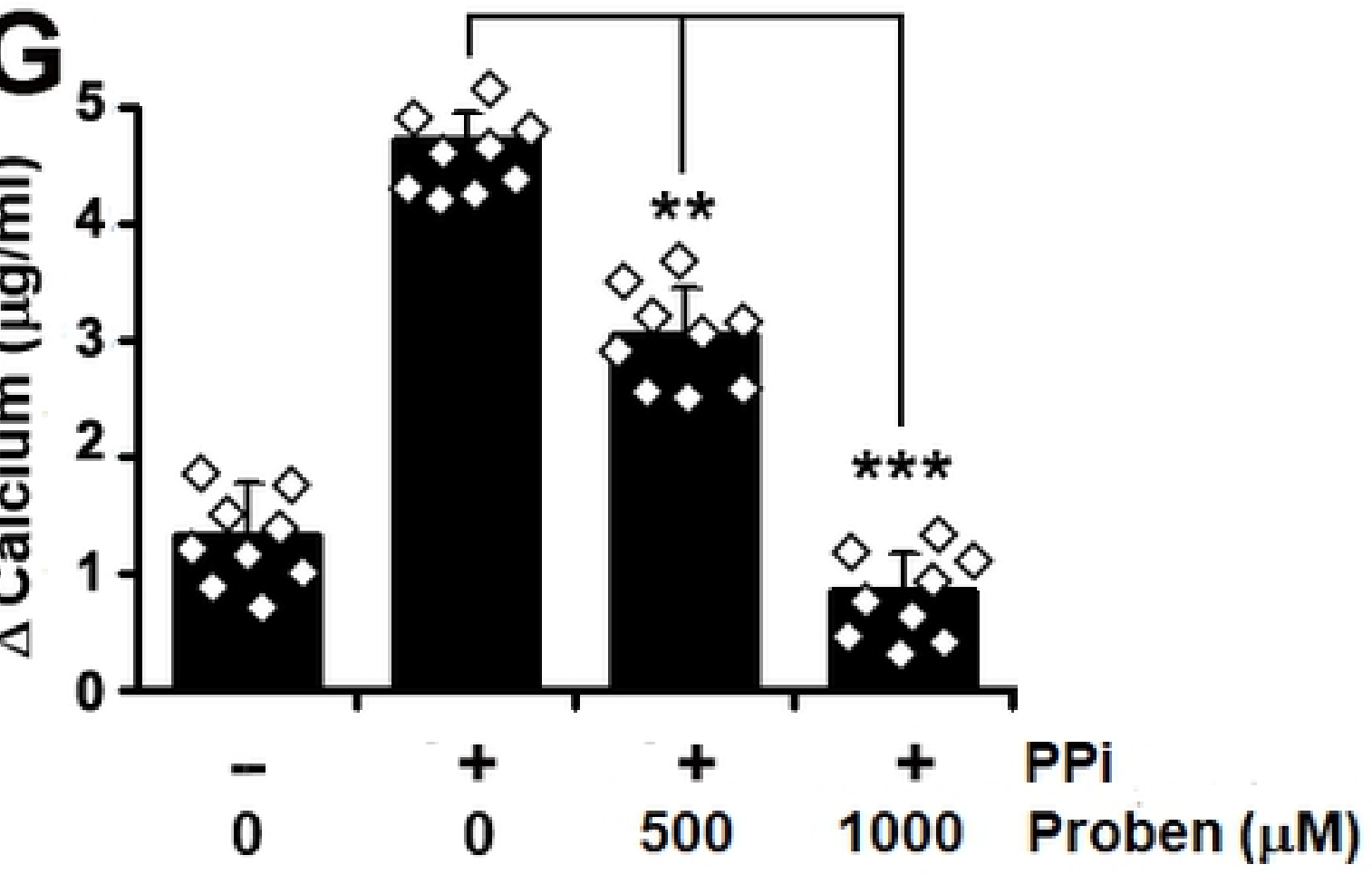

Figure-2 


\section{$\mathbf{A}$}

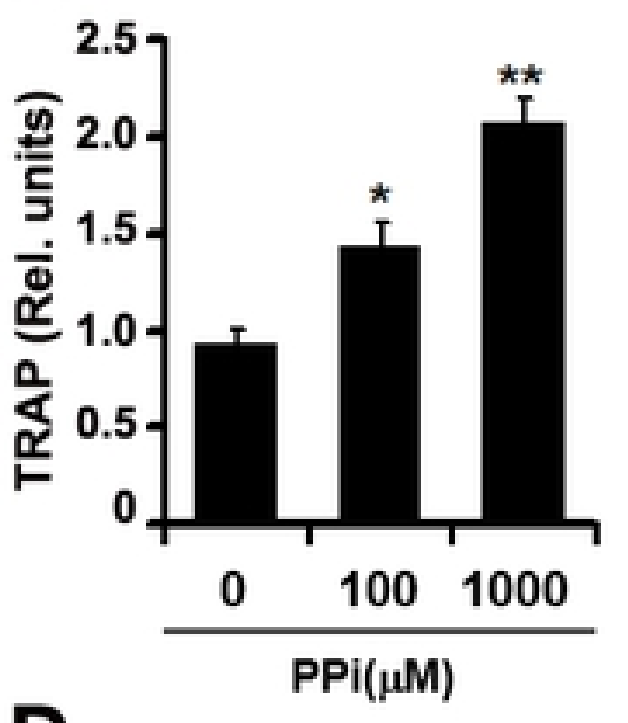

D

\section{(-) Control}

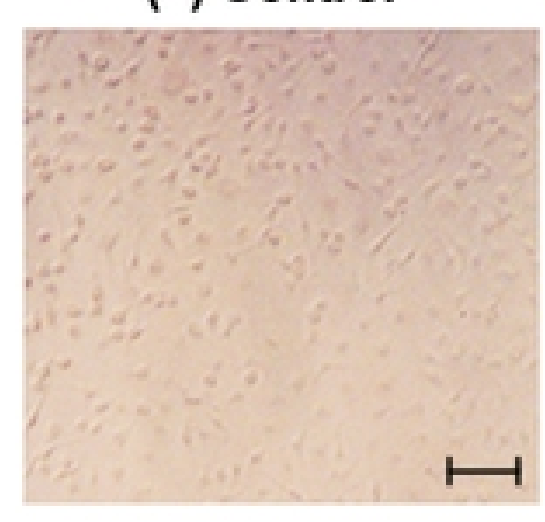

$F$

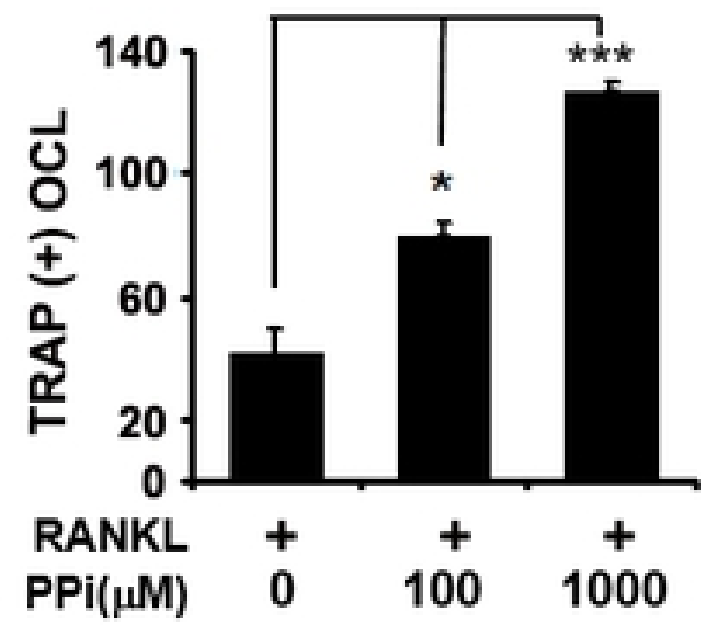

Figure-3

\section{B}
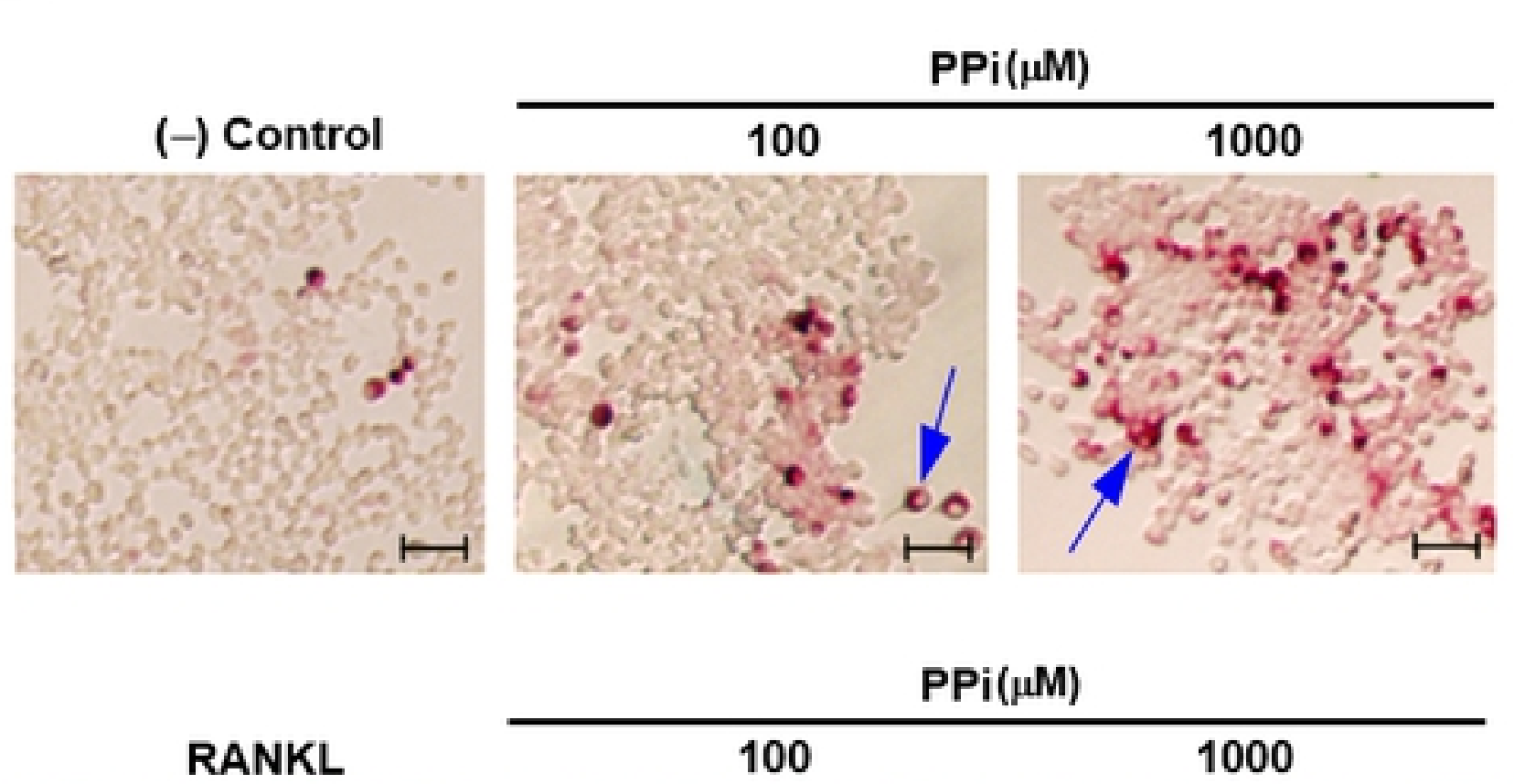

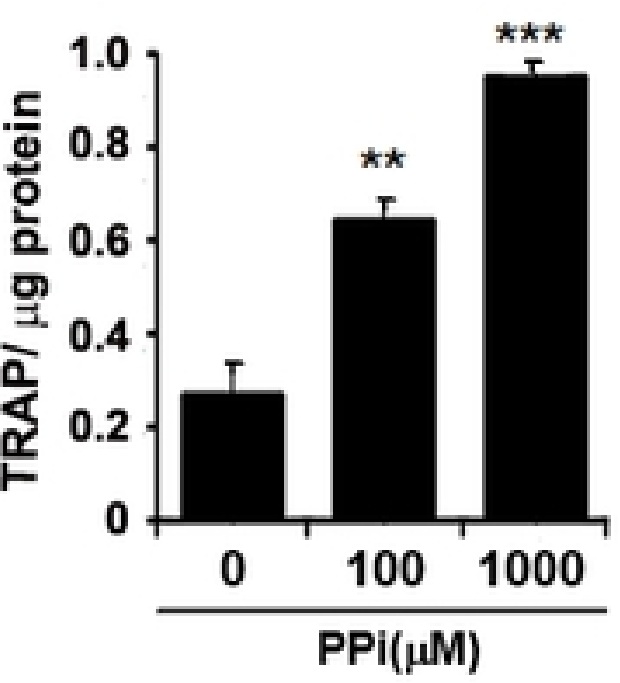

E
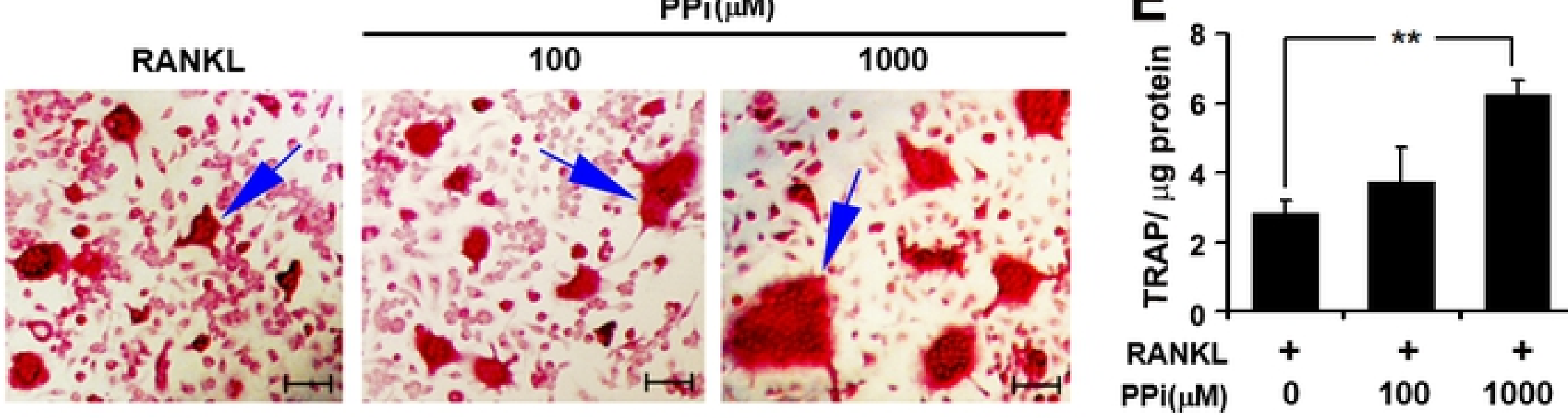

\section{H}

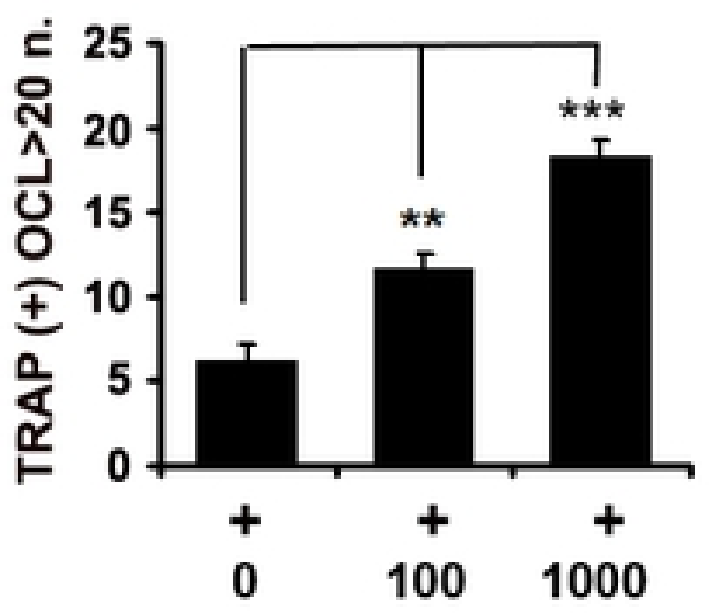

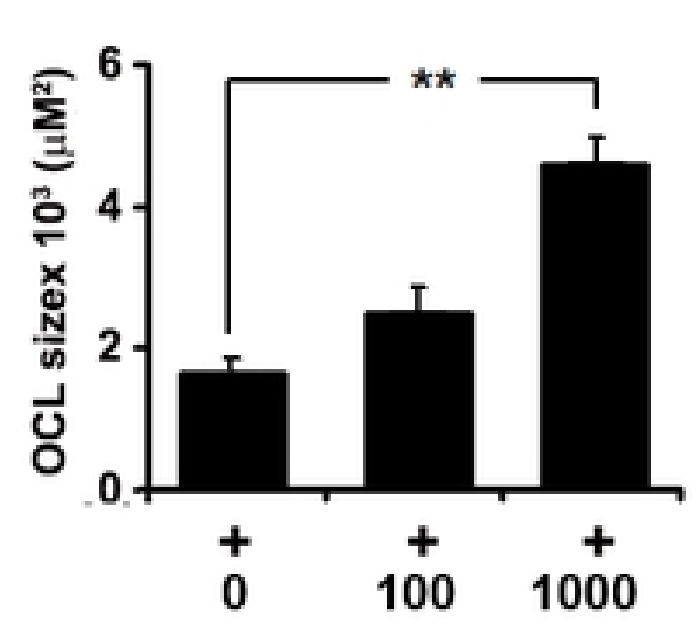
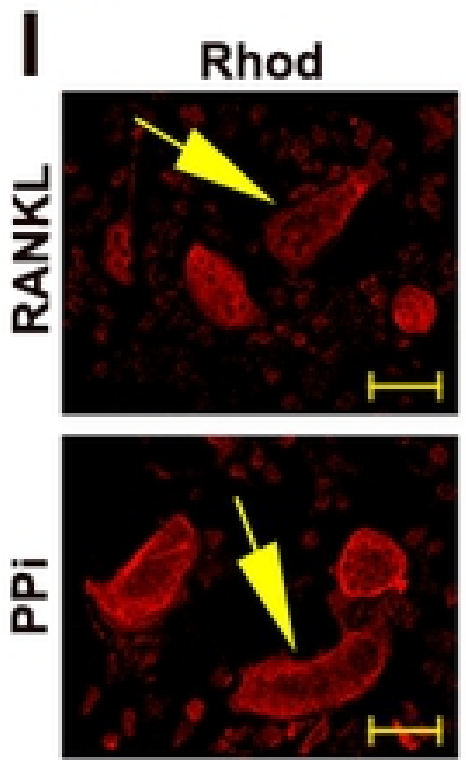

Rhod+DAPI
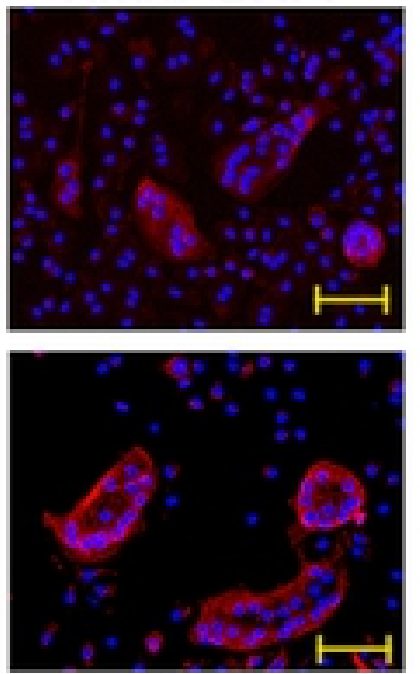
RANKL

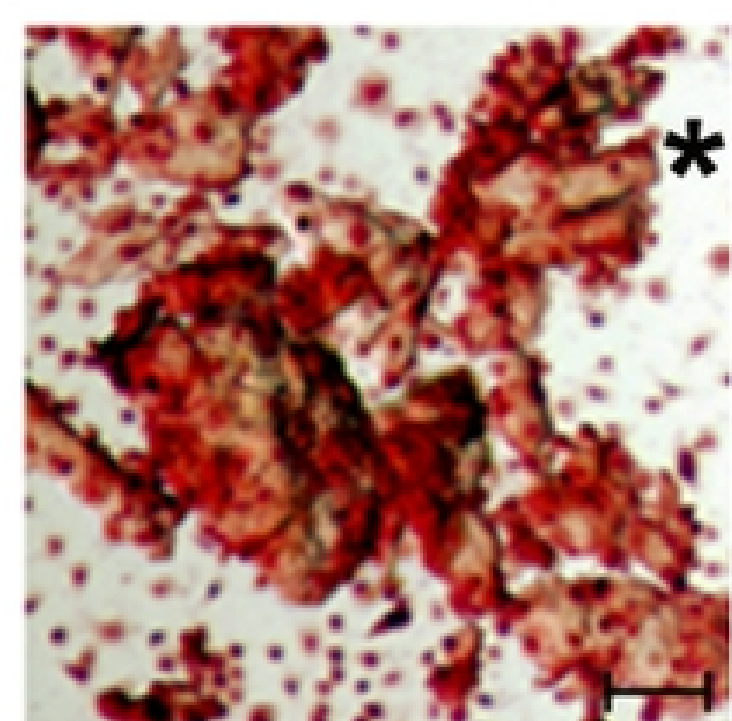

C

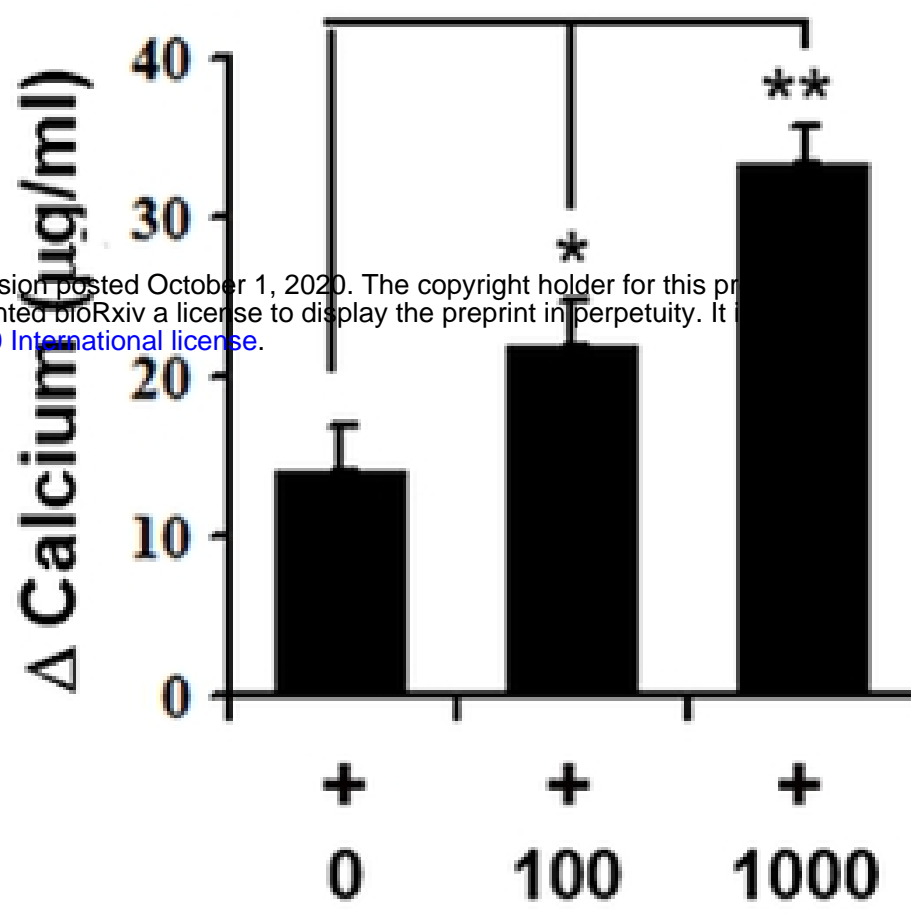

1000
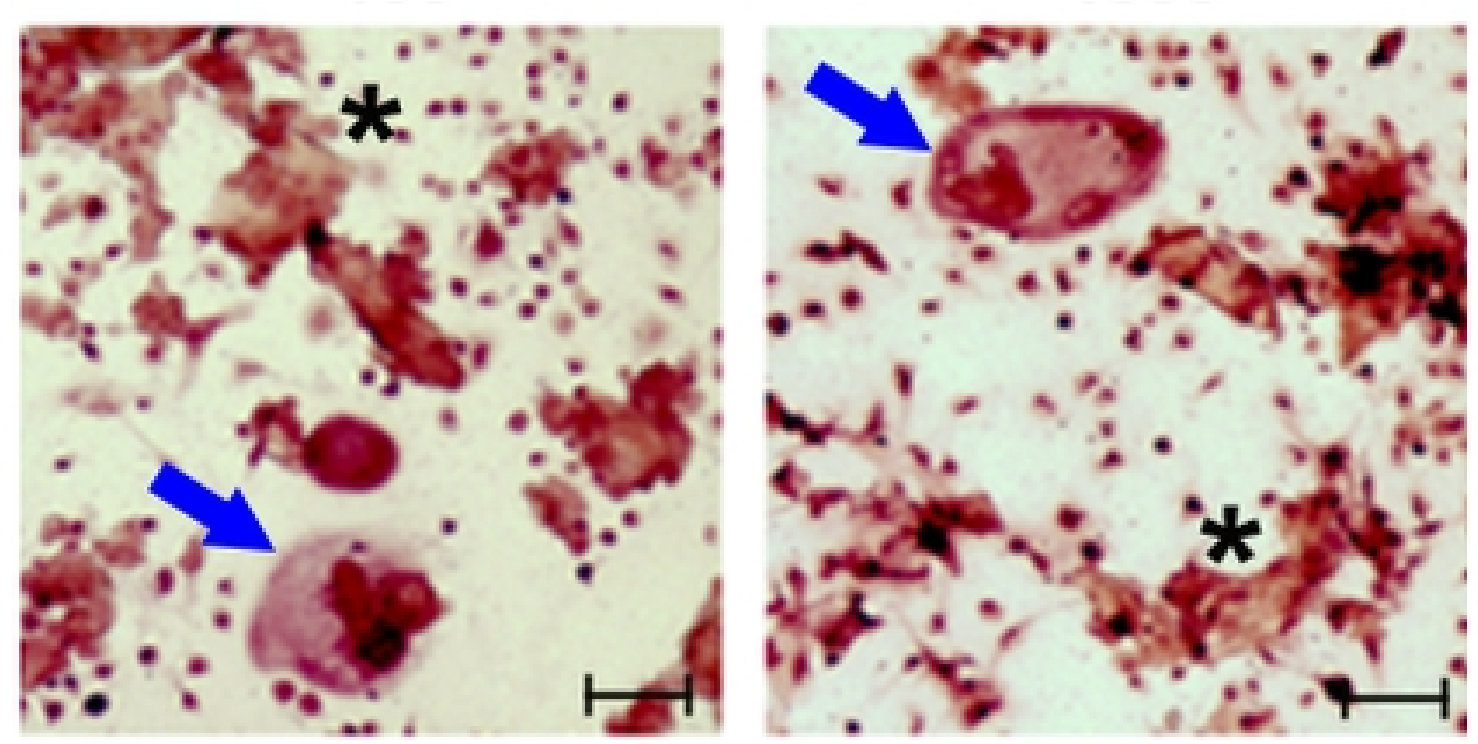

(-) Control

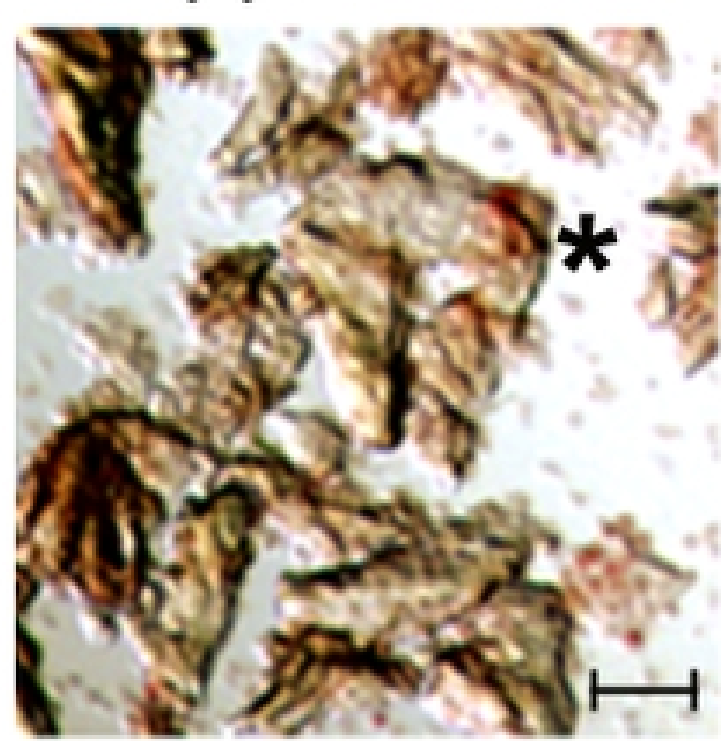

B

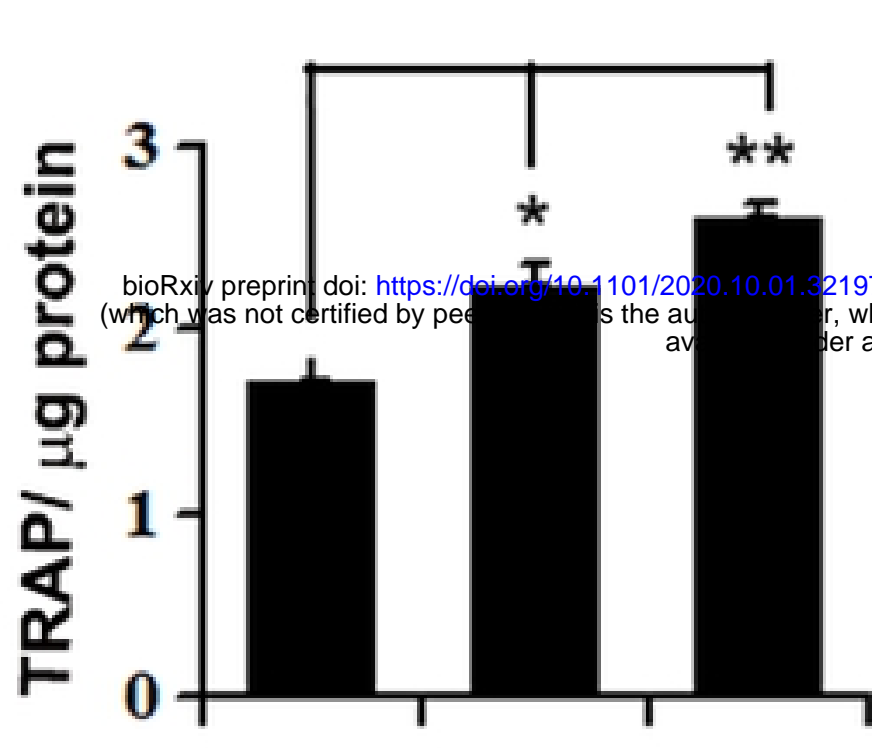

$\mathrm{R}$
$\mathrm{PI}$
$\mathrm{E}$

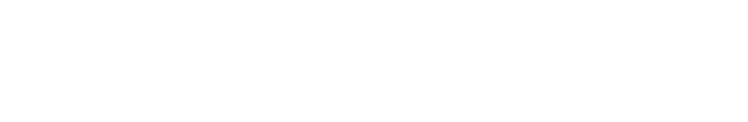

$\begin{array}{lll}+ & 100 & 1000\end{array}$
A

(-) Control
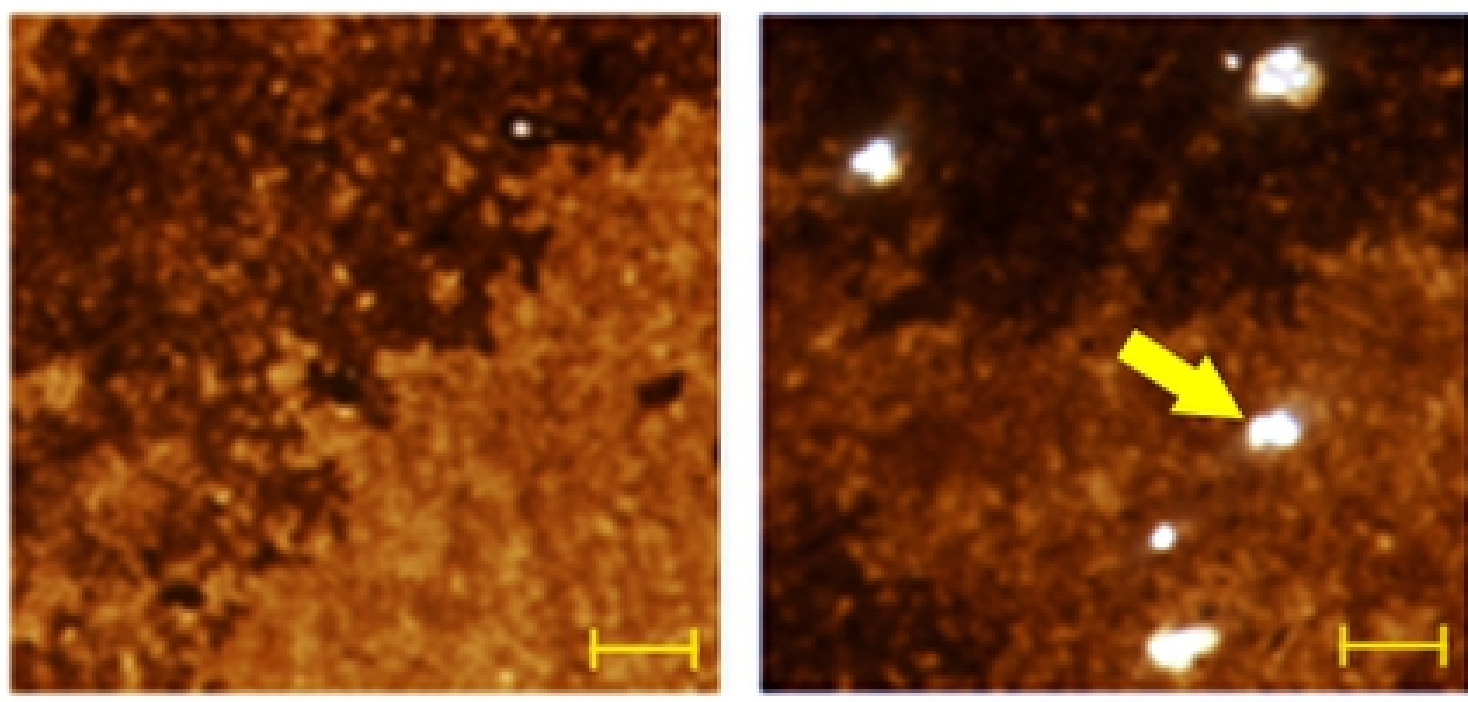

RANKL

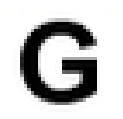

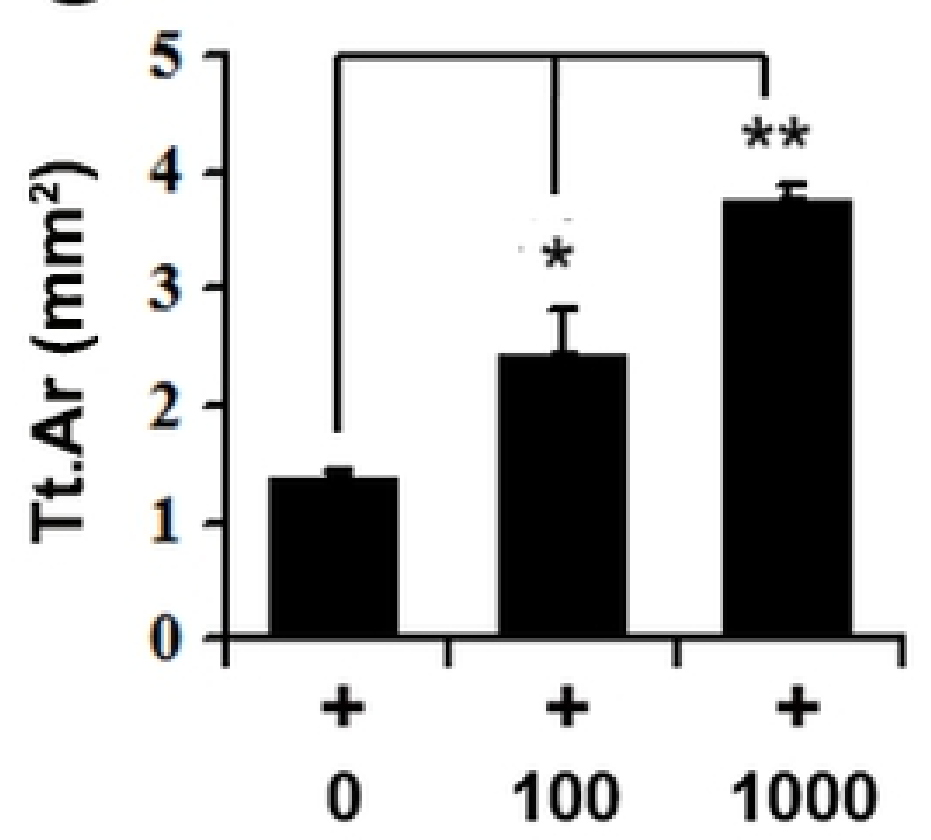
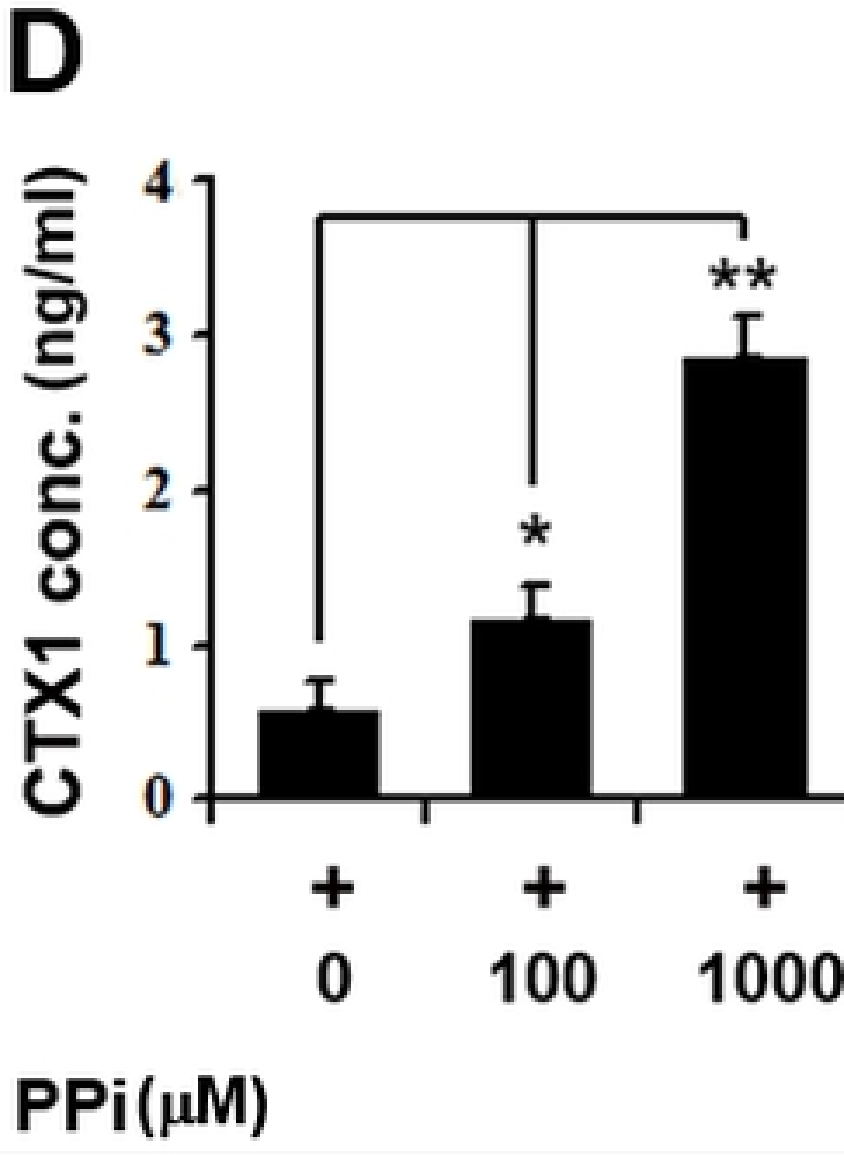

.

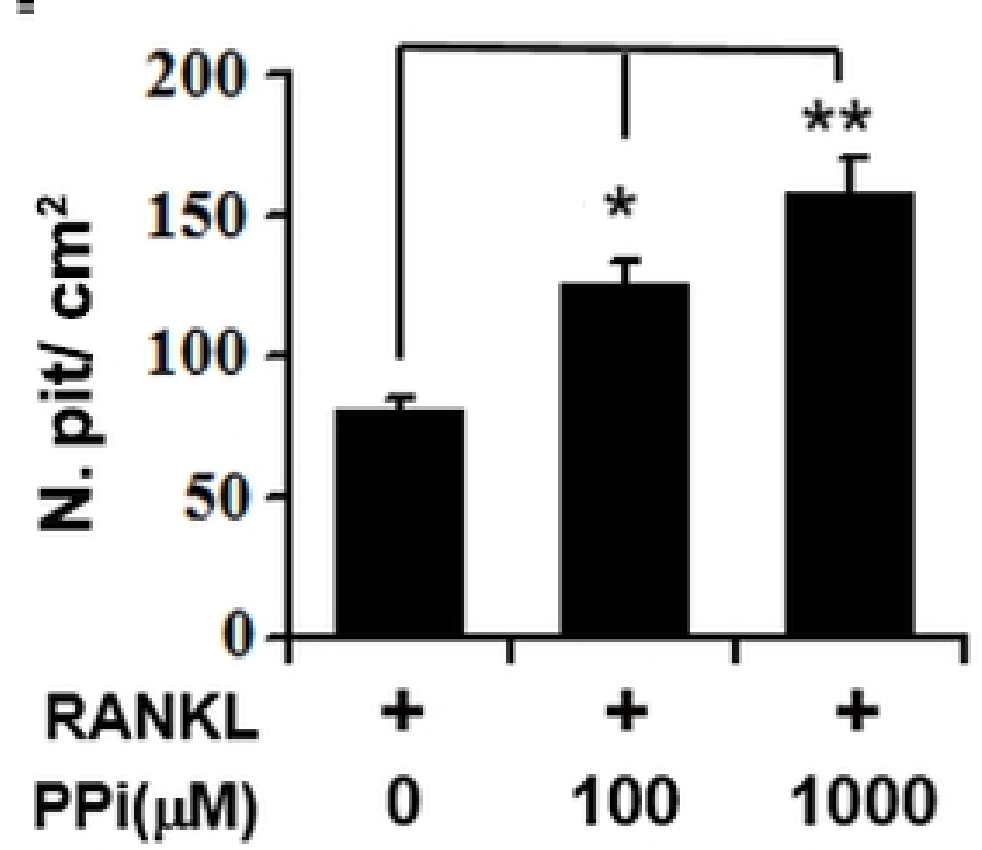

F

Figure-4

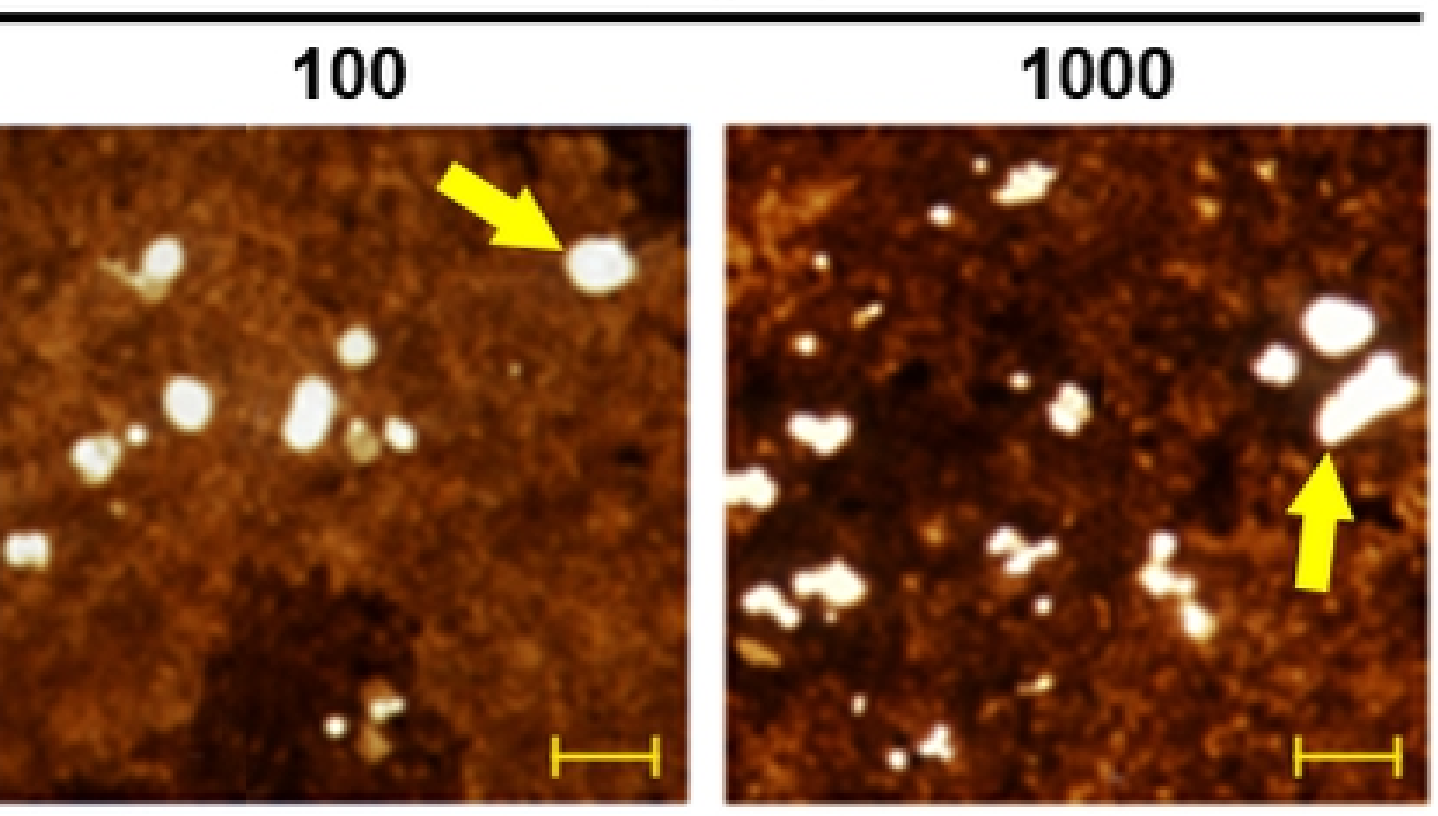

$\mathrm{H}$

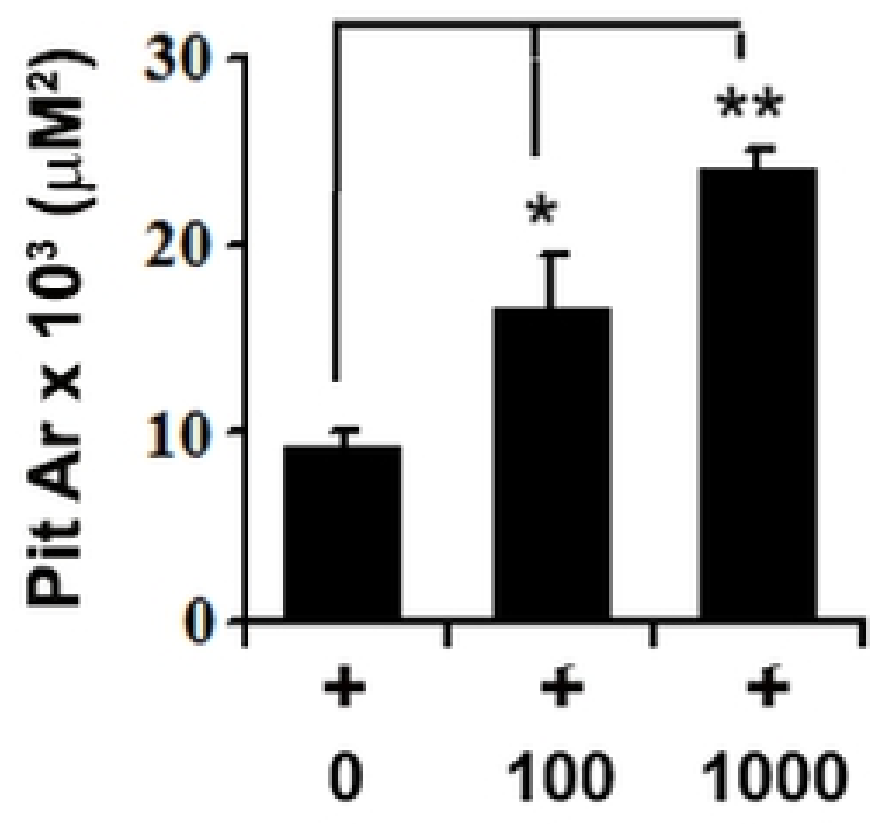


A

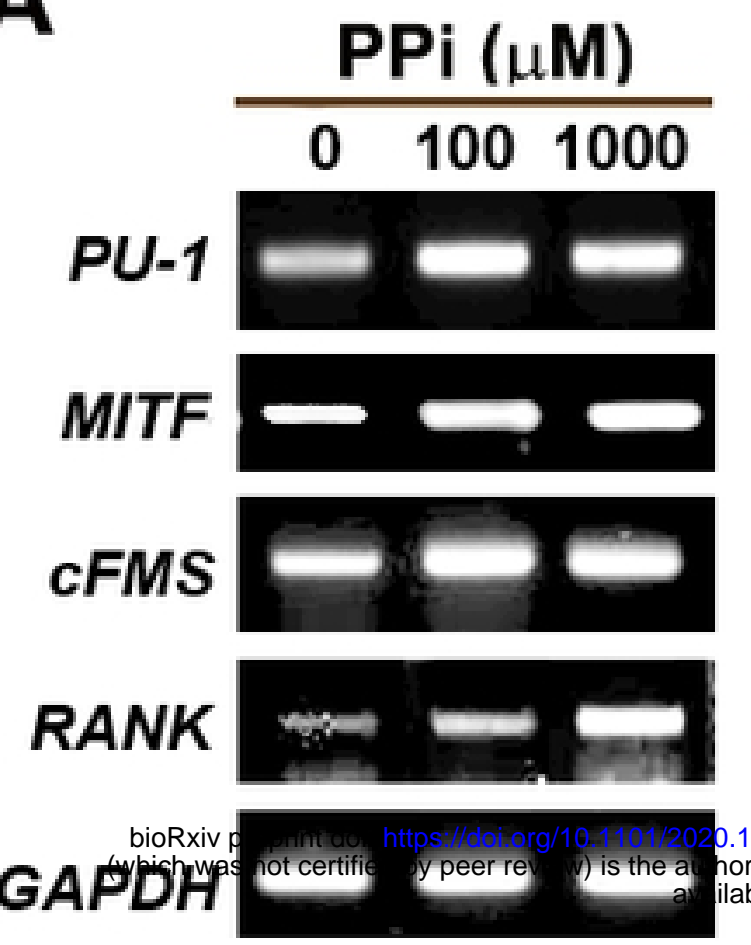

D

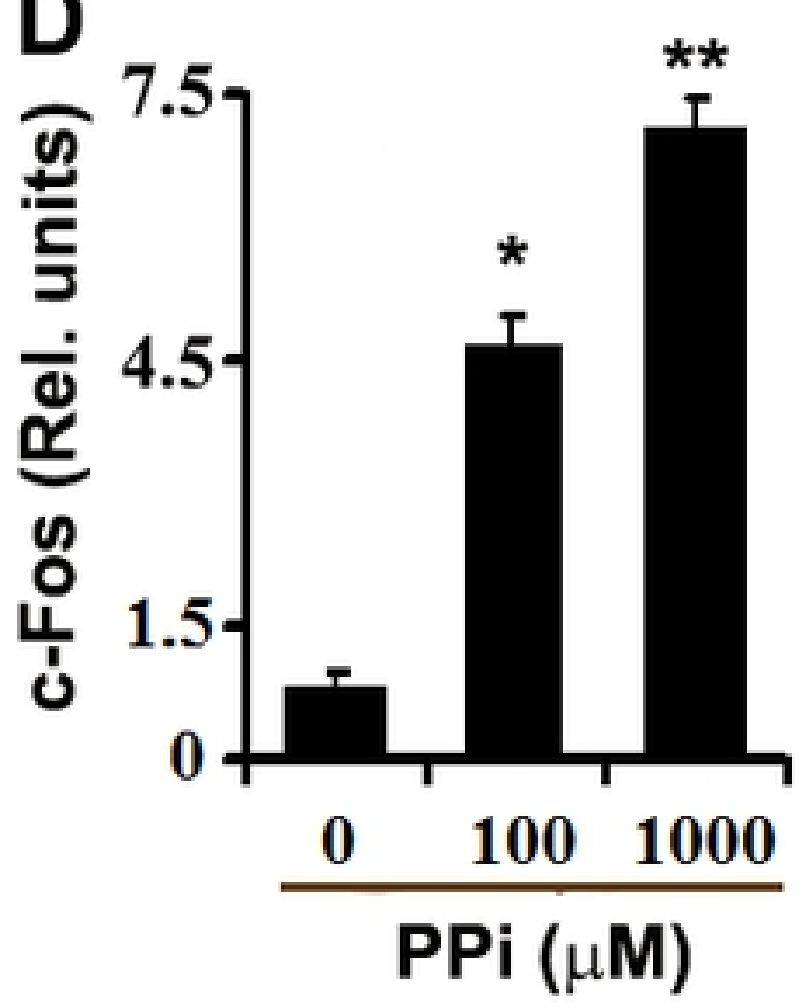

G

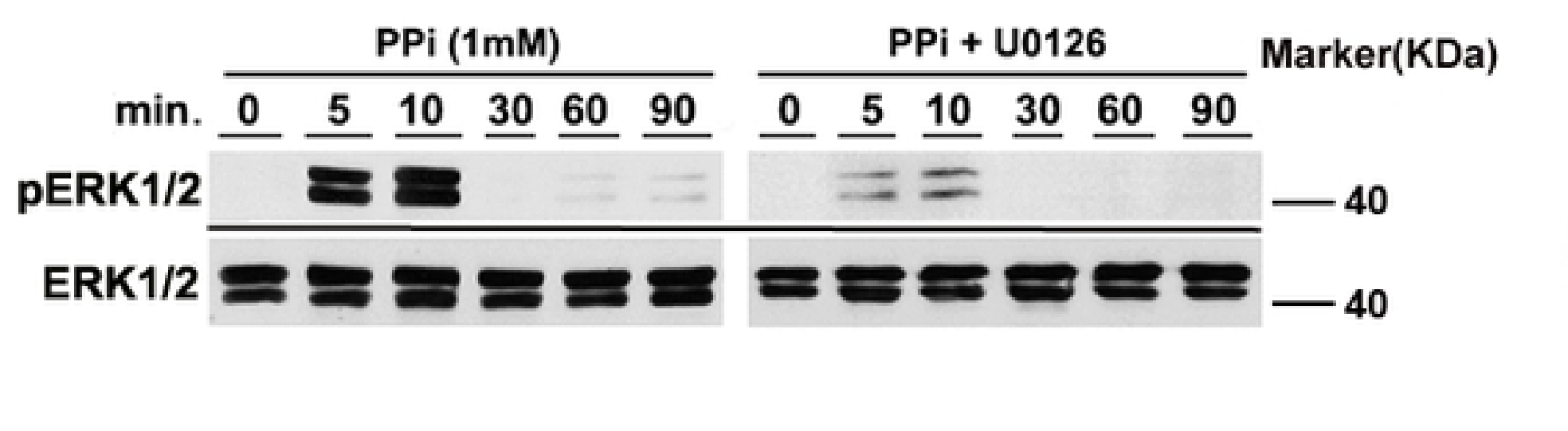

I

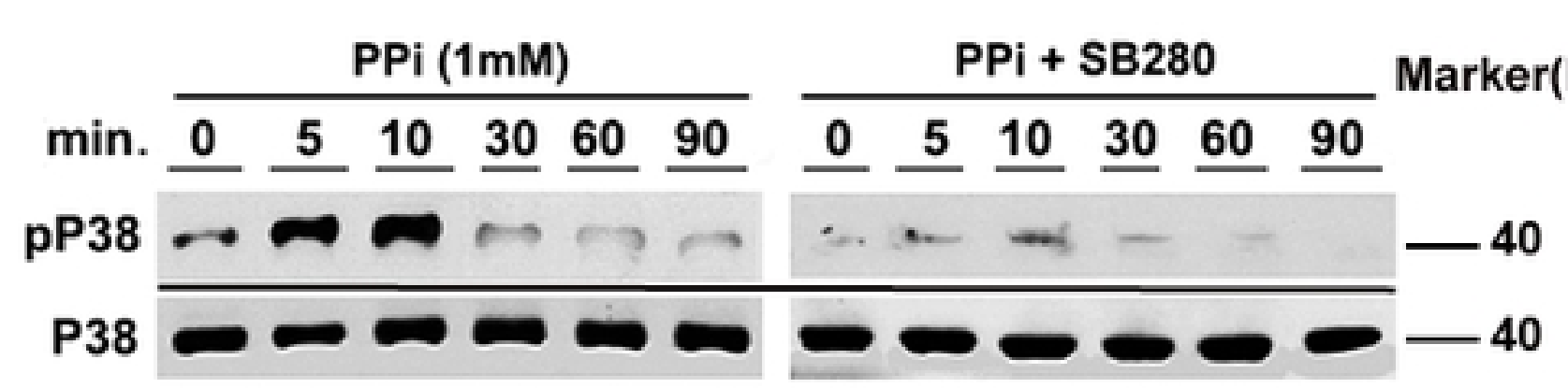

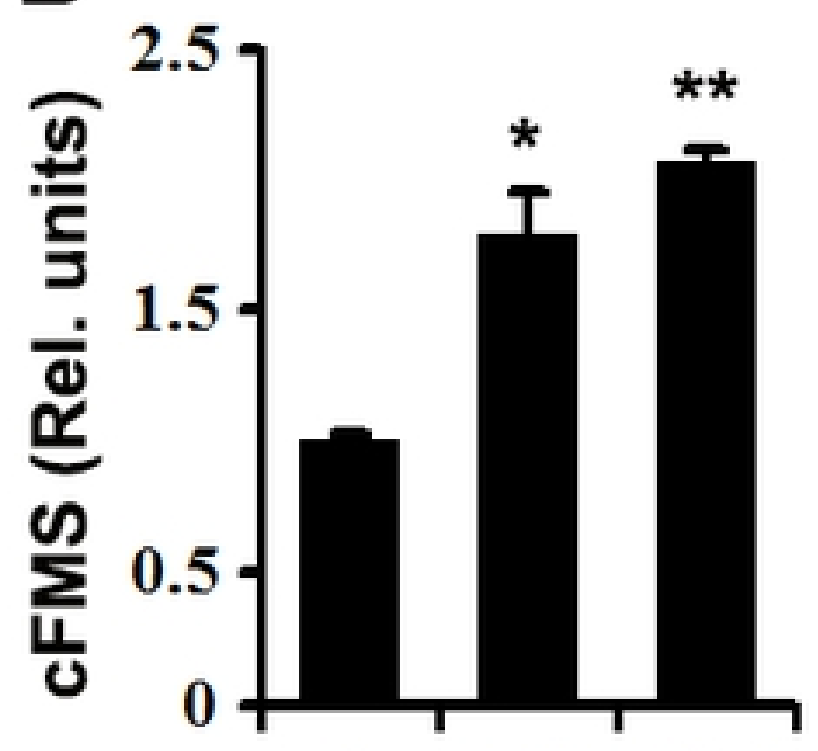

Ponder for tistopopopint 1000

PPi $(\mu \mathbf{M})$

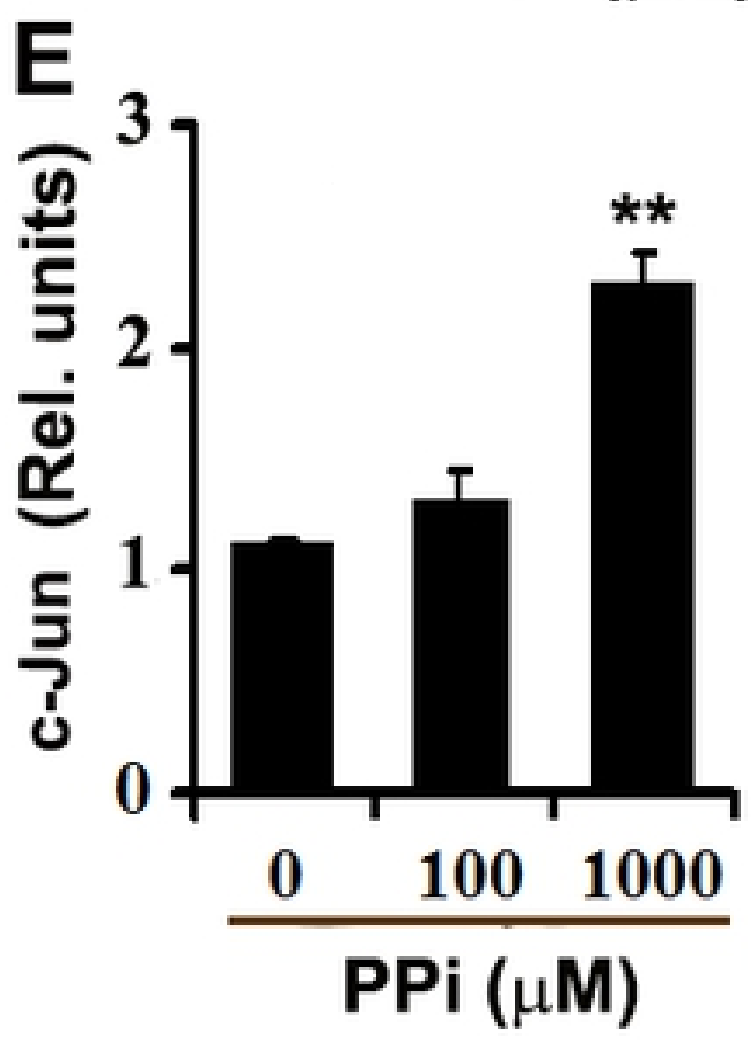

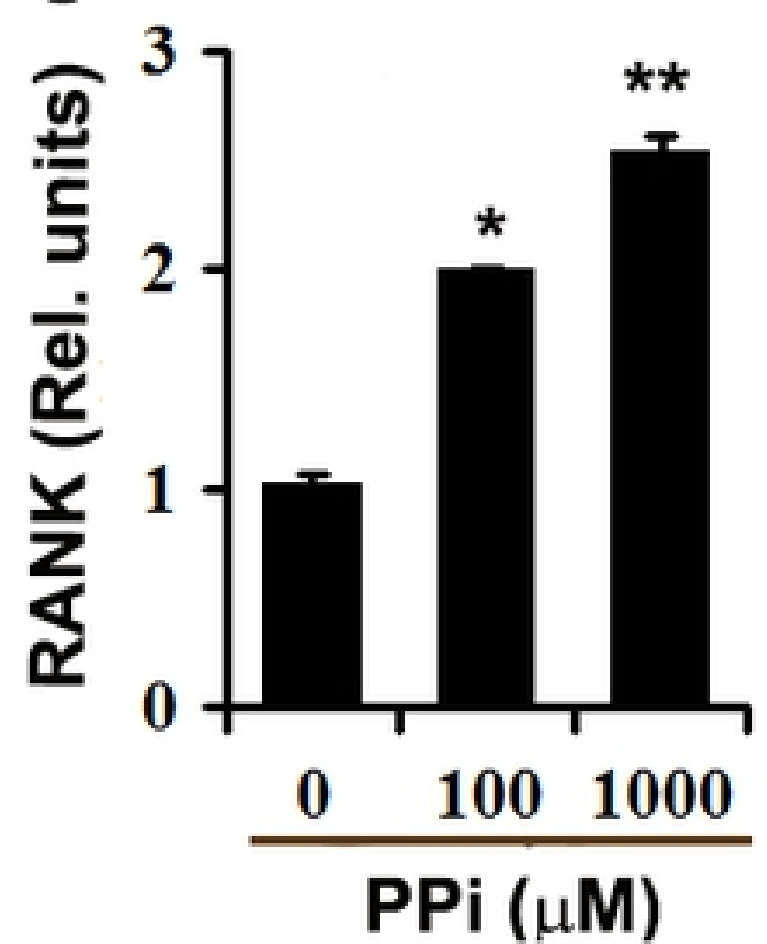

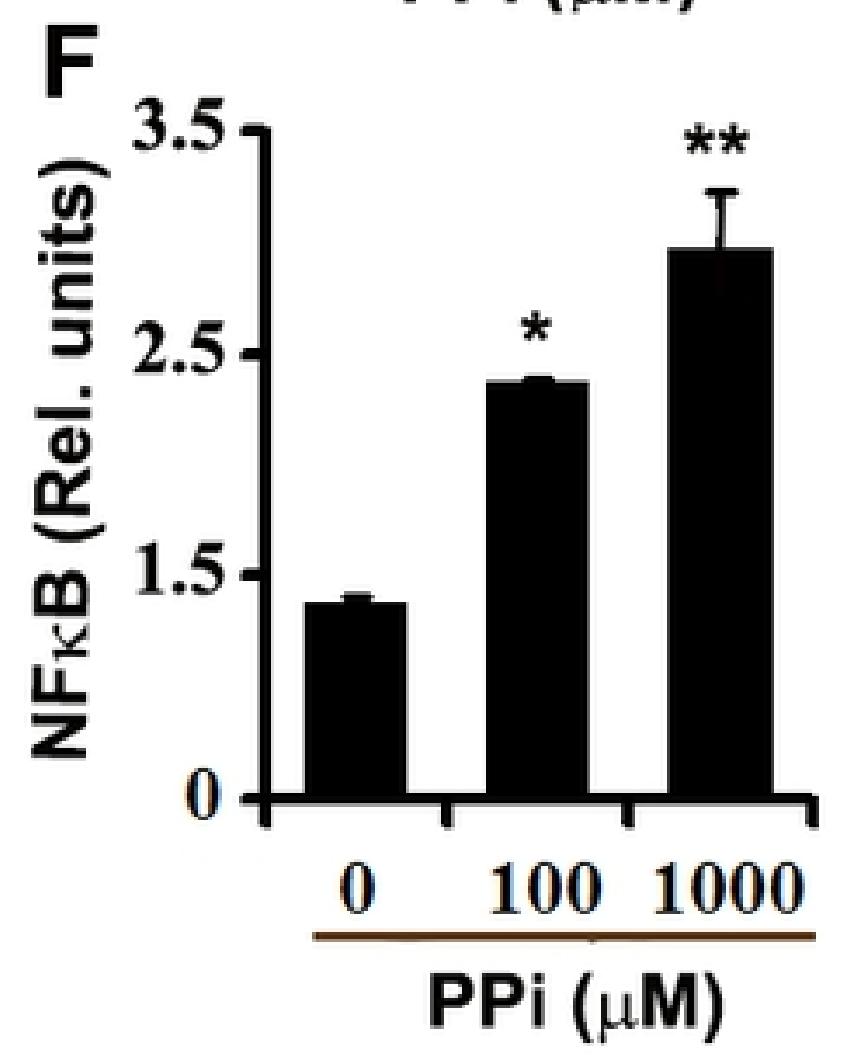

H

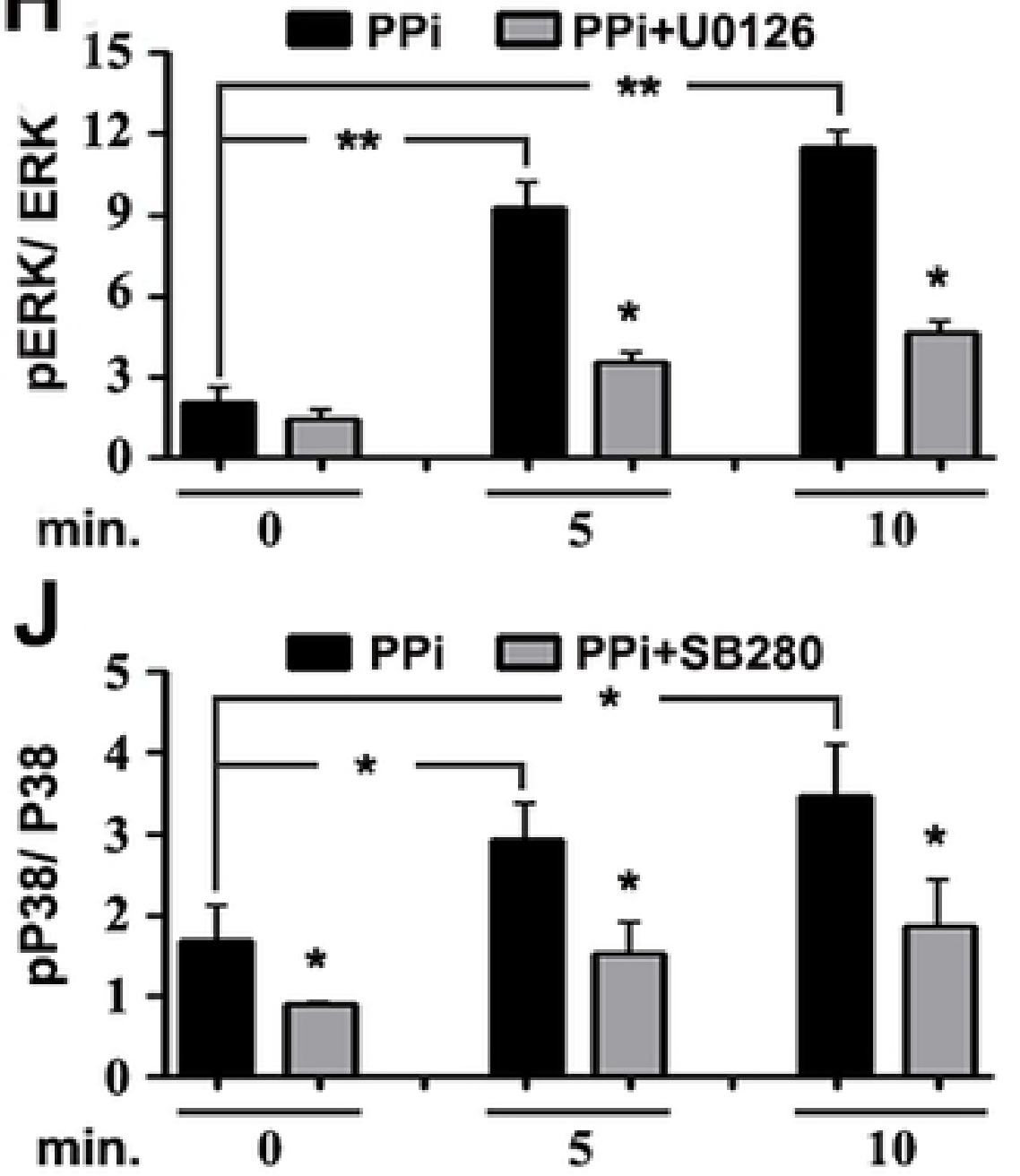

Figure-6 
A

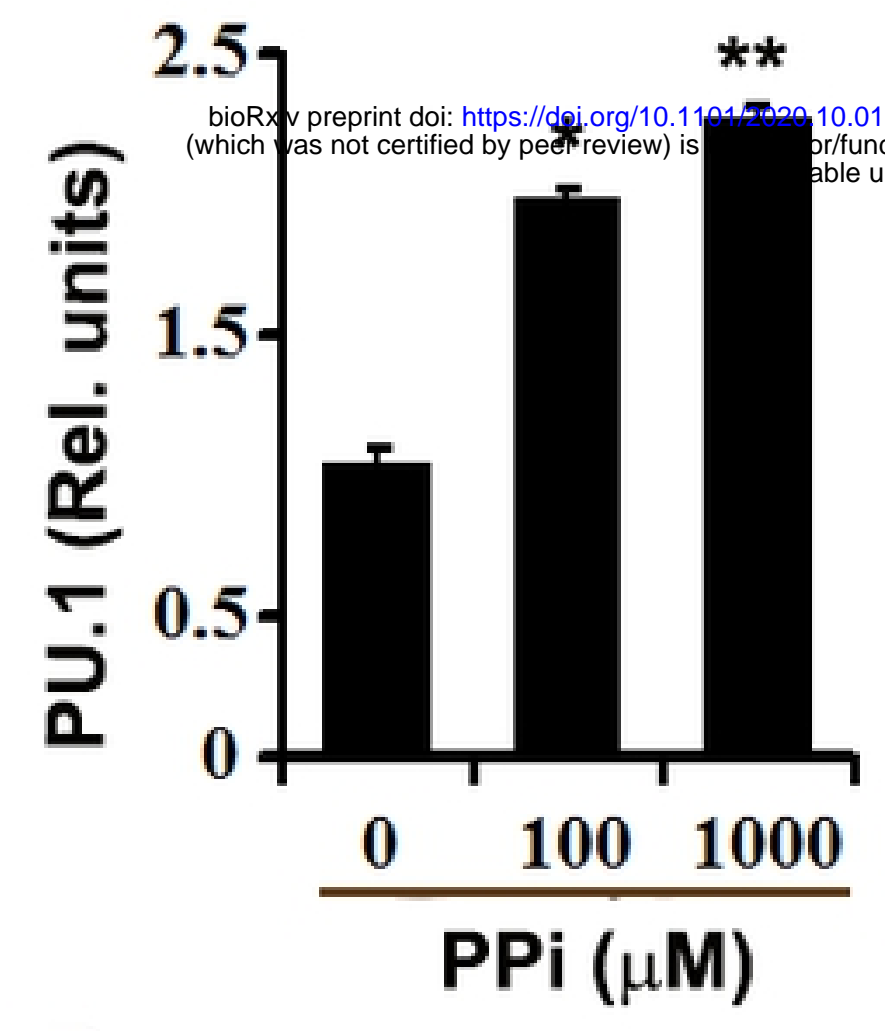

D

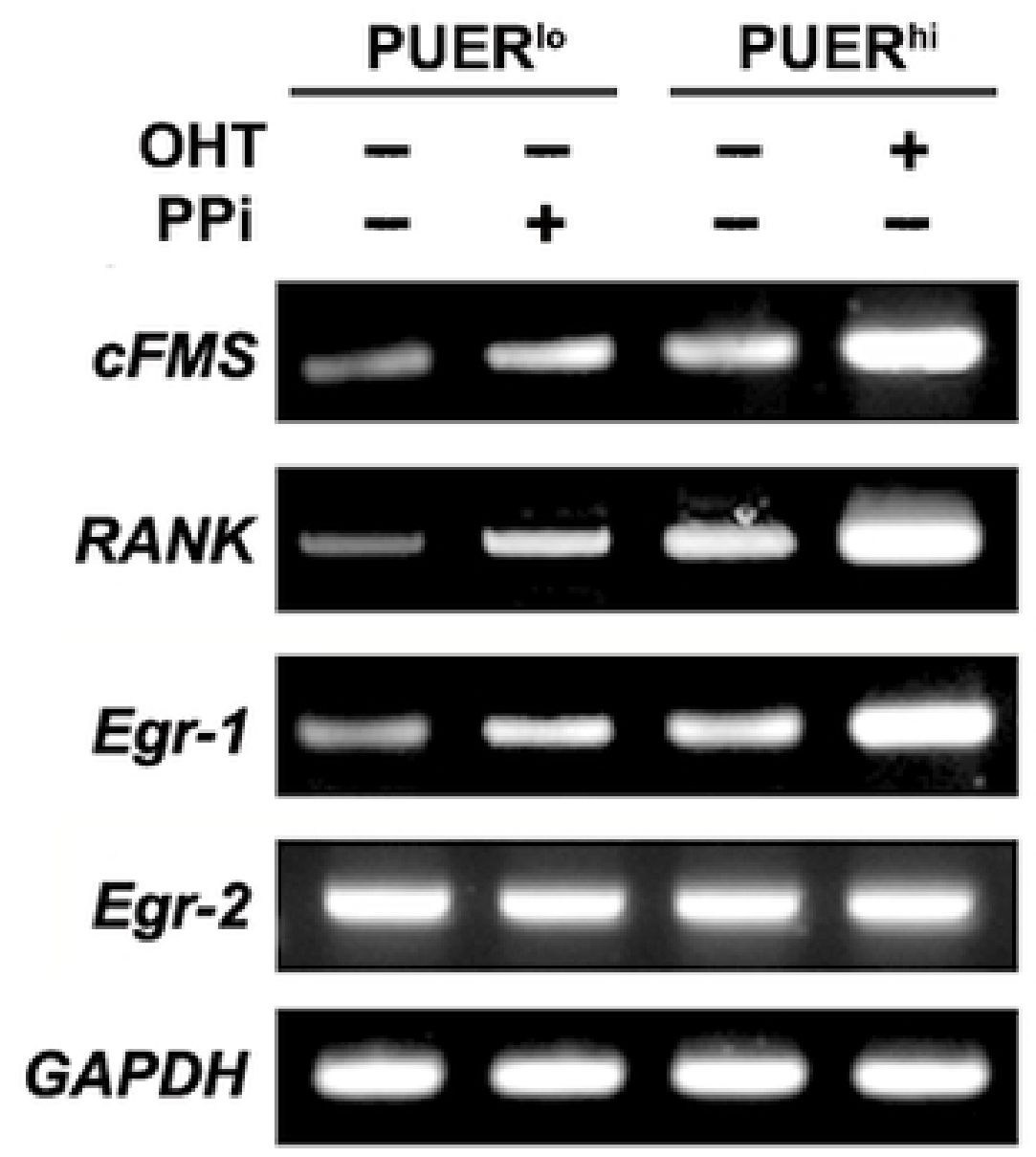

Figure-7

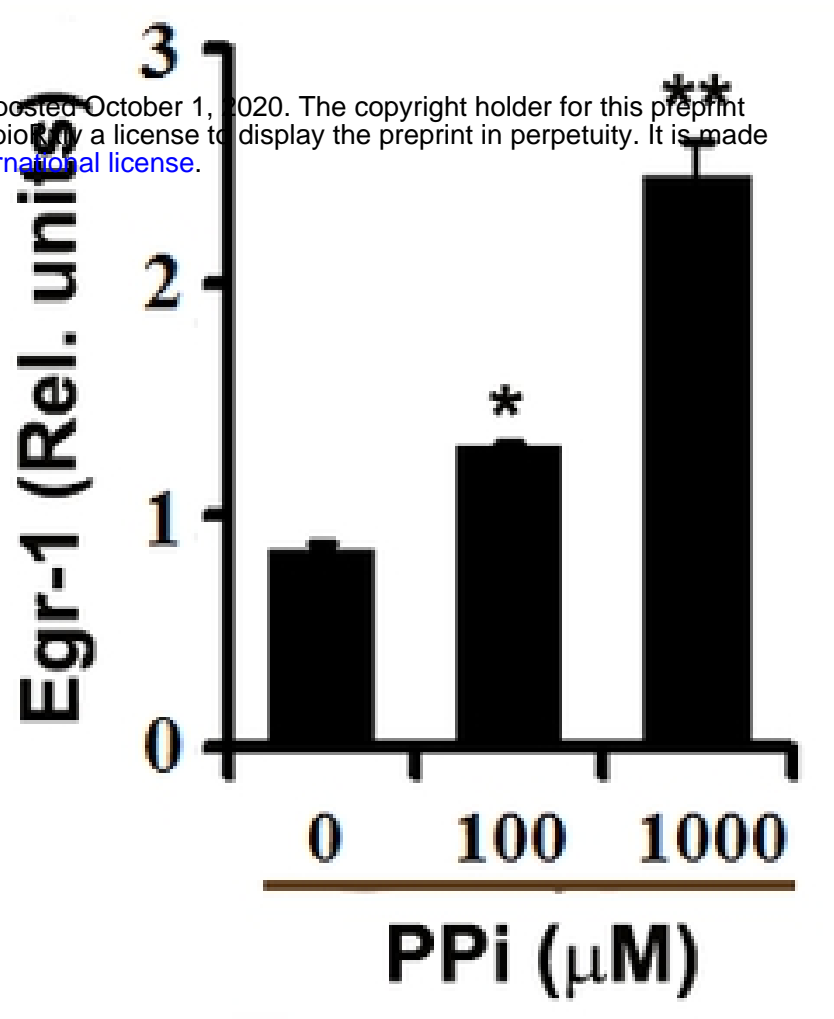

E
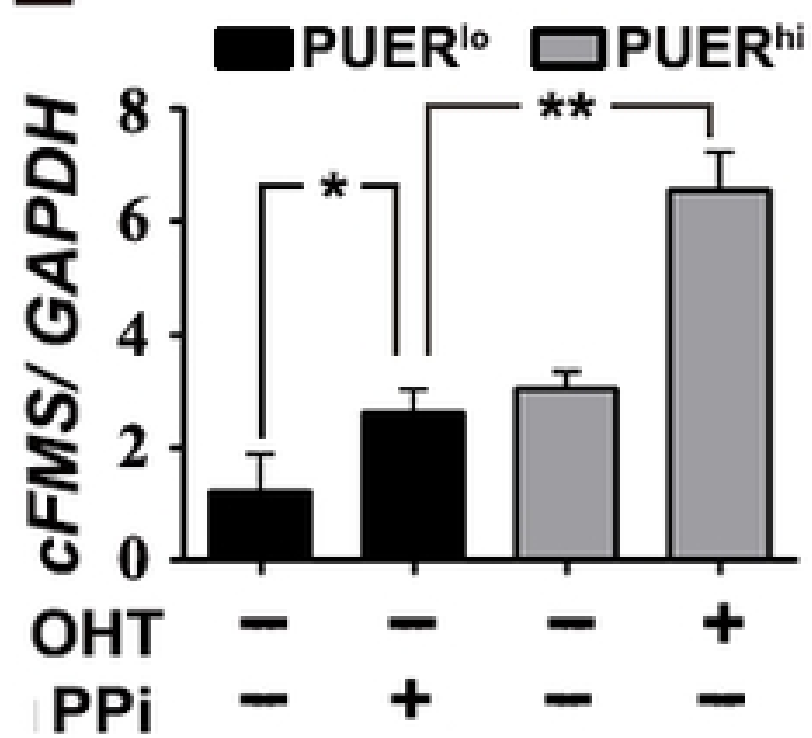

G

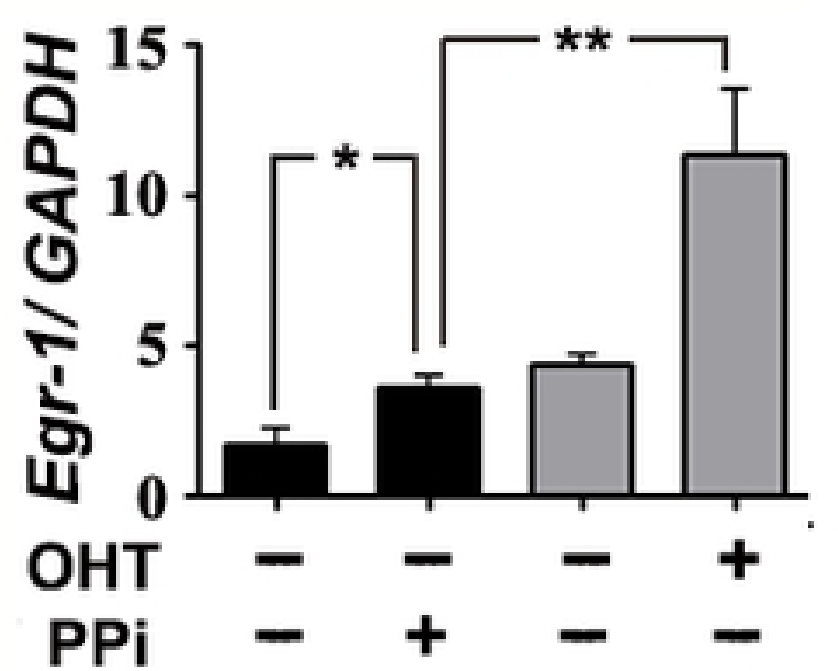

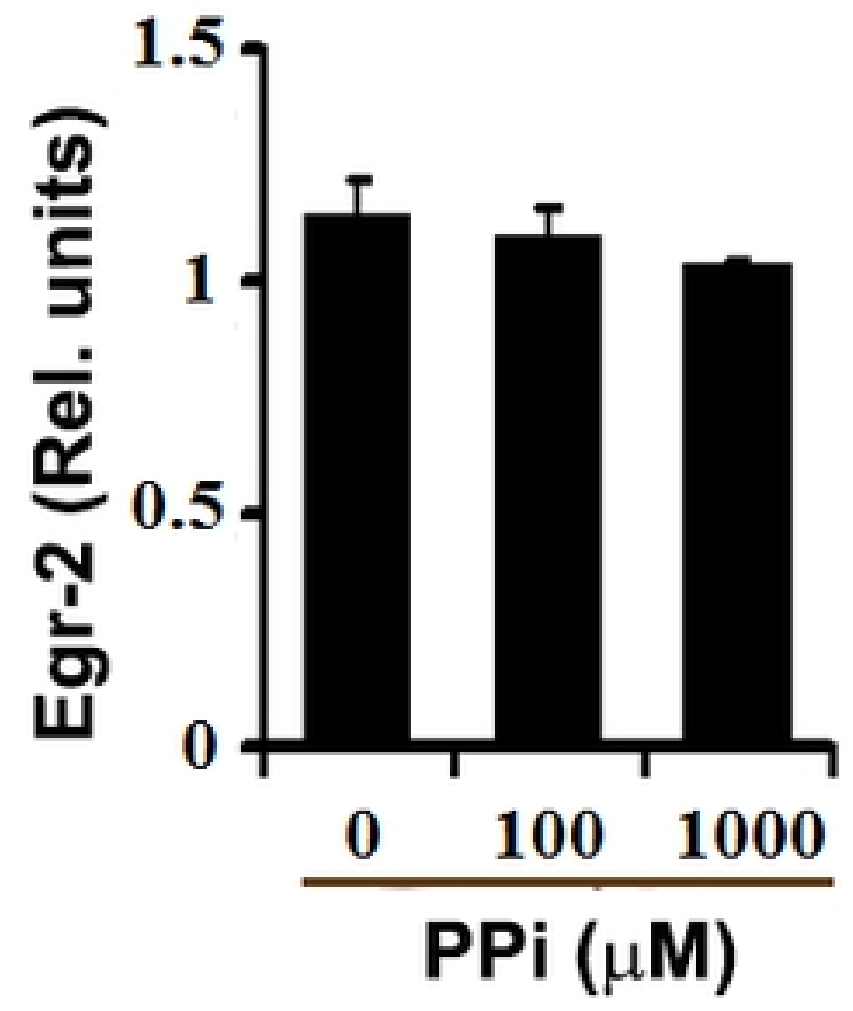

E

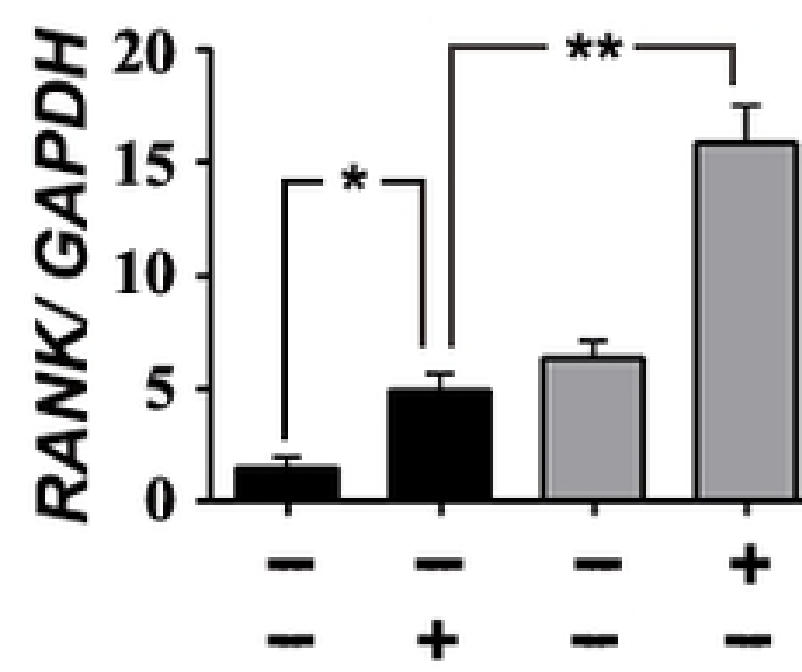

H

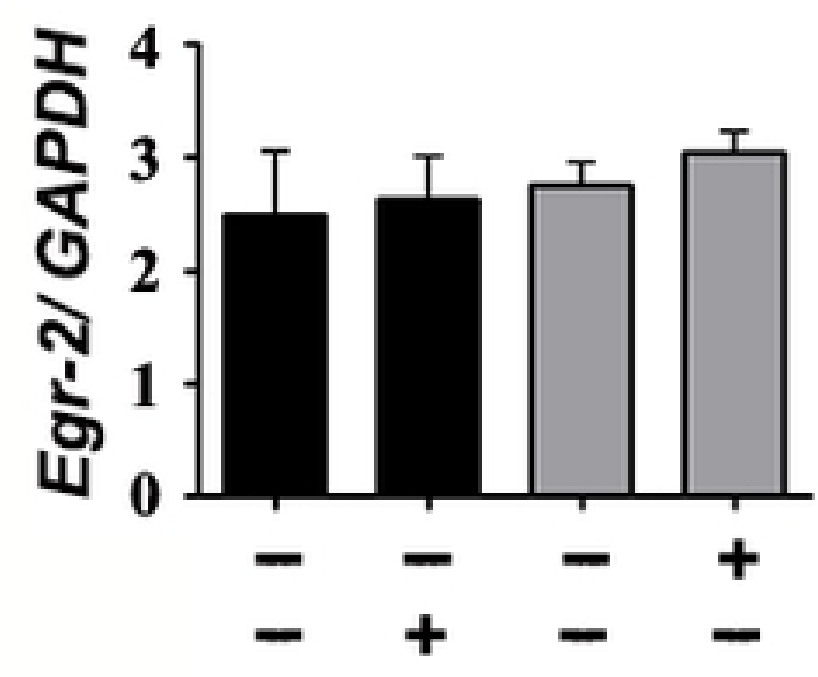




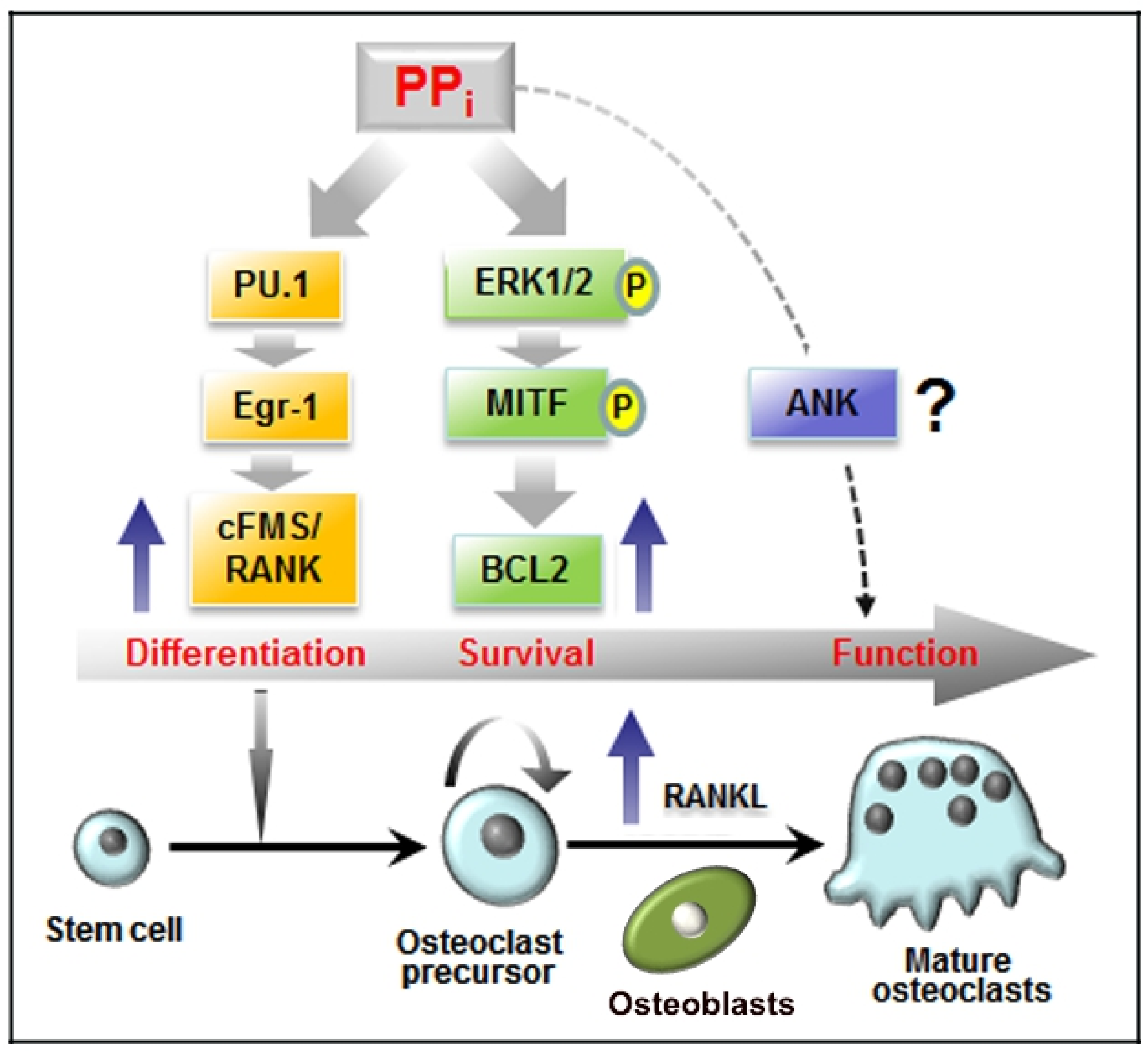

Figure-10 


\begin{tabular}{|c|c|c|c|c|}
\hline Gene name & Primer sequence $\left(5^{\prime}-3^{\prime}\right)$ & Amplicon size (bp) & GeneBank accession & Amplicon $T_{m}\left({ }^{\circ} \mathrm{C}\right)$ \\
\hline \multirow[t]{2}{*}{ TRAP } & F: GACCACCTTGGCAATGTCTCTG & \multirow[t]{2}{*}{176} & \multirow[t]{2}{*}{ NM_001102405 } & 59.9 \\
\hline & R: TGGCTGAGGAAGTCATCTGAGTTG & & & 54.9 \\
\hline \multirow[t]{2}{*}{ RANKI } & F: CACACCTCACCATCAATGCTGC & \multirow[t]{2}{*}{194} & \multirow[t]{2}{*}{ NM_011613.3 } & 58.9 \\
\hline & R: GAAGGGTTGGACACCTGAATGC & & & 58.4 \\
\hline \multirow[t]{2}{*}{ OPG } & F: AGTCCGTGAAGCAGGAGTG & \multirow[t]{2}{*}{171} & \multirow[t]{2}{*}{$\mathrm{NM}_{-} 008764$} & 57 \\
\hline & R: CCATCTGGACATTTTTTGCAAA & & & 52.5 \\
\hline \multirow[t]{2}{*}{ cFMS } & F: GAGAGCATCTTTGACTGCGTCTAC & \multirow[t]{2}{*}{164} & \multirow[t]{2}{*}{$\mathrm{NM}_{-} 001037859$} & 57.4 \\
\hline & R: ACAGGCTGGGCCATTTGGTA & & & 59.4 \\
\hline \multirow[t]{2}{*}{$\mathrm{RANK}$} & F: CGACTGGTTCACTGCTCCTAATC & \multirow[t]{2}{*}{112} & \multirow[t]{2}{*}{$\mathrm{NM}_{-} 009399$} & 57.3 \\
\hline & R: TTCTATTTCTTTTGTCAGGTGCTTTTC & & & 54.4 \\
\hline \multirow[t]{2}{*}{ cFOS } & F: GGAGCCAGTCAAGAGCATCAG & \multirow[t]{2}{*}{179} & \multirow[t]{2}{*}{$\mathrm{NM}_{-} 010234$} & 57.8 \\
\hline & R: GGGTAGGTGAAGACAAAGGAAGAC & & & 57.1 \\
\hline \multirow[t]{2}{*}{ cJun } & F: GCGTTAGCATGAGTTGGCAC & \multirow[t]{2}{*}{150} & \multirow[t]{2}{*}{$\mathrm{NM}_{-} 010591$} & 55.7 \\
\hline & R: CGCATGAGGAACCGCATCGC & & & 56.8 \\
\hline \multirow[t]{2}{*}{$N F \kappa B$} & F: GCCAGCTTCCGTGTTTGTTC & \multirow[t]{2}{*}{80} & \multirow[t]{2}{*}{ NM_o0s689 } & 57.2 \\
\hline & R: TCAGGGTAGTAGAGAAAGGGTTTCG & & & 57.6 \\
\hline \multirow[t]{2}{*}{ PL'.1 } & F: AGAAGCTGATGGCTTGGAGC & \multirow[t]{2}{*}{70} & \multirow[t]{2}{*}{$\mathrm{NM}_{-} 011355$} & 57.7 \\
\hline & R: GCGAATCTTTTTCTTGCTGCC & & & 55.4 \\
\hline \multirow[t]{2}{*}{ EGR1 } & F: GACGAGTTATCCCAGCCAAA & \multirow[t]{2}{*}{202} & \multirow[t]{2}{*}{ NM_007913 } & 54.8 \\
\hline & R: GGCAGAGGAAGACGATGAAG & & & 55.3 \\
\hline \multirow[t]{2}{*}{ EGR2 } & F: GAAGGAACGGAAGAGCAGTG & 194 & NM_001373987 & 55.7 \\
\hline & R: ATCTCACGGTGTCCTGGTTC & & & 56.8 \\
\hline MITF & F: GGACTTTCCCTTATCCCATCCA & 70 & NM_00111319S & 56.3 \\
\hline & R: GTTCTTGCTTGATGATCCGATTC & & & 54.2 \\
\hline $\mathrm{BCL} 2$ & F: CTGGCATCTTCTCCTTCCAG & 183 & NM_009741 & 55.1 \\
\hline & R: GACGGTAGCGACGAGAGAAG & & & 57 \\
\hline $\mathrm{ANK}$ & F: TAAACTGGCGAACACAAGCAA & 201 & NM_020332 & 55.4 \\
\hline & R: $A A G A A G G A G A A G A T A C G C A G A G G A A$ & & & 57.3 \\
\hline $\mathrm{GAPDH}$ & F: CCGGTGCTGAGTATGTCGTGGAG & 100 & NM_oosost.2 & 56 \\
\hline & R: GCAGAAGGGGCGGAGATGAT & & & 56 \\
\hline
\end{tabular}

\section{Table-1}

